ALBERTO LEMOS DURÁN

\title{
APLICAÇÃO DE CÉLULAS ULTRASSÔNICAS PARA A CARACTERIZAÇÃO DE EMULSÕES ÁGUA EM ÓLEO
}




\title{
ALBERTO LEMOS DURÁN
}

\section{APLICAÇÃO DE CÉLULAS ULTRASSÔNICAS PARA A CARACTERIZAÇÃO DE EMULSÕES ÁGUA EM ÓLEO}

\author{
Versão Corrigida
}

Dissertação apresentada à Escola Politécnica da Universidade de São Paulo para obtenção do Título de Mestre em Ciências.

Área de Concentração:

Engenharia de Controle

e Automação Mecânica

Orientador:

Prof. Dr. Flávio Buiochi

Coorientador:

Prof. Dr. Ediguer Enrique Franco 
Autorizo a reprodução e divulgação total ou parcial deste trabalho, por qualquer meio convencional ou eletrônico, para fins de estudo e pesquisa, desde que citada a fonte.

Este exemplar foi revisado e corrigido em relação à versão original, sob responsabilidade única do autor e com a anuência de seu orientador.

São Paulo, 11 de dezembro de 2021.

Assinatura do autor

Assinatura do orientador

Durán, Alberto

APLICAÇÃO DE CÉLULAS ULTRASSÔNICAS PARA A CARACTERIZAÇÃO DE EMULSÕES ÁGUA EM ÓLEO/ Alberto Lemos Durán. - versão corr. - São Paulo, 2021.

$111 \mathrm{p}$.

Dissertação (Mestrado) - Escola Politécnica da Universidade de São Paulo. Departamento de Engenharia Mecatrônica e de Sistemas Mecânicos.

1. Células ultrassônicas. 2. Célula de espalhamento. 3. Caracterização de fluidos. 4. Emulsões de água em óleo. 5. Processamento de sinais. I. Universidade de São Paulo. Escola Politécnica. Departamento de Engenharia Mecatrônica e de Sistemas Mecânicos. II. t. 
Nome: LEMOS DURÁN, ALBERTO

Título: APLICAÇÃO DE CÉLULAS ULTRASSÔNICAS PARA A CARACTERIZAÇÃO DE EMULSÕES ÁGUA EM ÓLEO

Dissertação apresentada à Escola Politécnica da Universidade de São Paulo para obtenção do Título de Mestre em Ciências.

Aprovado em:

Banca Examinadora

Assinatura:

Instituição:

Julgamento:

Assinatura:

Instituição:

Julgamento:

Assinatura:

Instituição:

Julgamento: 
A mi madre. 


\section{AGRADECIMENTOS}

Agradeço primeiramente aos meus pais, Rosmira Durán Ocampo e Alberto Lemos Garcia, pelo carinho, apoio e suporte desde a distância.

Aos meus "pais brasileiros", Patricia Fraga e Júlio Parreira, por acolher-me, apoiar-me, ouvir-me e orientar-me.

À Elen Cristina e Maurício Mocha, por ajudar-me durante o processo seletivo.

Ao meu orientador, Flávio Buiochi, pelo conhecimento transmitido, pela constante ajuda e pela confiança em mim depositada.

Ao meu professor, amigo e coorientador, Ediguer Enrique, por ensinar-me, motivar-me e apoiar-me. E pela constante disposição para atender às questões sobre o trabalho.

À Lina Pérez e Juracy Cabral, pela ajuda, apoio e cuidados nos momentos difíceis.

À Thalita Cabral, pelo amor, apoio e paciência. E pela ajuda na revisão do texto.

Aos meus colegas de laboratório e professores, por auxiliar-me no dia a dia.

Ao professor Nicolás Perez e ao Raphael Oliveira, pela ajuda no projeto e construção da célula de espalhamento.

À CAPES e à Petrobras (convênio 5850.0108871.18.9) pelo suporte financeiro. 


\section{SUMÁRIO}

\section{Lista de Ilustrações}

\section{Lista de Tabelas}

\section{Símbolos}

RESUMO

\section{ABSTRACT}

1 Introdução 19

1.1 Introdução e justificativa $\ldots \ldots$. . . . . . . . . . . . . . . 19

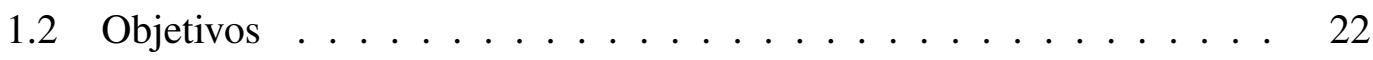

1.2.1 Objetivo Geral .................... 22

1.2.2 Objetivos Específicos .................. 22

1.3 Organização . . . . . . . . . . . . . . . . 22

2 Conceitos Teóricos $\quad 24$

2.1 Classificação de misturas . . . . . . . . . . . . . . . . . . 24

$2.1 .1 \quad$ Mistura ........................... 24

2.1 .2 Emulsão . . . . . . . . . . . . . . . . 24

2.1.3 Partículas em suspensão . . . . . . . . . . . . . 26

2.2 Fenômeno Acústico . . . . . . . . . . . . . . . . . 26

2.2.1 Equação de estado . . . . . . . . . . . . . . . 26

2.2.2 Equação de continuidade . . . . . . . . . . . . . 27

2.2.3 Equação de força: equação de Euler . . . . . . . . . . . . . . 27 
2.2.4 Equação linear de onda . . . . . . . . . . . . . . . . . . 28

2.2.5 Solução para ondas planas harmônicas . . . . . . . . . . . . . 29

2.2.6 Impedância acústica específica . . . . . . . . . . . . . 30

2.2.7 Coeficientes de reflexão e transmissão . . . . . . . . . . . . . 30

2.2 .8 Absorção acústica . . . . . . . . . . . . . . . 32

2.3 Processamento de sinais . . . . . . . . . . . . . . . . 34

2.3.1 Transformada de Fourier . . . . . . . . . . . . . . . . 34

2.3.2 Transformada discreta de Fourier (DFT) . . . . . . . . . . 35

2.3.3 Algoritmo de Goertzel . . . . . . . . . . . . . . 36

2.3.4 Energia de um sinal . . . . . . . . . . . . . 38

2.3.5 Teorema de Parseval . . . . . . . . . . . . . . 39

2.3.6 Transformada de Hilbert . . . . . . . . . . . . . . . . . 40

2.3.7 Correlação cruzada . . . . . . . . . . . . . . . . . 41

2.3.8 Correlação cruzada com os sinais normalizados . . . . . . . 43

2.3.9 Métodos $k$-means e $k$-medoids . . . . . . . . . . 43

3 Materiais e metodologia $\quad 46$

3.1 Célula com linhas de retardo . . . . . . . . . . . . 46

3.2 Cálculo das propriedades acústicas usando a célula com linhas de retardo 49

3.2.1 Velocidade de propagação . . . . . . . . . . . . . 50

3.2.2 Coeficiente de reflexão . . . . . . . . . . . . . 52

3.2.3 Impedância acústica . . . . . . . . . . . . . 54

3.2 .4 Densidade ........................ 54

3.2 .5 Atenuação acústica . . . . . . . . . . . . . 55

3.2.6 Comparação com o modelo teórico de misturas de Urick . . . 55 
3.2.7 Análise da propagação da incerteza de medição na determinação das propriedades . . . . . . . . . . . . . . 56

3.3 Procedimento experimental para a aquisição de dados usando a célula com linhas de retardo . . . . . . . . . . . . . . . . 60

3.4 Célula de espalhamento . . . . . . . . . . . . . . . . 62

3.5 Detecção de variações nas amostras usando a célula de espalhamento . 63

3.6 Determinação da velocidade de propagação com a célula de espalha-

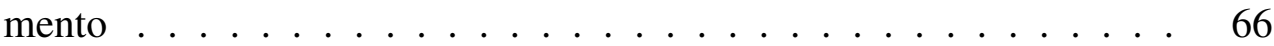

3.7 Procedimento experimental para a aquisição de dados com a célula de espalhamento ...................... 68

3.8 Célula de espalhamento modificada . . . . . . . . . . . . . . . 69

3.9 Procedimento experimental para a aquisição de dados com a célula de espalhamento modificada . . . . . . . . . . . . . . . . 72

4 Resultados e discussão $\quad \mathbf{7 5}$

4.1 Resultados obtidos usando a célula com linhas de retardo . . . . . . 75

4.1.1 Velocidade de propagação da amostra . . . . . . . . . . . 76

4.1.2 Coeficiente de reflexão na interface vidro-amostra . . . . . . . 77

4.1.3 Impedância acústica da amostra . . . . . . . . . . . . 78

4.1 .4 Densidade da amostra . . . . . . . . . . . . . . 79

4.1.5 Atenuação acústica da amostra . . . . . . . . . . . . . . 80

4.1.6 Análise da propagação das incertezas de medição . . . . . . . 82

4.2 Resultados obtidos usando a célula de espalhamento . . . . . . . . . . 84

4.2.1 Variações na amostra usando a célula de espalhamento . . . . 84

4.2.2 Velocidade de propagação usando a célula de espalhamento . $\quad 88$

4.3 Resultados obtidos usando a célula de espalhamento modificada . . . 91

4.3.1 Variações nas amostras usando a célula de espalhamento modificada . . . . . . . . . . . . . . . 93 
4.3.2 Velocidade de propagação usando a célula de espalhamento modificada . . . . . . . . . . . . . 97

5 Conclusões e trabalhos futuros

5.1 Conclusões . . . . . . . . . . . . . . . . . . . 101

5.2 Trabalhos futuros . . . . . . . . . . . . . . 106

Referências 


\section{LISTA DE ILUSTRAÇÕES}

1 Aplicação do algoritmo de Goertzel . . . . . . . . . . . . . . . 37

2 Aplicação da variante do algoritmo de Goertzel . . . . . . . . . . . . 38

3 Exemplo de aplicação do método k-means em um problema com 30 observações de dimensão 2. As estrelas representam os centroides e os círculos as observações. . . . . . . . . . . . . . . . . . . 44

4 Fotografia da célula com linhas de retardo e esquema dos seu funcionamento. . . . . . . . . . . . . . . . . . . 4 47

5 Sinais experimentais adquiridos com a célula com linhas de retardo: a) ensaios realizados com ar na câmara da amostra, e b) ensaios realizados com emulsões. c) Transformada discreta de Fourier dos ecos obtidos com emulsões, na banda de frequência 1-6 MHz. . . . . . . . 50

6 Fotos do processo experimental utilizando a célula com linhas de retardo. 61

7 Esquema da montagem experimental para a utilização da célula com linhas de retardo. . . . . . . . . . . . . . . . . . . 62

8 Fotografia da célula de espalhamento e esquema com a configuração dos dispersores. . . . . . . . . . . . . . . . . . . . 63

9 a) Sinal experimental obtido com a célula de espalhamento, extraído do ensaio com $10 \%$ de água. O sinal foi segmentado em três partes $a_{n}(t)$ como indicado na seção 3.6. b) Transformada discreta de Fourier do sinal de espalhamento na banda de frequência 1-5 MHz.

10 Esquema da montagem experimental para a utilização da célula de espalhamento.

11 Fotografia da célula de espalhamento modificada e esquema com a nova configuração para os dispersores. 
12 Comparação entre dois sinais de dispersão obtidos com a célula de espalhamento em experimentos a $25^{\circ} \mathrm{C}$. Em a) prévio às modificações da célula, usando uma concentração de água de 10\%, e em b) após às modificações, usando uma concentração de água de $11 \%$. . . . . . .

13 Fotos do processo experimental utilizando a célula de espalhamento modificada. Ensaio realizado a $30^{\circ} \mathrm{C} \ldots \ldots$. . . . . . . . . . 73

14 Hora do dia em que cada sinal foi adquirido segundo o experimento. . 73

15 Esquema da montagem experimental para a utilização da célula de espalhamento modificada. . . . . . . . . . . . . . . . . . . . . 74

16 Velocidade de propagação na emulsão em função da concentração de água, medida com a célula com linhas de retardo. . . . . . . . . . . 76

17 Coeficiente de reflexão na interface vidro-amostra em função da concentração de água, medido com a célula com linhas de retardo. . . . 77

18 Impedância acústica da emulsão em função da concentração de água, medida com a célula com linhas de retardo. . . . . . . . . . . . 78

19 Densidade da emulsão em função da concentração de água, medida com a célula com linhas de retardo. . . . . . . . . . . . . . . 79

20 Atenuação acústica da emulsão em função da concentração de água, medida com a célula com linhas de retardo. . . . . . . . . . . . 80

21 Transformada de Fourier experimental e teórica do terceiro eco, junto ao erro relativo entre as curvas. Calculado para o ensaio realizado com água pura . . . . . . . . . . . . . . . . . 81

22 Atenuação acústica experimental e teórica da água em função da frequência. ...................... 82

23 Resumo das propriedades obtidas (linhas azuis), com seus desvios de medição sem realizar calibração (linhas tracejadas), e modelo teórico de Urick (linhas vermelhas). . . . . . . . . . . . . . . .

24 Variações relativas das amostras em função do tempo de medição, obtidas através da correlação cruzada, correlação cruzada normalizada e energia de onda. . . . . . . . . . . . . . . . 
25 Valor médio e desvio padrão dos valores relativos de correlação cruzada, correlação cruzada com os sinais normalizados e energia de onda, em função da concentração de água nas emulsões. . . . . . . . .

26 Velocidade de propagação em função da concentração de água das emulsões, medida com a célula de espalhamento. Valores obtidos pelos métodos absolutos. . . . . . . . . . . . . . .

27 Velocidade de propagação em função da concentração de água das emulsões, medida com a célula de espalhamento. Valores obtidos pelos métodos relativos. . . . . . . . . . . . . . . . .

28 Valor médio da velocidade de propagação em função da concentração de água para cada método relativo. Valores obtidos usando todos os sinais de todos os experimentos. . . . . . . . . . .

29 Valor médio e desvio padrão da temperatura em função da concentração de água para cada experimento. Resultados obtidos usando termômetro digital durante as aquisições com a célula de espalhamento modificada. . . . . . . . . . . . . . . .

30 Valor médio e desvio padrão dos valores relativos de correlação cruzada, correlação cruzada com os sinais normalizados e energia de onda, em função da concentração de água das emulsões. Resultados obtidos com a célula de espalhamento modificada, usando a totalidade do sinal de dispersão. Para uma melhor visualização das curvas, à direita não se mostram os parâmetros para a concentração de $100 \%$. . .

31 Valor médio e desvio padrão dos valores relativos de correlação cruzada, correlação cruzada com os sinais normalizados e energia de onda, em função da concentração de água das emulsões. Resultados obtidos com a célula de espalhamento modificada, usando o primeiro segmento do sinal de dispersão. Para uma melhor visualização das curvas, à direita não se mostram os parâmetros para a concentração de

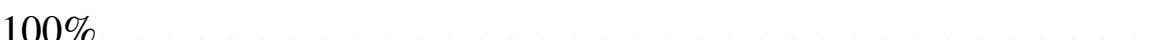

32 Velocidade de propagação em função da concentração de água das emulsões, medida com a célula de espalhamento modificada. Valores obtidos pelos métodos absolutos. . . . . . . . . . . . . . . . 
33 Velocidade de propagação em função da concentração de água das emulsões, medida com a célula de espalhamento modificada. Valores obtidos pelos métodos relativos. . . . . . . . . . . . . . . . . . 99 


\section{LISTA DE TABELAS}

1 Propriedades dos materiais de composição da Célula I (medidos a

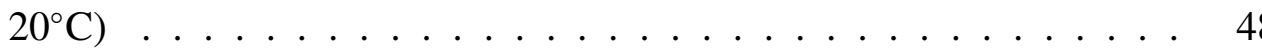

2 Fluxo de cálculo utilizado para a determinação das variações relativas com a célula de espalhamento. . . . . . . . . . . . . . . 66

3 Informações do Teste 1. Número de sinais adquiridos e duração do ensaio para cada concentração. . . . . . . . . . . . . . . 68

4 Erro relativo devido às incertezas dos equipamentos de medição e, máxima diferença relativa entre o modelo teórico de misturas de Urick e as curvas experimentais, com e sem calibração. . . . . . . . . . 8

5 Comparação dos resultados obtidos com a célula de espalhamento para as variações relativas. $\mathrm{CE}_{1}$ e $\mathrm{CE}_{2}$ representam o estado da célula, antes e depois de ter sido modificada, respectivamente, e $\phi$ representa a concentração volumétrica de água das emulsões. . . . . . . . . . . . 105

6 Comparação dos resultados obtidos com a célula de espalhamento para a velocidade de propagação. $\mathrm{CE}_{1}$ e $\mathrm{CE}_{2}$ representam o estado da célula, antes e depois de ter sido modificada, respectivamente, e $\phi$ representa a concentração volumétrica de água das emulsões. . . . . . . . . . . . 105 


\begin{tabular}{|c|c|c|}
\hline Quantidade física & Símbolo & Unidade SI \\
\hline Pressão instantânea & $\mathcal{P}$ & $\mathrm{Pa}$ \\
\hline Pressão de equilíbrio & $\mathcal{P}_{0}$ & $\mathrm{~Pa}$ \\
\hline Pressão relativa & $p$ & $\mathrm{~Pa}$ \\
\hline Densidade instantânea & $\rho$ & $\mathrm{Kg} / \mathrm{m}^{3}$ \\
\hline Densidade de equilíbrio & $\rho_{0}$ & $\mathrm{Kg} / \mathrm{m}^{3}$ \\
\hline Fator de condensação instantânea & $s$ & Adim. \\
\hline Módulo volumétrico adiabático & $\mathcal{R}$ & $\mathrm{Pa}$ \\
\hline Velocidade de uma partícula de fluido & $\vec{u}$ & $\mathrm{~m} / \mathrm{s}$ \\
\hline Velocidade de propagação do meio $\mathrm{n}$ & $c_{n}$ & $\mathrm{~m} / \mathrm{s}$ \\
\hline Compressibilidade adiabática & $\beta$ & $\mathrm{Pa}^{-1}$ \\
\hline Frequência & $f$ & $\mathrm{~Hz}$ \\
\hline Frequência de amostragem & $f_{s}$ & $\mathrm{~Hz}$ \\
\hline Frequência de operação do transdutor & $f_{o}$ & $\mathrm{~Hz}$ \\
\hline Frequência angular & $\omega$ & $\mathrm{rad} / \mathrm{s}$ \\
\hline Frequência angular de operação do transdutor & $\omega_{o}$ & $\mathrm{rad} / \mathrm{s}$ \\
\hline Período de amostragem & $T_{s}$ & $\mathrm{~s}$ \\
\hline Número de onda & $k$ & $\mathrm{~m}^{-1}$ \\
\hline Impedância acústica do meio $i$ & $Z_{i}$ & rayl \\
\hline Pressão acústica da onda $i$ & $p_{i}$ & $\mathrm{~Pa}$ \\
\hline Coeficiente de reflexão do meio $i$ para o meio $j$ & $R_{i j}$ & Adim. \\
\hline Coeficiente de transmissãodo meio $i$ para o meio $j$ & $T_{i j}$ & Adim. \\
\hline Tempo de relaxação & $\tau_{s}$ & $\mathrm{~s}$ \\
\hline Coeficiente de viscosidade por cisalhamento & $\eta$ & $\mathrm{Pa} \cdot \mathrm{s}$ \\
\hline Coeficiente de absorção viscoso & $\alpha_{s}$ & $\mathrm{~Np} / \mathrm{m}$ \\
\hline Coeficiente de absorção devido à condutividade térmica & $\alpha_{k}$ & $\mathrm{~Np} / \mathrm{m}$ \\
\hline Coeficiente de absorção clássico & $\alpha_{c}$ & $\mathrm{~Np} / \mathrm{m}$ \\
\hline Corrente elétrica & $I$ & A \\
\hline Resistência elétrica & $R$ & $\Omega$ \\
\hline Tensão elétrica & $V$ & V \\
\hline Energia elétrica (de onda) & $E$ & $\mathrm{~J}$ \\
\hline Potência elétrica instantânea & $\mathscr{P}$ & $\mathrm{W}$ \\
\hline Potência elétrica média & $\overline{\mathscr{P}}$ & $\mathrm{W}$ \\
\hline Eco da linha de retardo $n$ & $a_{n}$ & $\mathrm{~V}$ \\
\hline Amplitude do eco da linha de retardo $n$ & $A_{n}$ & Adim. \\
\hline Tempo de chegada do eco $n$ & $t_{n}$ & $\mathrm{~s}$ \\
\hline Distância percorrida pela onda & $x$ & $\mathrm{~m}$ \\
\hline Comprimento da camada $n$ da célula com linhas de retardo & $l_{n}$ & $\mathrm{~m}$ \\
\hline Coeficiente de atenuação acústica do meio $n$ & $\alpha_{n}$ & $\mathrm{~Np} / \mathrm{m}$ \\
\hline Concentração volumétrica da fase dispersa (água) & $\phi$ & Adim. \\
\hline Separação entre a face do transdutor e a primeira fila de dispersores & $e$ & $\mathrm{~m}$ \\
\hline Separação entre as filas de dispersores & $l_{z}$ & $\mathrm{~m}$ \\
\hline Separação entre os dispersores de uma mesma fila & $l_{x}$ & $\mathrm{~m}$ \\
\hline Início da janela temporal $n$ & $t_{i, n}$ & s \\
\hline Fim da janela temporal $n$ & $t_{f, n}$ & s \\
\hline
\end{tabular}




\section{RESUMO}

Neste trabalho foram usadas duas células ultrassônicas para a caracterização de emulsões de água em óleo, uma com linhas de retardo e a outra com espalhadores. Foi utilizado um transdutor ultrassônico comercial de 3,50 MHz, operando no modo pulso-eco, e as amostras testadas foram de água em óleo hidráulico, e de água em petróleo, com concentrações de água entre $0 \%$ e $50 \%$ em volume. A primeira célula permitiu medir as seguintes propriedades acústicas das amostras em função da concentração de água: velocidade de propagação, coeficiente de reflexão, impedância acústica, densidade e atenuação acústica. As primeiras quatro propriedades foram comparadas às obtidas pelo modelo teórico de misturas de Urick, resultando em uma diferença inferior a $2 \%$. A atenuação acústica da água foi comparada com valores da literatura, tendo-se obtido um erro bastante maior. Com a segunda célula, foi realizado o monitoramento das emulsões, com a intenção de estudar a sensibilidade da célula e a estabilidade das emulsões em função da temperatura e da concentração de água. Para isto, foram utilizados os parâmetros: correlação cruzada, correlação cruzada com os sinais normalizados e energia de onda. Os resultados obtidos com a célula de espalhamento mostraram uma maior dependência com a concentração do que com o efeito de coalescência, o que sugere uma menor sensibilidade ao tamanho de gota. Inicialmente, foram realizados testes à temperatura de $25^{\circ} \mathrm{C}$, observando-se boa resolução para concentrações de água inferiores a $20 \%$ ao se empregar os métodos de correlação cruzada, e boa resolução em toda a faixa de concentrações medidas usando a energia de onda. Entretanto, após serem realizadas algumas modificações na célula, e na janela de análise dos sinais, a resolução aumentou para todos os parâmetros. Com a célula modificada, foram realizados experimentos às temperaturas de 20,25 e $30^{\circ} \mathrm{C}$. As curvas de correlação cruzada e de energia de onda foram dependentes da concentração e independentes da temperatura (todas em superposição). Já a correlação cruzada com os sinais normalizados foi dependente de ambas as variáveis, sendo que, para cada temperatura, formaram-se retas de diferentes inclinações, cada vez mais negativa com o aumento da temperatura. O máximo desvio nas curvas de energia foi de $16 \%$, nas de correlação cruzada foi de $6 \%$ e nas de correlação cruzada com os sinais normalizados foi de $0,37 \%$. O modelo teórico sugeriu uma curva convexa para a velocidade de propagação e os resultados apresentaram um comportamento linear. No entanto, a partir do método proposto para o cálculo da velocidade, foram obtidos resultados coerentes, com uma diferença inferior a $2 \%$. 


\begin{abstract}
In this work, two ultrasonic sensors for the characterization of water-in-oil emulsions were used: one with delay lines and the other with scatterers. A $3.50 \mathrm{MHz}$ commercial ultrasonic transducer operating in pulse-eco mode was used, and the samples tested were water in hydraulic oil and water in crude oil, with concentrations between $0 \%$ and $50 \%$. The first sensor was used to measure the following acoustic properties of the samples as a function of the water concentration: propagation velocity, reflection coefficient, acoustic impedance, density and acoustic attenuation. The first four properties were compared with the Urick's theoretical model, resulting in an difference of less than $2 \%$. The acoustic attenuation of the water was compared to the values from the literature, resulting in a greater error. With the second sensor, the emulsions were monitored to study the sensitivity of the sensor and the stability of the emulsions as a function of temperature and water concentration. For this, the parameters used were: cross correlation, cross correlation with normalized signals and wave energy. The main observation was a greater dependence on concentration than on the effect of coalescence, which suggests less sensitivity to the droplet size. Initially, tests were carried out at a temperature of $25^{\circ} \mathrm{C}$, with good resolution for water concentrations below $20 \%$ using the cross correlation methods, good resolution over the entire range of concentrations measured using wave energy. However, after making some modifications to the cell, and to the signal analysis window, the resolution increased for all parameters. Using the modified cell, experiments were carried out at temperatures of 20,25 and $30^{\circ} \mathrm{C}$. The cross correlation and wave energy curves were dependent on concentration and independent on temperature (all of them in superposition). On the other hand, the cross correlation with the normalized signals was dependent on both variables. For each test temperature, the experimental data composed a different slope, which was more negative as the temperature increased. The maximum deviation is $16 \%$ in energy curves, $6 \%$ in cross correlation curves and $0.37 \%$ in cross correlation curves with normalized signals. The theoretical model suggests a convex curve for the velocity and the results presented a linear behavior. Nonetheless, using the proposed method for determining the propagation velocity, coherent results were obtained, with a theoretical relative difference of less than $2 \%$.
\end{abstract}




\section{INTRODUÇÃO}

\subsection{Introdução e justificativa}

Uma emulsão é uma mistura heterogênea composta por dois líquidos imiscíveis, onde um deles encontra-se disperso no outro em forma de gotículas (BROWN et al., 2004). Por exemplo, estão presentes na indústria alimentícia na forma de leite, molhos e óleo, e na indústria metalmecânica na forma de fluídos de corte para usinagem (HIGUTI et al., 1999; SANTOS et al., 2017). Há também alguns processos em que o produto intermediário é uma emulsão, tais como o óleo de palma (PÉREZ-PÁEZ et al., 2007) e o petróleo (MANDAL et al., 2010). Por outro lado, óleos lubrificantes e combustíveis podem contaminar-se com água, devido à umidade, possíveis vazamentos (em trocadores de calor) ou pelo uso compartilhado de tubulações de transporte, dando passo a emulsões "indesejadas".

$\mathrm{Na}$ indústria do petróleo, o óleo cru extraído dos poços tem água misturada em diferentes proporções. A quantidade é geralmente maior nos processos de recuperação melhorada (EOR) e na extração offshore, onde utiliza-se a água como fluido de deslocamento. Sua presença pode produzir envenenamento do catalisador no processo de refinamento, e, se for salgada, pode produzir problemas adicionais de corrosão em bombas e equipamentos. Sabe-se, que a quantidade permitida no óleo cru para seu transporte e refinamento é inferior a 1\% (UMAR et al., 2018). Por estes motivos, o monitoramento online e em tempo real das propriedades dos fluídos de trabalho é importante no controle e melhoramento dos processos industriais. Além disso, a concentração volumétrica de água é uma das propriedades mais relevantes, já que desta dependem fortemente outras propriedades, como a densidade, a absortividade, a viscosidade e o poder calorífico.

As técnicas de caracterização de emulsões de água em óleo incluem a microscopia eletrônica (STOKES; THIEL; DONALD, 1998), o espalhamento de luz (GODDEERIS 
et al., 2006) e de neutrônios (ALVAREZ et al., 2009), e a ressonância magnética nuclear (D’AVILA et al., 2003). Não obstante, essas técnicas não se desempenham bem com emulsões diluídas e opacas, como é o caso das emulsões de água em petróleo. Outras técnicas, que apresentam melhor desempenho em emulsões opacas, usam os raios-X (HEINDEL, 2011) e os raios gama (ABRO; JOHANSEN, 1999). No entanto, a radiação ionizante requer um tratamento especial. Provavelmente, as melhores técnicas estabelecidas sejam as eletrônicas, baseadas na medição da condutividade elétrica, a permitividade dielétrica, e a capacitância e admitância elétrica (GARCIA-GOLDING et al., 1995; JAWORSKI; DYAKOWSKI, 2005). Embora, estas técnicas podem ver-se afetadas pela salinidade e pela condutividade resultante da mistura. Por outro lado, métodos para a determinação da quantidade de água no petróleo, como a centrifugação (JADOON; MALIK; AMIN, 2017), a titulação de Karl Fisher (IVANOVA; ANEVA, 2006) e os métodos de geração de imagem por tomografia (JOHANSEN et al., 1996), requerem a extração de uma amostra dos dutos para seu posterior processamento em laboratório; o que provoca atrasos nos processos subsequentes do petróleo.

Também, têm-se utilizado métodos ultrassônicos na determinação da fração volumétrica das fases constitutivas das emulsões, baseados na medição dos coeficientes de reflexão, transmissão e atenuação. Usar estas técnicas é uma proposta interessante, devido à sua robustez, a seu custo relativamente baixo, a que sua radiação é não ionizante, e a que permite analisar meios opacos (MENG; JAWORSKI; WHITE, 2006). Contudo, a propagação de ondas acústicas em emulsões é um fenômeno complexo que depende, além das propriedades físicas de cada fase, da distribuição do tamanho das gotas da fase dispersa (SU et al., 2009).

Em um meio não dispersivo, a atenuação acústica é consequência da absorção das ondas através de alguns mecanismos que convertem a energia em calor, como perdas viscosas, perdas por condução de calor e perdas por relaxação acústica (KINSLER et al., 2000). Em um meio dispersivo, observa-se um excesso de atenuação e mudanças na velocidade de propagação, relacionadas com o tamanho de gota, a fração volumétrica e a frequência de operação. Apesar disso, sabe-se da teoria que, para grandes comprimentos de onda, as mudanças na velocidade de propagação, devidas à dispersão, são pequenas e que estas se devem, principalmente, às mudanças na concentração (MCCLEMENTS; POVEY, 1989; MCCLEMENTS et al., 1990). Isso proporciona uma faixa de medição útil para o monitoramento de emulsões usando ondas acústicas.

Na literatura, reportam-se vários trabalhos relacionados à caracterização de líqui- 
dos por ultrassom. Utilizando células com linhas de retardo, foi determinada a densidade de líquidos homogêneos com baixo e alto coeficiente de atenuação (BUIOCHI, 1994; HIGUTI, 2001). Outras técnicas ultrassônicas, aplicadas em misturas de água e óleo, foram úteis para detectar água em óleos lubrificantes (JULIASTUTI; TANOGONO; KURNIADI, 2017), assim como para detectar pequenas quantidades de substâncias oleosas na água (FRANCO; ADAMOWSKI; BUIOCHI, 2012). Para determinar a concentração das fases em uma mistura, várias abordagens foram investigadas. A espectroscopia ultrassônica permitiu determinar, além da concentração, a distribuição do tamanho de gota mediante a velocidade de propagação e os espectros de atenuação (SU et al., 2009; RICHTER; VOIGT; RIPPERGER, 2007), porém a técnica é restrita a emulsões diluídas (DUKHIN; GOETZ, 2010). Alguns autores, estudaram a resposta de sensores ultrassônicos (operando no modo emissão-recepção), em um canal vertical mediante filtragem dinâmica simbólica. Mostraram que a técnica tem potencial para determinar o teor de emulsões de óleo em água para concentrações de óleo inferiores a 35\% (ZHAI et al., 2013). Outros autores reportaram experimentos com misturas de água em petróleo em um loop de fluxo; um sensor baseado em métodos acústicos permitiu a medição da concentração de água (entre 64 e 96\%) com um desvio de 2\%, comparado com a concentração calculada mediante o fluxo de massa das fases, medido com um sensor de Coriolis (CHAUDHURI et al., 2014). Os detalhes sobre a geometria e fabricação do sensor não foram mostrados.

Outros estudos utilizaram o retroespalhamento ultrassônico para medir a concentração de sedimentos em líquidos (MERAL, 2008) e, de forma direta, em rios (MOORE et al., 2013). Sinais de espalhamento de alta frequência (50 MHz) foram utilizados para medir a concentração em células de cultivo, permitindo diferenciar glóbulos vermelhos de vários tamanhos (CHEN et al., 2012). A técnica também foi utilizada para medir a concentração de levedura em suspensões, mostrando maior sensibilidade que a obtida por técnicas de espectrofotometria (ELVIRA et al., 2016). Um sensor de medição de retroespalhamento acústico foi utilizado para o monitoramento da coagulação do leite (BLASINA et al., 2017) e para o estudo de emulsões água em óleo hidráulico com baixa concentração de água (inferior a 15\%) (PÉREZ et al., 2019). Essa última configuração foi empregada na caracterização de emulsões neste trabalho.

Neste trabalho, é reportada a aplicação de duas células ultrassônicas, considerando os trabalhos de (HIGUTI, 2001) e (BLASINA et al., 2017). A primeira, com linhas de retardo, é utilizada no estudo da determinação de propriedades em emulsões de água em 
óleo; e a segunda, com espalhadores, é utilizada para o monitoramento de emulsões de água em petróleo. As duas células ultrassônicas foram desenvolvidas no Laboratório de Ultrassom do PMR USP, sendo que a segunda foi desenvolvida especificamente para este trabalho. Foram realizados testes com amostras a 20,25 e $30^{\circ} \mathrm{C}$, com concentrações de água na faixa de $0 \%$ a $50 \%$ em volume. O trabalho foca-se na utilização da segunda célula, onde o principal interesse é a determinação da concentração de água em petróleo em processos online e em tempo real. Assim, foram analisados os seguintes parâmetros: correlação cruzada, correlação cruzada com os sinais normalizados e energia de onda em função do tempo, da concentração de água e da temperatura. Além disso, foi proposta uma metodologia de processamento dos sinais para determinar a velocidade de propagação a partir do sinal de retroespalhamento. Esta metodologia e a aplicação de sensores de retrodispersão em emulsões de água em petróleo não tem sido reportada na literatura.

\subsection{Objetivos}

\subsubsection{Objetivo Geral}

O objetivo deste trabalho é desenvolver e implementar células ultrassônicas para a caracterização de emulsões água em óleo.

\subsubsection{Objetivos Específicos}

- Implementar técnicas de processamento de sinais que aumentem a acurácia e a resolução na determinação da quantidade de água em óleo.

- Caracterizar as emulsões de água em óleo com as células ultrassônicas.

- Determinar as relações entre as propriedades das emulsões e a concentração volumétrica de água.

\subsection{Organização}

No capítulo 2, são apresentados os conceitos teóricos necessários para a compreensão deste trabalho. Inicia com uma classificação dos diferentes tipos de misturas de líquidos, focando-se nas emulsões água em óleo. Apresentam-se algumas causas de 
emulsificação no petróleo, e as consequências de ter água nos processos de extração e refinamento. Posteriormente são abordados os conceitos relacionados aos fenômenos acústicos, tais como: a equação de onda, os coeficientes de reflexão e transmissão, e a absorção acústica. Além disso, são apresentadas as técnicas de processamento dos sinais empregadas na determinação das propriedades acústicas.

No capítulo 3, descrevem-se as duas células de medição utilizadas neste trabalho, apresentando seus componentes e materiais, o princípio de funcionamento e os sinais com elas obtidos. Detalham-se as equações utilizadas para determinar as propriedades acústicas e para realizar o monitoramento das emulsões. Enuncia-se o modelo de misturas de Urick, que permite comparar e validar alguns resultados. Finalmente, relata-se o procedimento experimental e o equipamento utilizado.

No capítulo 4, são apresentados e discutidos os resultados obtidos com as duas células de medição. Usando a célula com linhas de retardo, foram obtidas curvas das propriedades de interesse em função da concentração de água. Logo, usando a célula de espalhamento, foram obtidas curvas alusivas à variação das emulsões, e à velocidade de propagação, em função do tempo, da temperatura e da quantidade de água.

Para finalizar, no capítulo 5, são apresentadas as conclusões do trabalho e as propostas para trabalhos futuros. 


\section{CONCEITOS TEÓRICOS}

\subsection{Classificação de misturas}

Nesta seção são descritas algumas classificações de misturas de líquidos, úteis para o entendimento das nomenclaturas no presente trabalho. Apresentam-se as causas de emulsificação no petróleo e alguns problemas que isto produz na sua extração e refinamento. Também são mencionados alguns procedimentos utilizados para a desemulsificação do mesmo.

\subsubsection{Mistura}

As misturas podem ser classificadas em homogêneas ou heterogêneas. Quando a mistura apresenta uma única fase e suas propriedades permanecem iguais em todos seus pontos, diz-se que é homogênea, como uma mistura de água e álcool. Com frequência, estas também são denominadas soluções. Quando é possível observar a olho nu duas ou mais fases distintas, a mistura é heterogênea; nesse caso, a composição varia com relação à porção analisada, por exemplo uma mistura de água e óleo (BROWN et al., 2004).

\subsubsection{Emulsão}

As emulsões caracterizam-se como um tipo de dispersão e podem ser descritas como uma mistura de dois líquidos imiscíveis formando duas fases, uma contínua e outra dispersa. Estes sistemas são termodinamicamente instáveis, no entanto sua estabilidade pode ser aumentada por meio de agentes emulsificantes (THOMAS, 2001). Normalmente, sua classificação é feita de acordo com a distribuição e proporção das suas fases: um sistema constituído por gotículas de óleo dispersas em água é denominado emulsão óleo em água $(\mathrm{O} / \mathrm{A})$, enquanto um sistema com gotículas de água 
dispersas em óleo é chamado de emulsão água em óleo (A/O) ou emulsão inversa (KOKAL et al., 2005).

$\mathrm{Na}$ indústria petroquímica, as emulsões podem ser encontradas em quase todas as fases de produção e processamento do petróleo. Nos poços, além da presença do óleo cru, também há água, micro-organismos, sais e gases dissolvidos. O processo de emulsificação pode começar desde a extração, onde o óleo cru e a água são espremidos pelos poros estreitos das rochas e a tensão superficial torna-se a força motriz para a formação de gotículas esféricas. Estas gotículas formam-se na presença de altas pressões e temperaturas, ou quando experimentam-se altos gradientes de pressão (SJÖBLOM et al., 2003). Devido aos componentes nativos do petróleo, a emulsão pode atingir níveis de estabilidade mais altos, dificultando a separação das fases, pois esses componentes, tais como asfaltenos e resinas, atuam como emulsificantes (THOMAS, 2001).

A presença de água no óleo cru gera diversos problemas no seu processo produtivo, como corrosão em tubulações e equipamentos, quedas de pressão em linhas de fluxo, envenenamento dos catalisadores no processo de refinamento, e produtos finais fora da especificação (KOKAL et al., 2005). Por tais motivos é importante sua remoção. Grande parte da água e do gás são separados por decantação. Cada um, é dirigido a outra unidade de processamento. A água é condicionada para seu posterior uso, ou descarte, e o óleo é submetido a novos processamentos para eliminar a água restante até alcançar valores aceitáveis para seu transporte e refinamento (concentração de aproximadamente 1\%) (UMAR et al., 2018).

A desestabilização da emulsão pode ser conseguida por aquecimento, com ajuda de desemulsificantes ou por meio da aplicação de um campo elétrico. O tratamento térmico é realizado na faixa de $45^{\circ} \mathrm{C}$ a $60^{\circ} \mathrm{C}$ em tanques de lavagem e tratadores. $\mathrm{O}$ aquecimento reduz a estabilidade do filme interfacial, ao reduzir a viscosidade do óleo e aumentar a coalescência da água, fazendo com que a colisão de partículas dê-se com maior frequência. O campo elétrico aplicado é de alta voltagem (de $15000 \mathrm{~V}$ a $50000 \mathrm{~V}$ ). Na sua presença, as gotículas de água adquirirem uma forma elíptica e alinham-se na direção do campo, com polos induzidos de sinais contrários, levando à criação de uma força atrativa que promove sua colisão. Os desemulsificantes, quando adicionados, migram para a interface entre os líquidos, rompendo ou enfraquecendo a película interfacial e permitindo a coalescência entre as gotículas de água (THOMAS, 2001; KOKAL et al., 2005). 


\subsubsection{Partículas em suspensão}

As suspensões são outro tipo de dispersão. Distinguem-se por ter um sólido disperso em uma fase líquida contínua, onde os sólidos possuem um tamanho característico que varia na faixa de $1 \mathrm{~nm}$ a $1 \mu \mathrm{m}$. As suspensões podem conter gotículas emulsificadas ou bolhas de gás. Devido à intersecção entre dois tipos de dispersões, a nomenclatura pode tornar-se um pouco confusa. Para denominar o sistema, analisa-se a interação entre as partículas sólidas e as gotículas dispersas. Caso as partículas sólidas sejam adsorvidas pelas gotículas dispersas, o sistema é considerado como uma emulsão que contém sólidos. Se as partículas sólidas e as gotículas não estiverem mutuamente associadas, então o sistema pode ser uma suspensão ou uma emulsão e cabe analisar o contexto para selecionar a classificação mais adequada. Neste último caso, frequentemente, determina-se que uma das fases é a dispersão, enquanto a outra passa a ser considerada um aditivo ou contaminante (SCHRAMM, 2006).

\subsection{Fenômeno Acústico}

Nesta seção, abordam-se os conceitos relacionados ao fenômeno acústico, essenciais para o entendimento das metodologias desenvolvidas neste trabalho e para a análise e interpretação dos resultados. A teoria aqui descrita baseia-se no livro do (KINSLER et al., 2000).

As forças responsáveis pela propagação das ondas provêm das mudanças de pressão no fluido, quando este se expande ou se contrai. Porções do fluido movem-se para trás e para frente na direção das forças, produzindo regiões adjacentes de compressão e rarefação. Assume-se que o fluido não tem perdas, ou seja, que não há efeitos dissipativos como a viscosidade e a transferência de calor; e que as amplitudes de deslocamento das ondas são relativamente pequenas, fazendo com que as mudanças de densidade no meio sejam desprezíveis com relação aos valores de equilíbrio. Tais simplificações são satisfatórias e permitem descrever adequadamente a maioria dos fenômenos acústicos.

\subsubsection{Equação de estado}

Em um fluido, a equação de estado relaciona três quantidades físicas, descrevendo seu comportamento termodinâmico. No estudo dos fluidos, determinam-se experi- 
mentalmente as relações isentrópicas entre as variações de pressão e de densidade. Esta relação pode ser representada por séries de Taylor, segundo a eq. 2.1. Quando consideram-se pequenas variações, como mencionado, as derivadas de ordens superiores podem ser desconsideradas, obtendo uma expressão linear.

$$
\mathcal{P}=\mathcal{P}_{0}+\left.\frac{\partial \mathcal{P}}{\partial \rho}\right|_{\rho_{0}}\left(\rho-\rho_{0}\right)+\left.\frac{1}{2} \frac{\partial^{2} \mathcal{P}}{\partial \rho^{2}}\right|_{\rho_{0}}\left(\rho-\rho_{0}\right)^{2}+\cdots
$$

Sendo $p$ a diferença entre a pressão instantânea e a pressão de equilíbrio, $p=$ $\mathcal{P}-\mathcal{P}_{0} ; s$ o fator de condensação instantânea, definido como a diferença relativa entre a densidade instantânea $(\rho)$ e a densidade de equilíbrio $\left(\rho_{0}\right), s=\left(\rho-\rho_{0}\right) / \rho_{0}$; e $\mathcal{R}$ o módulo volumétrico adiabático, $\mathcal{R}=\left.\rho_{0} \frac{\partial \mathcal{P}}{\partial \rho}\right|_{\rho_{0}}$; tem-se que:

$$
p=\mathcal{R} s
$$

\subsubsection{Equação de continuidade}

Para correlacionar o movimento do fluido com sua compressão ou expansão, precisa-se de uma relação funcional entre a velocidade da partícula do fluido $\vec{u}$ e a densidade instantânea $\rho$. Essa relação é obtida a partir da conservação de massa, considerando um cubo de volume infinitesimal submetido a um fluxo de entrada e saída de fluido. O resultado, assumindo que o volume do cubo permanece o mesmo, é:

$$
\frac{\partial \rho}{\partial t}+\nabla \cdot(\rho \vec{u})=0
$$

A expressão acima é a equação exata da continuidade não linear. Para obter a equação linear aproximada, considera-se que a condensação $s$ é muito pequena, assim, lembrando que $\rho=\rho_{0}(1+s)$, tem-se que:

$$
\frac{\partial s}{\partial t}+\nabla \cdot \vec{u}=0
$$

\subsubsection{Equação de força: equação de Euler}

Nos fluidos reais, a viscosidade e o fato de que os processos acústicos não são perfeitamente adiabáticos, introduzem termos dissipativos. Contudo, estes são des- 
considerados por enquanto e retomados em seções posteriores. Assim, a equação não linear de Euler para fluidos invíscidos fica expressa por:

$$
\rho\left(\frac{\partial \vec{u}}{\partial t}+(\vec{u} \cdot \nabla) \vec{u}\right)=-\nabla p
$$

Considerando a relação $\rho=\rho_{0}(1+s)$, tem-se que:

$$
(1+s)\left(\frac{\partial \vec{u}}{\partial t}+(\vec{u} \cdot \nabla) \vec{u}\right)=-\frac{\nabla p}{\rho_{0}}
$$

Supõe-se que $|s| \ll 1$ e que $(\vec{u} \cdot \nabla) \vec{u} \ll \frac{\partial \vec{u}}{\partial t}$, obtendo:

$$
\rho_{0} \frac{\partial \vec{u}}{\partial t}=-\nabla p
$$

\subsubsection{Equação linear de onda}

As equações de estado, de continuidade e de força são utilizadas para encontrar a equação de onda. Combinando o divergente da eq. 2.7 com a derivada no tempo da eq. 2.4 e substituindo a eq. 2.2, obtém-se a equação linear de onda sem perdas:

$$
\nabla^{2} p=\frac{1}{c^{2}} \frac{\partial^{2} p}{\partial t^{2}}
$$

onde $c$ é a velocidade de propagação do meio, que para um fluido é dada por:

$$
c^{2}=\frac{\mathcal{R}}{\rho_{0}}
$$

Em (KINSLER et al., 2000) menciona-se que os parâmetros, $\mathcal{R}$ e $\rho_{0}$, variam de acordo com a temperatura e a pressão de equilíbrio do sistema, e não se tem uma teoria simples disponível para predizer esta variação. Assim, esses parâmetros devem ser medidos experimentalmente, e, consequentemente, a velocidade de propagação deve ser expressa como uma fórmula numérica. Cabe mencionar que o módulo volumétrico adiabático $\mathcal{R}$ corresponde ao inverso da compressibilidade adiabática, isto é $\beta=1 / \mathcal{R}$ (MASON, 2013). 


\subsubsection{Solução para ondas planas harmônicas}

Nesta seção, analisa-se a solução da equação de onda para fluidos homogêneos e isotrópicos, onde a velocidade de propagação é constante. Considera-se, que as ondas que se propagam são planas e harmônicas, cuja característica principal é que cada variável acústica tem amplitude constante e fase constante sobre um plano perpendicular à direção de propagação. As ondas divergentes podem ser tratadas como planas quando encontram-se suficientemente distantes de sua fonte (distância muito maior que o comprimento de onda).

Para um eixo $x$, escolhido ao longo da direção de propagação de uma onda plana, a equação de onda reduz-se à eq. 2.10. Esta pode ser resolvida por separação de variáveis, $p(x, t)=\zeta(x) \eta(t)$.

$$
\frac{\partial^{2} p}{\partial x^{2}}=\frac{1}{c^{2}} \frac{\partial^{2} p}{\partial t^{2}}
$$

Logo, a forma complexa da solução harmônica para a pressão acústica de uma onda plana é:

$$
p=A e^{i(\omega t-k x)}+B e^{i(\omega t+k x)}
$$

onde $\omega$ é a frequência angular da onda e $k$ é o número de onda, $k=\|\vec{k}\|$.

A pressão acústica de uma onda que se propaga para a frente (direção $+x$ ) estaria dada pelo primeiro termo da eq. 2.11, e a pressão de uma onda que se propaga para trás (direção $-x$ ), pelo segundo termo. Determinada a pressão acústica, a velocidade de uma partícula de fluido $\vec{u}$ pode ser deduzida a partir da eq. 2.7, obtendo:

$$
\vec{u}=u \hat{x}=\left[\left(\frac{A}{\rho_{0} c}\right) e^{i(\omega t-k x)}-\left(\frac{B}{\rho_{0} c}\right) e^{i(\omega t+k x)}\right] \hat{x}
$$

Análogo à pressão acústica, a velocidade de uma partícula excitada por uma onda que se propaga para a frente, estaria dada pelo primeiro termo da eq. 2.12, e quando excitada por uma onda que se propaga para trás, pelo segundo termo. 


\subsubsection{Impedância acústica específica}

A impedância acústica corresponde à razão entre a pressão acústica e a velocidade que experimenta uma partícula, dada por:

$$
Z=\frac{p}{u}
$$

Para ondas planas esta razão é o produto entre a densidade e a velocidade de propagação do meio.

$$
Z= \pm \rho_{0} c
$$

Embora a impedância é uma quantidade positiva, o sinal acima utiliza-se para indicar a direção de propagação da onda: positivo se for para a frente e negativo se for para trás. Trata-se de uma quantidade real na propagação de ondas planas, mas é uma quantidade complexa na propagação de ondas divergentes.

\subsubsection{Coeficientes de reflexão e transmissão}

Quando uma onda, que se propaga em um meio, encontra uma interface com um segundo meio, são geradas uma onda refletida e uma transmitida. Logo, a relação entre a amplitude da onda refletida e a da onda incidente é denominada coeficiente de reflexão $R$, e a relação entre a amplitude da onda transmitida e a da onda incidente é denominada coeficiente de transmissão $T$. A abordagem deste fenômeno é simplificada nesta seção, pois assume-se que a incidência da onda é perpendicular à interface. Apesar da simplificação, as equações desenvolvidas para incidência normal em líquidos também são válidas para sólidos.

Considera-se uma interface localizada em $x=0$, a qual delimita os meios 1 e 2 , cujas impedâncias acústicas são $Z_{1}$ e $Z_{2}$, respectivamente. Agora, seja $p_{i}$ uma onda incidente viajando na direção $+x ; p_{r}$ a onda refletida viajando na direção $-x$; e $p_{t}$ a 
onda transmitida viajando na direção $+x$.

$$
\begin{aligned}
& p_{i}=P_{i} e^{i\left(\omega t-k_{1} x\right)} \\
& p_{r}=P_{r} e^{i\left(\omega t+k_{1} x\right)} \\
& p_{t}=P_{t} e^{i\left(\omega t-k_{2} x\right)}
\end{aligned}
$$

Todas as ondas devem ter a mesma frequência angular $\omega$. Como as velocidades de propagação $c_{1}$ e $c_{2}$ são distintas, os números de onda $k_{1}$ e $k_{2}$ também são distintos.

Na interface $x=0$, devem ser satisfeitas duas condições de contorno: a pressão acústica e a velocidade das partículas em ambos os lados da fronteira devem ser iguais. Isto é:

$$
\begin{gathered}
p_{i}+p_{r}=p_{t} \\
u_{i}+u_{r}=u_{t}
\end{gathered}
$$

Dividindo a eq. $2.16 \mathrm{a}$ entre a eq. $2.16 \mathrm{~b}$, tem-se que:

$$
\frac{p_{i}+p_{r}}{u_{i}+u_{r}}=\frac{p_{t}}{u_{t}}
$$

Substituindo cada velocidade $u$, usando a eq. 2.13, e lembrando a convenção para o sinal que precede a impedância acústica, obtém-se:

$$
Z_{1} \frac{p_{i}+p_{r}}{p_{i}-p_{r}}=Z_{2}
$$

Rearranjando os termos da eq. 2.18, encontra-se o coeficiente de reflexão:

$$
R_{12}=\frac{p_{r}}{p_{i}}=\frac{Z_{2}-Z_{1}}{Z_{2}+Z_{1}}
$$

O coeficiente de transmissão é obtido dividindo a eq. 2.16 a por $p_{i}$, e posteriormente 
substituindo na eq. 2.19:

$$
T_{12}=\frac{p_{t}}{p_{i}}=\frac{2 Z_{2}}{Z_{2}+Z_{1}}
$$

Os subscritos 1 e 2 em $R$ e $T$ indicam a direção em que a onda se propaga (do meio 1 para o meio 2). Nota-se que ao dividir a eq. 2.16a por $p_{i}$, obtém-se a relação entre $R$ e $T$ :

$$
1+R_{12}=T_{12}
$$

\subsubsection{Absorção acústica}

As fontes de dissipação de energia em um meio podem ser devidas à viscosidade, à condução de calor e aos processos moleculares. As perdas viscosas têm lugar quando há movimento relativo entre porções adjacentes de fluido, como as deformações intrínsecas à propagação de ondas acústicas. As perdas por condução de calor resultam da diferença de temperaturas no meio. E as perdas por processos moleculares são devidas às conversões de energia a um nível molecular. Stokes desenvolveu a primeira teoria válida para determinar a absorção devida à viscosidade e, posteriormente, Kirchhoff contribuiu à teoria, usando a condutividade térmica, para obter o coeficiente "clássico" de absorção.

Para determinar a absorção devida à viscosidade, parte-se da equação não linear de Navier-Stokes, a qual, na ausência de forças externas, está dada por:

$$
\rho\left(\frac{\partial \vec{u}}{\partial t}+(\vec{u} \cdot \nabla) \vec{u}\right)=-\nabla p+\left(\frac{4}{3} \eta+\eta_{B}\right) \nabla(\nabla \cdot \vec{u})-\eta \nabla \times \nabla \times \vec{u}
$$

O coeficiente de viscosidade por cisalhamento $\eta$ pode ser medido diretamente e está relacionado com a difusão de momento devida a colisões entre regiões de fluido que possuem distintas velocidades. Apesar do seu nome, este parâmetro também tem lugar no movimento puramente longitudinal. Experimentalmente tem-se visto que não depende da frequência, mas sim da temperatura, para a maioria dos fluidos (KINSLER et al., 2000). O coeficiente de viscosidade aparente $\eta_{B}$ parece ser uma medida de algumas conversões entre energia cinética e potencial nas moléculas. O último termo da eq. $2.22(\eta \nabla \times \nabla \times \vec{u})$ representa a energia acústica dissipada por meio da turbulência, 
fluxo laminar, vorticidade, entre outros. Em acústica linear estes efeitos estão restritos a pequenas regiões próximas às fronteiras e são de menor importância.

A eq. 2.22 é linearizada usando a expressão linear de continuidade (eq. 2.4) e a expressão de pressão para processos adiabáticos (união das eq. 2.2 e 2.9). Lembrando que $\rho=\rho_{0}(1+s)$, obtém-se a equação de onda com perdas:

$$
\left(1+\tau_{s} \frac{\partial}{\partial t}\right) \nabla^{2} p=\frac{1}{c^{2}} \frac{\partial^{2} p}{\partial t^{2}}
$$

O termo $\tau_{s}$ é o tempo de relaxação e está dado pela eq. 2.24. Adota valores com ordem de grandeza $10^{-10}$ em gases e $10^{-12}$ em líquidos (KINSLER et al., 2000).

$$
\tau_{s}=\left(\frac{4}{3} \eta+\eta_{B}\right) \frac{1}{\mathcal{R}}
$$

Assumindo um movimento dado por uma onda monofrequência, a eq. 2.23 reduzse à equação de Helmholtz (com perdas), dada por:

$$
\nabla^{2} p+\boldsymbol{k}^{2} p=0
$$

Dada a definição do número de onda complexo e o obtido da equação de Helmholtz, tem-se:

$$
\boldsymbol{k}=k-i \alpha_{s}=\frac{\omega}{c}\left(1+i \omega \tau_{s}\right)^{-1 / 2}
$$

Igualando as partes real e imaginária da eq. 2.26 e resolvendo o sistema, obtém-se o coeficiente de absorção $\alpha_{s}$ :

$$
\alpha_{s}=\frac{\omega}{c}\left[\frac{\sqrt{1+\left(\omega \tau_{s}\right)^{2}}-1}{2+2\left(\omega \tau_{s}\right)^{2}}\right]^{1 / 2}
$$

Logo, para uma onda plana viajando na direção $+x$, a solução da equação de Helmholtz é:

$$
\begin{aligned}
& p=P_{0} e^{i(\omega t-k x)} \\
& p=P_{0} e^{-\alpha_{s} x} e^{i(\omega t-k x)}
\end{aligned}
$$


Dado que a amplitude da onda decai segundo o termo $e^{-\alpha_{s} x}, \alpha_{s}$ também é chamado de coeficiente de absorção espacial. Logo, sabe-se que, quando o termo $\omega \tau_{s}$ é pequeno, o coeficiente de absorção viscoso é proporcional ao quadrado da frequência.

$$
\alpha_{s} \approx \frac{\tau_{s}}{2 c} \omega^{2}
$$

Já o coeficiente de absorção devido à condutividade térmica, $\alpha_{k}$, tem a mesma dependência com a frequência que a absorção viscosa, e tende a desaparecer na ausência de flutuações térmicas durante a propagação da onda acústica. Nos gases, este tipo de absorção é um pouco menor que a viscosa, mas da mesma ordem de grandeza. Entretanto, para a maioria dos líquidos não metálicos, a absorção devido à variação de temperatura é desprezível.

Finalmente, o coeficiente "clássico" de absorção $\alpha_{c}$ corresponde à soma das perdas térmicas e viscosas, assumindo $\eta_{B}=0$.

\subsection{Processamento de sinais}

A pressão acústica é medida de forma indireta utilizando transdutores ultrassônicos, os quais convertem a energia de deformação em energia elétrica através do efeito piezoelétrico. A tensão elétrica proveniente do transdutor é adquirida com um osciloscópio em forma de sinal temporal, que contém toda a informação "codificada" sobre as propriedades do fenômeno acústico. Nesta seção, são apresentadas as técnicas de processamento dos sinais utilizadas no presente trabalho.

\subsubsection{Transformada de Fourier}

A transformada de Fourier é uma ferramenta matemática utilizada na análise de frequência. Permite a decomposição de um sinal em outros de caráter senoidal. O termo espectro é comumente utilizado para referir-se ao conteúdo de frequências de um sinal. Quando os sinais são periódicos, faz-se a decomposição mediante séries de Fourier e, quando têm energia finita, mediante a transformada de Fourier (PROAKIS; MANOLAKIS, 2007). Seja $f(t)$ um sinal de energia finita, sua transformada de Fourier 
$F(\omega)$ está dada por:

$$
F(\omega)=\mathcal{F}[f(t)]=\int_{-\infty}^{\infty} f(t) e^{-i \omega t} d t
$$

Similar à correlação cruzada, a transformada de Fourier mede o grau de similaridade entre as funções $f(t)$ e $e^{-i \omega t}$, para diferentes valores de $\omega$. Então, o espectro de frequências pode ser interpretado como uma medida do aporte de cada frequência à formação do sinal $f(t)$. Cabe mencionar que, devido à exponencial complexa, $F(\omega)$ tem uma componente real e outra complexa. A transformada de Fourier satisfaz a propriedade de linearidade e é inversível. Logo, sua inversa está dada por:

$$
f(t)=\mathcal{F}^{-1}[F(\omega)]=\frac{1}{2 \pi} \int_{-\infty}^{\infty} F(\omega) e^{i \omega t} d \omega
$$

Para complementar, sabe-se que a parte real da transformada de Fourier é par, e corresponde à transformada de Fourier da parte par da função $f(t)$; e que a parte complexa é ímpar, e corresponde à transformada de Fourier da parte ímpar da função $f(t)$. Isto é:

$$
\begin{array}{ccc}
f(t)=f_{\text {par }}(t)+f_{\text {impar }}(t) & \stackrel{\mathcal{F}}{\longleftrightarrow} & F(\omega)=A(\omega)+i \cdot B(\omega) \\
f_{\text {par }}(t) & \stackrel{\mathcal{F}}{\longleftrightarrow} & A(\omega) \\
f_{\text {impar }}(t) & \stackrel{\mathcal{F}}{\longleftrightarrow} & B(\omega)
\end{array}
$$

\subsubsection{Transformada discreta de Fourier (DFT)}

$\mathrm{Na}$ realidade, os sinais adquiridos não são contínuos e correspondem a uma sequência de pontos de duração finita, gerada através da amostragem de um sinal contínuo. Para estes casos, é necessário utilizar a DFT. Ela considera que o sinal analisado é apenas um período de um sinal, que se repete indefinidamente, e da mesma forma, o espectro resultante corresponde a "um período" de um espectro de frequências infinito (PROAKIS; MANOLAKIS, 2007).

O tempo é discretizado como $t=k T_{s}$ e as frequências como $f=n f_{s} / N$, sendo $f_{s}$ a frequência de amostragem, $T_{s}$ o inverso da frequência de amostragem, $N$ o número de pontos que compõem o sinal discreto e $k$ e $n$ inteiros com valor entre 0 e $N-1$. O sinal contínuo também é discretizado (no processo de amostragem) e torna-se uma 
sequência de pontos indexados por $k$, isto é $v_{k}$. A integral da eq. 2.30 é substituída por uma somatória, e o diferencial $d t$ passa a ser 1 , porque $v_{k}$ não é mais uma função do tempo. Assim, substituindo $t$ e $f$ tem-se que:

$$
F_{n}=\sum_{k=0}^{N-1} v_{k} e^{-i 2 \pi n k / N}
$$

\subsubsection{Algoritmo de Goertzel}

A transformada discreta de Fourier (DFT), dada pela eq. 2.32, parte de uma sequência de pontos, indexados pelo contador $k$, e fornece outra sequência de pontos, indexados pelo contador $n$. Quando tem-se um sinal discreto, associa-se $k$ à variável temporal, e $n$ à variável frequencial. Para $k=0$ e $n=0$ os dados estão associados a $t=0$ e $f=0$, respectivamente; e, para $k=N-1$ e $n=N-1$ os dados estão associados a $t=T_{t}-\Delta t$ e $f=f_{s}-\Delta f$, respectivamente, sendo $T_{t}$ a duração total do sinal e $f_{s}$ sua frequência de amostragem.

A variável $n$ permite identificar uma frequência compreendida na faixa $\left[0, f_{s}\right] \mathrm{e}$, com esta premissa, o algoritmo de Goertzel propõe calcular o valor da DFT para determinadas frequências de interesse, ao invés de calcular o espectro completo. Segundo a aplicação, isto pode representar um ganho em tempo de processamento (WEFERS, 2015).

$$
n_{x}=\operatorname{int}\left[\frac{f_{x}}{f_{s}} N\right]
$$

A Figura 1 mostra um exemplo da aplicação do algoritmo de Goertzel. Foi capturado um sinal com um transdutor ultrassônico de 3,50 MHz, operando no modo pulsoeco e utilizando uma frequência de amostragem $f_{s}=200 \mathrm{MHz}$. Criou-se um vetor com as frequências a serem analisadas, $f_{x}=\{2 ; 3,50 ; 4,75\} \mathrm{MHz}$, determinaram-se os índices associados $n_{x}$ usando a eq. 2.33, e calculou-se a DFT para estes. Para verificar os resultados, fez-se a comparação com os valores da DFT (em azul).

Neste trabalho, foi feito um código baseado no algoritmo de Goertzel, o qual permite calcular a DFT numa determinada banda do espectro e aumenta a resolução ao mesmo tempo. A dedução é a seguinte: a solução convencional para aumentar a resolução do espectro é adicionar zeros no final do sinal experimental. Isto faz com que o 
Figura 1: Aplicação do algoritmo de Goertzel

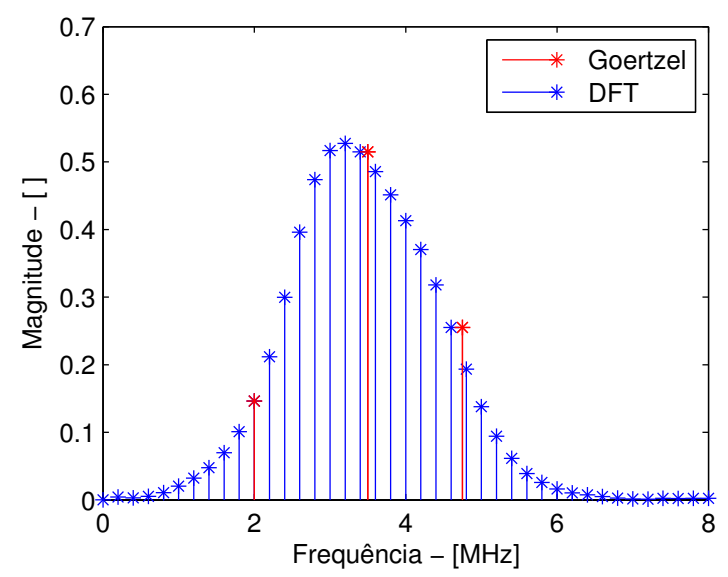

Fonte: Autor.

tamanho do sinal modificado seja $N_{T}=N+N_{z}$. Estes $N_{T}$ pontos distribuem-se uniformemente entre 0 e $f_{s}$, o que se traduz numa maior resolução. O efeito deste processo sobre a equação da DFT é aumentar o valor de $N$ a $N_{T}$, mas note que a somatória pode continuar sendo até $N-1$ porque $v_{k}=0$ para todo $k \geq N$ (devido aos zeros adicionados). Então, basta apenas determinar o valor de $N_{T}$ que garante a resolução desejada.

Seja $M$ o número de frequências desejadas, na faixa $\left[f_{i}, f_{f}\right] \subset\left[0, f_{S}\right]$, o número $N_{T}$ que garante a resolução desejada é:

$$
N_{T}=\frac{f_{s}}{f_{f}-f_{i}} M
$$

Modificando a equação da DFT tem-se que:

$$
G_{n}=\sum_{k=0}^{N-1} v_{k} e^{-i 2 \pi n k / N_{T}}
$$

Finalmente, recorre-se à expressão do algoritmo de Goertzel (eq. 2.33), para determinar os índices associados às frequências da faixa $\left[f_{i}, f_{f}\right]$.

A Figura 2 mostra um exemplo da aplicação do algoritmo implementado, usando o contexto do exemplo mostrado na Figura 1. Foram calculadas 200 frequências na faixa de $2 \mathrm{MHz}$ a $5 \mathrm{MHz}$, e para verificar os resultados, fez-se a comparação com os valores da DFT convencional (em azul). Cabe ressaltar que o algoritmo apresentado é totalmente equivalente a utilizar a expressão convencional para a DFT (eq. 2.32), 
considerando $n_{x}$ como um valor real, e não como um inteiro.

Figura 2: Aplicação da variante do algoritmo de Goertzel

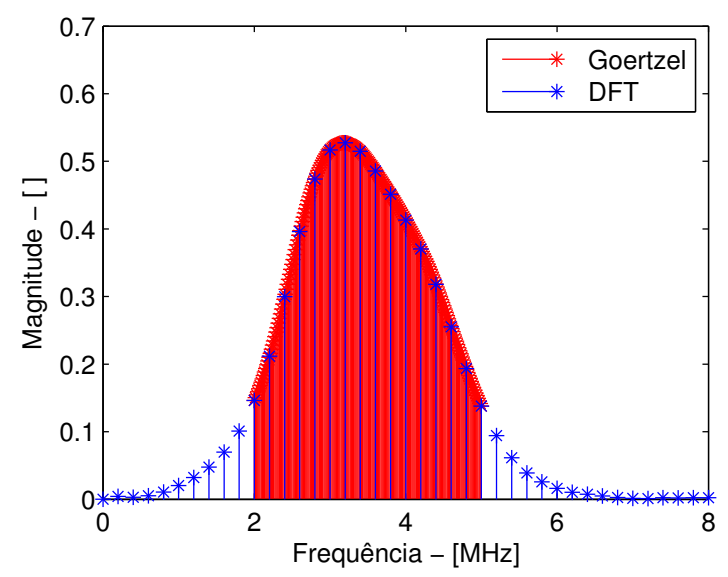

Fonte: Autor.

\subsubsection{Energia de um sinal}

Primeiro é necessário definir a potência elétrica instantânea como a variação da energia elétrica com relação ao tempo:

$$
\mathscr{P}(t)=\frac{d E}{d t}
$$

Se $V(t)$ e $I(t)$ são, respectivamente, a tensão elétrica e a corrente elétrica através de um resistor com resistência igual a $R$, a potência elétrica instantânea vem dada por (OPPENHEIM et al., 1998):

$$
\mathscr{P}(t)=\frac{[V(t)]^{2}}{R}
$$

Logo, a energia utilizada durante um intervalo de tempo $t_{a} \leq t \leq t_{b}$, determina-se como:

$$
E=\int_{t_{a}}^{t_{b}} \frac{[V(t)]^{2}}{R} d t
$$

e a potência média durante este intervalo, como:

$$
\overline{\mathscr{P}}=\frac{1}{t_{b}-t_{a}} \int_{t_{a}}^{t_{b}} \frac{[V(t)]^{2}}{R} d t
$$


Vale a pena destacar que, dependendo da natureza dos sinais, seus valores podem não estar relacionados com a tensão elétrica, não obstante generaliza-se o termo de energia e potência para qualquer tipo de sinal, e considera-se um valor de resistência unitário, $R=1$. Também é importante ressaltar que os valores dos sinais experimentais são quantidades reais, mas com fins teóricos, considera-se a possibilidade destes serem quantidades complexas. Assim, sendo $x(t)$ um sinal qualquer, sua energia, no intervalo de tempo $t_{a} \leq t \leq t_{b}$, está dada por:

$$
E=\int_{t_{a}}^{t_{b}}|x(t)|^{2} d t
$$

\subsubsection{Teorema de Parseval}

Na seção anterior, expressou-se a energia de um sinal, em um intervalo de tempo finito, através da eq. 2.40. O teorema de Parseval enuncia que a energia deste segmento de sinal, está relacionada com sua transformada de Fourier. A seguir desenvolve-se um procedimento para obter a relação de Parseval.

Primeiro, utiliza-se a expressão para a transformada inversa de Fourier:

$$
E=\int_{t_{a}}^{t_{b}}\left[\frac{1}{2 \pi} \int_{-\infty}^{\infty} X(\omega) e^{i \omega t} d \omega\right] x(t) d t
$$

A constante $1 / 2 \pi$ é extraída das integrais, o termo $x(t)$ é introduzido na integral com respeito a $\omega$, e logo, é alterada a ordem de integração:

$$
E=\frac{1}{2 \pi} \int_{-\infty}^{\infty} X(\omega)\left[\int_{t_{a}}^{t_{b}} x(t) e^{i \omega t} d t\right] d \omega
$$

Faz-se a mudança de variável $k=-t$, obtendo:

$$
E=\frac{1}{2 \pi} \int_{-\infty}^{\infty} X(\omega)\left[\int_{-t_{b}}^{-t_{a}} x(-k) e^{-i \omega k} d k\right] d \omega
$$

A função $x(k)$ pode ser decomposta na soma de duas funções, uma par e uma ímpar. A par cumpre que $x_{p a r}(-k)=x_{p a r}(k)$ e a ímpar que $x_{i m p a r}(-k)=-x_{\text {impar }}(k)$. Desta forma, tem-se que: 


$$
E=\frac{1}{2 \pi} \int_{-\infty}^{\infty} X(\omega)\left[\int_{t_{a}}^{t_{b}}\left(x_{p a r}(k)-x_{\text {impar }}(k)\right) e^{-i \omega k} d k\right] d \omega
$$

Como foi visto na seção 2.3.1, se a transformada de Fourier de $x(k)$ é $A(\omega)+i B(\omega)$, a transformada de Fourier de $x(-k)$, lembrando as relações de paridade, seria $A(\omega)-$ $i B(\omega)$, ou seja, o conjugado da transformada de Fourier de $x(k)$.

$$
\begin{aligned}
& E=\frac{1}{2 \pi} \int_{-\infty}^{\infty} X(\omega) X^{*}(\omega) d \omega \\
& E=\frac{1}{2 \pi} \int_{-\infty}^{\infty}|X(\omega)|^{2} d \omega
\end{aligned}
$$

onde $X^{*}(\omega)$ é o conjugado de $X(\omega)$.

Finalmente, lembrando que $X(\omega)$ corresponde à transformada de Fourier do sinal $x(t)$ no intervalo de tempo $t_{a} \leq t \leq t_{b}$, tem-se que:

$$
E=\int_{t_{a}}^{t_{b}}|x(t)|^{2} d t=\frac{1}{2 \pi} \int_{-\infty}^{\infty}|X(\omega)|^{2} d \omega
$$

A relação de Parseval estabelece que a energia de um sinal, em um intervalo de tempo, pode ser determinada, mediante o sinal temporal, integrando $|x(t)|^{2}$ no intervalo de tempo em questão, ou mediante a transformada de Fourier do sinal, integrando $(1 / 2 \pi)|X(\omega)|^{2}$ no domínio das frequências. Por este motivo, o termo $|X(\omega)|^{2}$ é também conhecido como o espectro de densidade de energia do sinal $x(t)$ (PROAKIS; MANOLAKIS, 2007).

\subsubsection{Transformada de Hilbert}

A transformada de Hilbert $\widetilde{x}(t)$ é comumente utilizada para obter a envoltória de um sinal $x(t)$. Determina-se a transformada de Hilbert de $x(t)$ mediante a expressão:

$$
\mathcal{H}[x(t)]=\widetilde{x}(t)=\frac{1}{\pi} \int_{-\infty}^{\infty} \frac{x(u)}{u-t} d u
$$

A equação anterior é equivalente a passar a função $x(t)$ através de um filtro cuja 
função de transferência é $H(\omega)=-i \cdot \operatorname{sign}(\omega)$ (ZANUY, 2001), onde:

$$
\operatorname{sign}(\omega)=\left\{\begin{array}{rr}
1 & \omega>0 \\
0 & \omega=0 \\
-1 & \omega<0
\end{array}\right.
$$

Desta forma, sendo $G(\omega)$ a transformada de Fourier de $x(t)$, tem-se que:

$$
\widetilde{x}(t)=\mathcal{F}^{-1}[G(\omega) H(\omega)]
$$

Nota-se que a transformada de Hilbert defasa $-\frac{\pi}{2}$ todas as frequências positivas e $\frac{\pi}{2}$ todas as frequências negativas, fazendo com que $x(t)$ seja ortogonal a $\widetilde{x}(t)$. Isto é $\langle x(t), \widetilde{x}(t)\rangle=0$.

Complementando, tem-se que a energia de $x(t)$ é igual à energia de $\widetilde{x}(t)$, porque lembrando o teorema de Parseval, esta pode ser calculada através da transformada de Fourier do sinal temporal, e, das eq. 2.43 e 2.44, deduz-se que $|G(\omega) H(\omega)|=|G(\omega)|$.

Finalmente define-se a pro-envolvente de $x(t)$ como $x_{p}(t)=x(t)+i \cdot \widetilde{x}(t)$, e, a envolvente de $x(t)$, como sua norma, $x_{e}(t)=\left|x_{p}(t)\right|$ (ALBERTÍ, 2009).

\subsubsection{Correlação cruzada}

A correlação cruzada é um operador que permite medir o grau de similaridade entre duas funções, $X(t)$ e $Y(t)$. Pode interpretar-se como o cálculo do seu produto interno, considerando um deslocamento variável entre elas. Desta forma, a correlação cruzada torna-se dependente do deslocamento conhecido:

$$
R_{X Y}(\delta)=\int_{-\infty}^{\infty} X(\tau) Y(\tau+\delta) d \tau=\langle X(t), Y(t+\delta)\rangle
$$

A expressão anterior mostra que a função $X$ permanece fixa enquanto $Y$ deslocase uma quantidade $\delta$ (para a esquerda quando $\delta>0$ e para a direita quando $\delta<0$ ). Verifica-se que deslocar $Y$ à esquerda mantendo $X$ fixo, é equivalente a deslocar $X$ à direita mantendo $Y$ fixo, e vice-versa (PROAKIS; MANOLAKIS, 2007). Isto é:

$$
\int_{-\infty}^{\infty} X(\tau) Y(\tau+\delta) d \tau=\int_{-\infty}^{\infty} X(\tau-\delta) Y(\tau) d \tau
$$


Assim, mesmo tratando-se de uma operação não comutativa, $R_{X Y}$ e $R_{Y X}$ encontramse relacionadas mediante a expressão:

$$
R_{X Y}(\delta)=R_{Y X}(-\delta)
$$

É importante ressaltar que, quando as duas funções são iguais, obtém-se a expressão da autocorrelação $R_{X X}$ (a qual é simétrica e comutativa). Logo, vê-se que para este caso, em $\delta=0$, recupera-se a eq. 2.40, associada à energia de um sinal. Isto é $R_{X X}(0)=E$. A correlação cruzada também encontra-se relacionada com a operação de convolução e, consequentemente, com a transformada de Fourier.

A convolução entre duas funções $X$ e $Y$ é definida como:

$$
X(t) * Y(t)=\int_{-\infty}^{\infty} X(\tau) Y(t-\tau) d \tau
$$

e é fácil demostrar que a transformada de Fourier da convolução de duas funções corresponde ao produto das transformadas de Fourier de cada:

$$
\mathcal{F}[X(t) * Y(t)]=X(\omega) Y(\omega)
$$

Comparando as eq. 2.45 e 2.47, a correlação cruzada pode ser expressa como:

$$
R_{X Y}(\delta)=X(t) * Y(-t)
$$

e usando a eq. 2.48, obtém-se que a correlação cruzada corresponde à transformada inversa de Fourier do produto entre a transformada de Fourier da função fixa e o conjugado da transformada de Fourier da função móvel:

$$
R_{X Y}(\delta)=\mathcal{F}^{-1}\left[X(\omega) Y^{*}(\omega)\right]
$$

É muito importante conhecer a expressão anterior porque, numericamente, o custo computacional de implementar a eq. 2.45 é maior ao de implementar a eq. 2.50 (basta calcular o número de operações para verificá-lo). 


\subsubsection{Correlação cruzada com os sinais normalizados}

A correlação cruzada permite medir o grau de similaridade entre duas funções ou identificar a presença de um sinal em outro e, para isto, ela compara a magnitude e a fase das duas. A magnitude relaciona-se com a altura que alcançam os picos da correlação, e a fase com a localização destes. Não obstante, a altura dos picos depende de toda a informação contida em ambas as funções, e dependendo das suas escalas os picos podem tornar-se mais ou menos proeminentes (SCHILLING; HARRIS, 2016).

Quando deseja-se comparar um sinal com vários outros, e determinar com qual deles é mais parecido, pode ser necessário descontar os efeitos da amplitude através da normalização, a qual faz-se mediante a raiz quadrada da energia, apresentada na seção 2.3.4. Assim, sendo $X(t)$ e $Y(t)$ dois sinais quaisquer, a normalização desses sinais é determinada por:

$$
\begin{aligned}
& X_{n}(t)=\frac{X(t)}{\sqrt{E_{X}}} \\
& Y_{n}(t)=\frac{Y(t)}{\sqrt{E_{Y}}}
\end{aligned}
$$

Logo, a correlação cruzada é calculada substituindo $X_{n}(t)$ e $Y_{n}(t)$ na eq. 2.45.

\subsubsection{Métodos $k$-means e $k$-medoids}

O k-means é um método de agrupação de dados que consiste na segmentação de um conjunto de $N$ observações em $k$ grupos, onde cada observação pertence ao grupo cujo valor médio é mais próximo. As observações são um conjunto de pontos de dimensão $\zeta$, dada pela quantidade de atributos que possuem.

São distribuídos $k$ centroides no meio do conjunto de dados (um por cada grupo). Para cada elemento, é calculada a distância com relação aos centroides, com a intenção de determinar a que grupo pertencem (ao grupo cujo centroide é mais próximo). Para cada grupo, é atualizada a posição dos centroides, calculando a média dos atributos do grupo. O processo é realizado de forma recorrente até que os centroides estabilizam-se numa determinada posição (WU, 2012).

A maior dificuldade está na localização inicial dos centroides, a qual pode ser 
feita de forma aleatória, ou baseando-se em algum critério. Quando no chute inicial obtêm-se centroides sem elementos vinculados (grupos vazios), podem criar-se novos centroides. Este processo pode ser repetido algumas vezes; se continuar aparecendo centroides sem elementos, estes podem ser excluídos.

A Figura 3 mostra um exemplo que ilustra a aplicação do método $k$-means em um problema $\operatorname{com} N=30$ observações de dimensão $\zeta=2$ (dois atributos por observação). As estrelas representam os centroides e os círculos as observações. As cores indicam as dependências entre os dados e os centroides, ou seja, os grupos formados. O problema de duas dimensões permite visualizar o funcionamento do algoritmo explicado anteriormente.

Figura 3: Exemplo de aplicação do método k-means em um problema com 30 observações de dimensão 2. As estrelas representam os centroides e os círculos as observações.
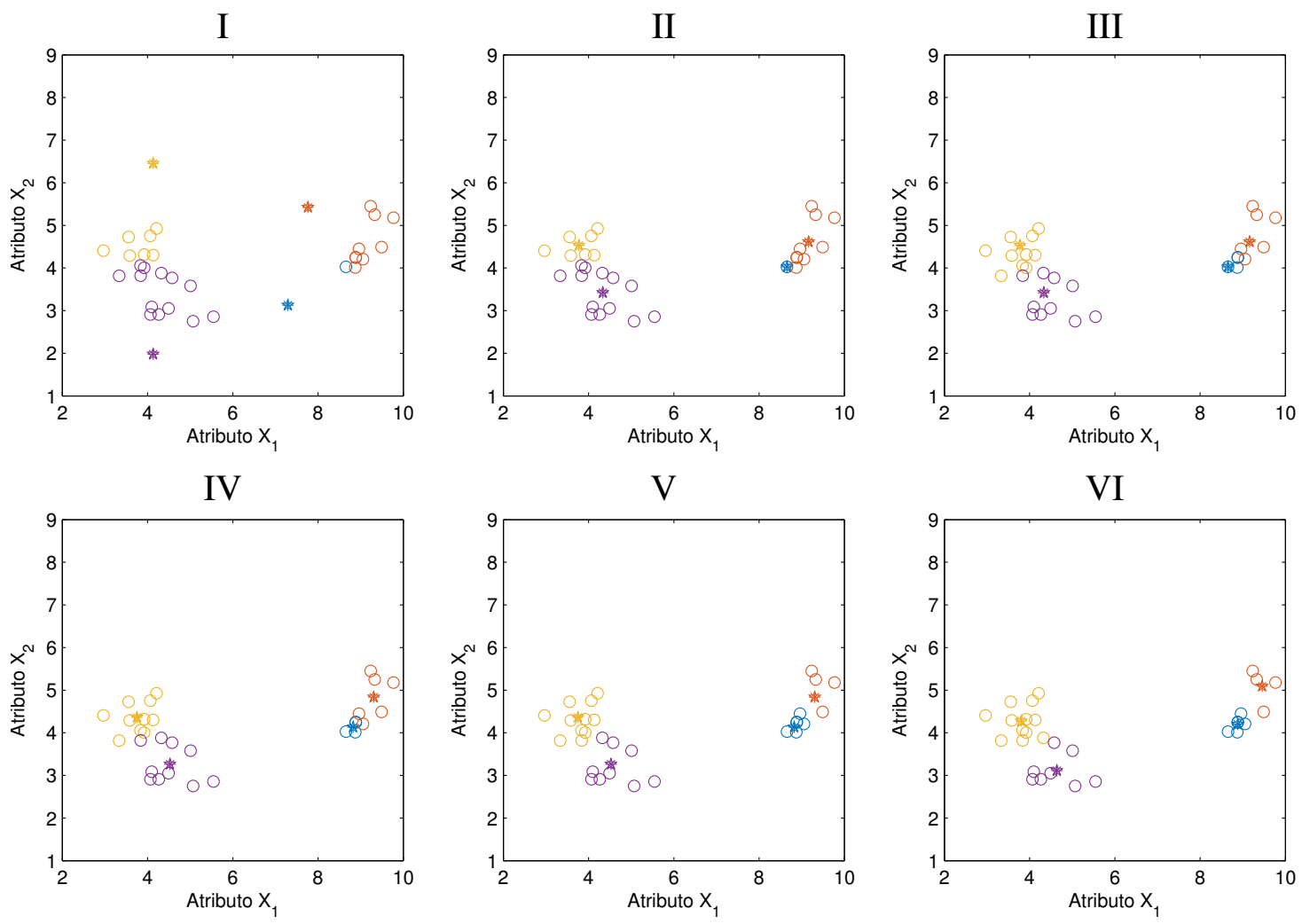

Fonte: Autor.

O erro da segmentação final, calculado pela eq. 2.52, é útil para otimizar a quantidade de grupos após levantar a curva de erro em função da quantidade de grupos.

$$
\text { erro }=\sum_{i=1}^{k} \sum_{e=1}^{E_{i}}\left\|\vec{C}_{i}-\vec{X}_{e, i}\right\|
$$


sendo $E_{i}$ a quantidade de elementos no grupo $i, C_{i}$ o centroide do grupo $i$, e $X_{e, i}$ o elemento $e$ pertencente ao grupo $i$.

O método $k$-medoids funciona da mesma forma que o método $k$-means, porém a posição dos centroides será sempre um ponto do conjunto de dados. Neste trabalho, na seção 3.6, foi utilizada a metodologia $k$-medoids para escolher um valor representativo de um conjunto de dados, obtidos a partir de um processamento de sinais. Estes dados, de dimensão $\zeta=1$, se aglomeravam formando grupos bem diferenciados em torno de certos valores discretos (com pouca dispersão). Como os dados provinham de medições realizadas com água, que tem um comportamento bastante estável, era esperado que os valores "corretos" tivessem maior frequência (maior repetitividade), e que os errados fossem os menos frequentes. Com esta premissa, a ideia era determinar o centroide do grupo com mais dados associados. Antes de recorrer a este método, pensou-se em utilizar o valor médio do conjunto de dados, mas isto faria com que os valores errôneos comprometessem o valor representativo global; também pensou-se em utilizar a moda, mas não funcionaria corretamente porque os valores eram distintos nos decimais. Desta forma, o método $k$-medoids parecia uma boa alternativa. 


\section{MATERIAIS E METODOLOGIA}

Neste capítulo, são apresentadas as duas células de medição utilizadas no presente trabalho: uma com linhas de retardo e outra com espalhadores. Descrevem-se seus componentes e materiais utilizados, explica-se seu princípio de funcionamento e mostra-se a forma dos sinais adquiridos com elas. Para a célula com linhas de retardo, detalham-se as equações e o processamento dos sinais realizado para determinar as propriedades de interesse das amostras: velocidade de propagação, coeficiente de reflexão, impedância acústica, densidade e atenuação acústica; apresenta-se uma análise da propagação da incerteza de medição na determinação das propriedades e, posteriormente, o modelo de misturas de Urick, usado na comparação com os resultados experimentais. Para a célula com espalhadores, detalham-se as equações e o processamento dos sinais utilizado na medição das variações relativas nas amostras ao adicionar água, empregando a correlação cruzada e a energia de onda; também são propostas algumas metodologias para calcular a velocidade de propagação a partir do sinal de dispersão. Finalmente, é relatado o procedimento experimental desenvolvido para adquirir os dados, explicando como foram preparadas as emulsões e descrevendo os equipamentos utilizados para a medição.

\subsection{Célula com linhas de retardo}

A célula com linhas de retardo encontrava-se disponível, porém desmontada, no Laboratório de Ultrassom da Escola Politécnica da USP. Foram realizadas alterações durante o processo de montagem, com relação à sua configuração original, baseadas nas dificuldades encontradas em (HIGUTI, 2001). A colagem de uma membrana de PVDF entre duas linhas de retardo sólidas implicava: tomar cuidado para não danificar a membrana (que é frágil), distribuir uniformemente a cola nas duas faces da membrana (evitando curto circuito entre os eletrodos) e compensar o valor da velocidade 
de propagação da amostra calculada em função da espessura da membrana e das duas camadas de cola. Por estes motivos, neste trabalho não foi empregada uma membrana de PVDF e a primeira linha de retardo foi substituída por água, no entanto, para mitigar os efeitos da difração, foi aplicado o método da reflexão relativa na determinação das propriedades acústicas (BUIOCHI, 1994).

A Figura 4 mostra a célula de medição utilizada e um esquema do seu funcionamento. Esta célula é composta por um transdutor ultrassônico comercial de 3,50 MHz e diâmetro de 19 mm (Panametrics V381-SU), duas linhas de retardo, uma câmara de amostra, um refletor e duas mangueiras que facilitam a injeção do fluido a ser medido. A primeira linha de retardo é água e a segunda é um vidro de borossilicato. Os ecos provenientes de cada interface proporcionam informações que permitem determinar as seguintes propriedades: velocidade de propagação, coeficiente de reflexão, impedância acústica, densidade e atenuação acústica.

Figura 4: Fotografia da célula com linhas de retardo e esquema dos seu funcionamento.

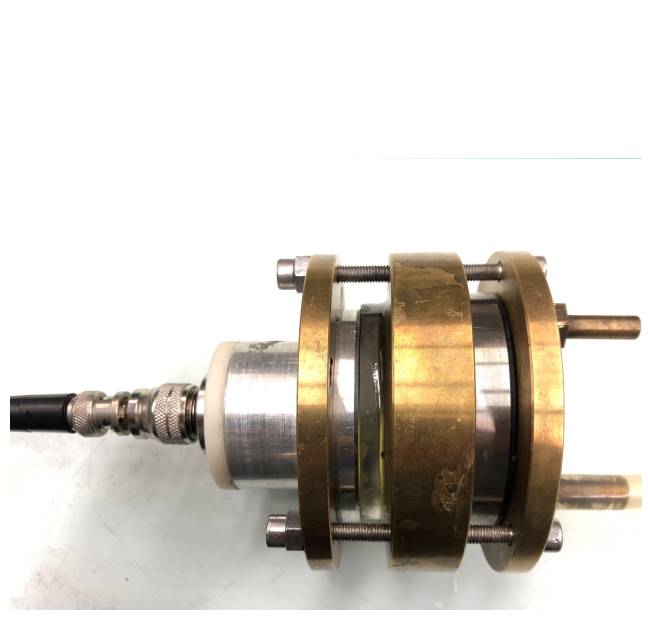

a) Fotografia da célula com linhas de retardo

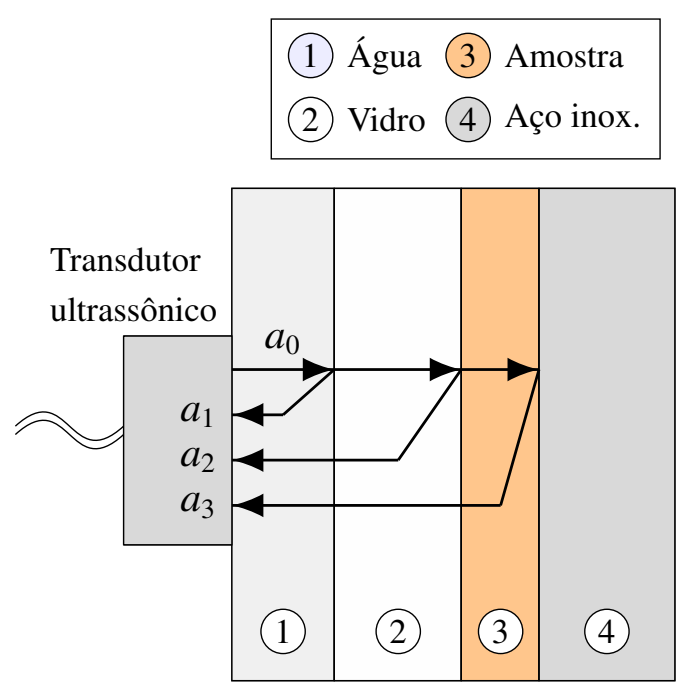

b) Esquema do funcionamento da célula

Fonte: Autor.

Usar água como primeira linha de retardo permite ajustar a distância percorrida pelos sinais para que não haja superposição dos mesmos. De um modo geral, o comprimento adequado de cada camada $\left(l_{n}\right)$ depende da velocidade de propagação de cada material $\left(c_{n}\right)$ e da frequência de operação do transdutor $\left(f_{0}\right)$. Como representado na Figura $4 \mathrm{~b}$, o transdutor emite um pulso $a_{0}$ que se propaga através dos diferentes meios e, cada vez que este atinge uma interface, um eco retorna sendo capturado pelo mesmo transdutor (no modo pulso-eco). O tempo $\left(t_{n}\right)$ em que é recebido cada eco pode ser 
calculado como:

$$
t_{n}=2 \sum_{i=1}^{n} \frac{l_{i}}{c_{i}}
$$

sendo $n$ o índice de cada camada, que coincide com os índices dos ecos no esquema.

Dependendo da análise, pode ser necessário um segundo e um terceiro eco provenientes da câmara da amostra. Nesse caso, precisa-se determinar os tempos de chegada destes ecos, usando a expressão:

$$
t_{3, k}=\left[2 \sum_{i=1}^{3} \frac{l_{i}}{c_{i}}\right]+\frac{2 l_{3}}{c_{3}} \cdot(k-1)
$$

sendo $k$ o índice do eco desejado (2 ou 3).

A ideia de conhecer o tempo de chegada dos ecos é evitar que estes se sobreponham. O tempo de duração do pulso também deve ser considerado na análise. Os tempos de chegada podem ser controlados a partir da escolha do material e do comprimento de cada camada, utilizando as eqs. 3.1 e 3.2. Embora a velocidade de propagação da amostra seja desconhecida, por tratar-se de emulsões água em óleo, utiliza-se a velocidade de propagação da água no dimensionamento da célula. As propriedades dos materiais que compõem a célula estão resumidas na Tabela 1.

A velocidade de propagação no vidro foi calculada de forma análoga à mencionada na seção 3.2.1, e sua densidade foi determinada a partir do seu peso e sua geometria, logo, as propriedades da água e do aço inoxidável foram extraídas da literatura (KINSLER et al., 2000; OLYMPUS, 2021). O comprimento da câmara da amostra e da camada de vidro foram medidos com paquímetro, sendo estes $2,00 \mathrm{~mm}$ e $25,60 \mathrm{~mm}$, respectivamente.

Tabela 1: Propriedades dos materiais de composição da Célula I (medidos a $20^{\circ} \mathrm{C}$ )

\begin{tabular}{|l|r|r|r|}
\hline \multicolumn{1}{|c|}{ Material } & \multicolumn{1}{|c|}{$\begin{array}{c}\text { Velocidade de } \\
\text { propagação }(\mathrm{m} / \mathrm{s})\end{array}$} & Densidade $\left(\mathrm{Kg} / \mathrm{m}^{3}\right)$ & $\begin{array}{c}\text { Impedância } \\
\text { acústica (Mrayl) }\end{array}$ \\
\hline Água $\left(20^{\circ} \mathrm{C}\right)$ & 1481 & 1000 & 1,48 \\
\hline Vidro (borossilicato) & 5648 & 2284 & 12,90 \\
\hline Aço inoxidável & 5740 & 7980 & 45,81 \\
\hline
\end{tabular}

Foi feito um programa no Matlab para simular o funcionamento da célula e antecipar a localização dos ecos, considerando um tempo de duração dos ecos igual a cinco 
períodos $\left(5 / f_{o}\right)$. Para o projeto da célula, a velocidade de propagação dos materiais que a compõem pode ser estimada utilizando dados da literatura, ou pode ser obtida experimentalmente em ensaios de pulso-eco, como mostrado na seção 3.2.1.

\subsection{Cálculo das propriedades acústicas usando a célula com linhas de retardo}

Os sinais adquiridos com a célula são da forma mostrada na Figura 5. Na Figura 5a e 5b, os ensaios foram realizados, respectivamente, com ar e com emulsão na câmara da amostra. Em azul, é representado o eco da primeira linha de retardo $\left(a_{1}\right)$, associado à interface água-vidro; em vermelho, é representado o eco da segunda linha de retardo $\left(a_{2}\right)$, associado à interface vidro-amostra; e em verde, são mostrados os ecos provenientes da câmara da amostra $\left(a_{3,1}\right.$ e $\left.a_{3,2}\right)$, associados à interface amostra-aço inoxidável. Observa-se que a amplitude do segundo eco é menor no ensaio realizado com a emulsão do que no ensaio com ar. Isso ocorre porque a reflexão do sinal na interface vidro-ar pode ser considerada como total, apresentando um coeficiente de reflexão igual a -1 . Na Figura 5c são mostradas as transformadas de Fourier dos ecos adquiridos no ensaio com a emulsão. Essas curvas são utilizadas para determinar quatro das cinco propriedades estudadas nas seções seguintes. As propriedades determinadas com a célula com linhas de retardo são: velocidade de propagação, coeficiente de reflexão, impedância acústica, densidade e atenuação acústica. 
Figura 5: Sinais experimentais adquiridos com a célula com linhas de retardo: a) ensaios realizados com ar na câmara da amostra, e b) ensaios realizados com emulsões. c) Transformada discreta de Fourier dos ecos obtidos com emulsões, na banda de frequência 1-6 MHz.

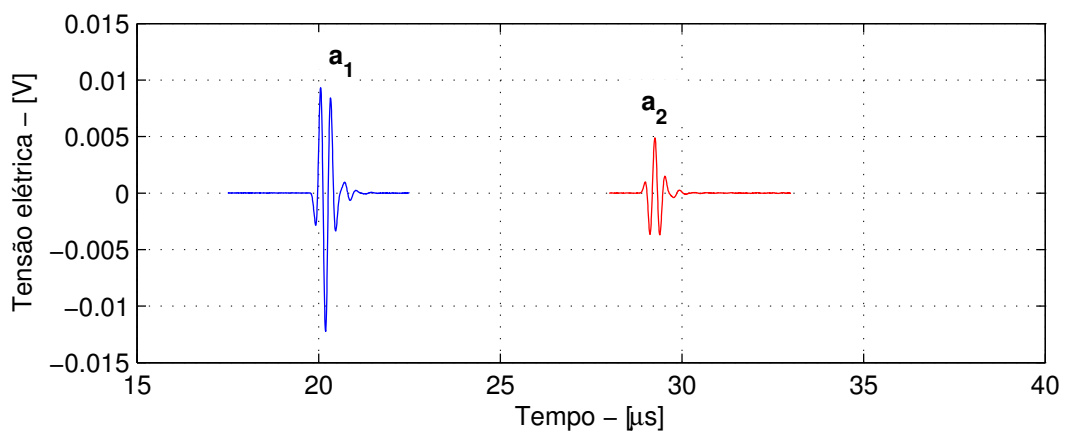

a)

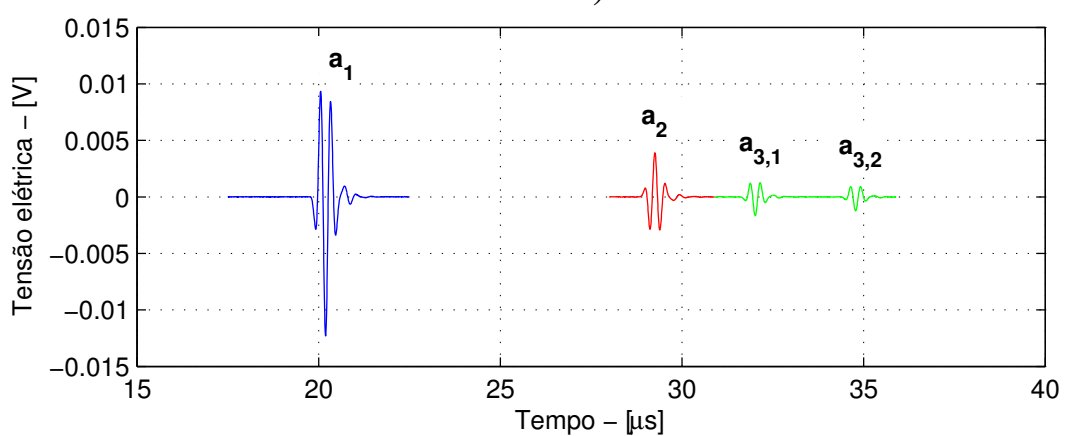

b)

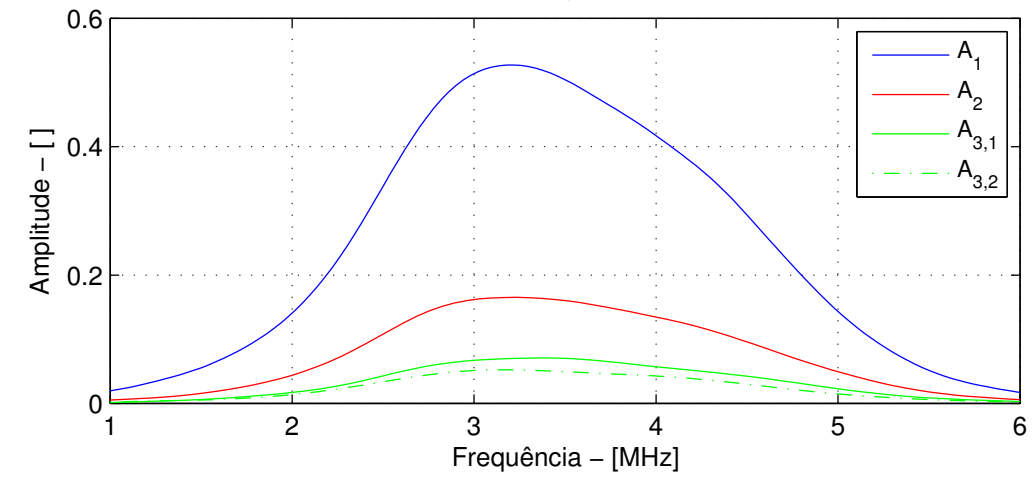

c)

Fonte: Autor.

\subsubsection{Velocidade de propagação}

A velocidade de propagação da amostra é obtida mediante a determinação do atraso temporal entre o eco proveniente da segunda linha de retardo $\left(a_{2}\right)$ e o primeiro eco da câmara da amostra $\left(a_{3,1}\right)$; isto é $\delta t_{23}$. $\mathrm{O}$ atraso pode ser medido de várias formas, 
não obstante, nesta seção foi medido aplicando a correlação cruzada:

$$
R_{x y}(\delta t)=\int_{-\infty}^{+\infty}\left[a_{2}(\tau)\right]\left[a_{3,1}(\delta t+\tau)\right] d \tau
$$

Localiza-se o delay associado ao máximo absoluto da correlação $\left(\delta t_{@ \max \left(\left|R_{x y}\right|\right)}\right)$, e posteriormente calcula-se $\delta t_{23}$ como:

$$
\delta t_{23}=t_{3}-t_{2}-\delta t_{@ \max \left(\left|R_{x y}\right|\right)}
$$

sendo $t_{2}$ e $t_{3}$ os inícios das janelas temporais dos ecos $a_{2}$ e $a_{3,1}$, respectivamente. Cabe mencionar que a correlação cruzada não é comutativa, consequentemente, o sinal que precede a $\delta t_{@ \max \left(\left|R_{x y}\right|\right)}$ pode ser positivo ou negativo, dependendo de qual seja a função móvel na eq. 3.3.

Finalmente, calcula-se a velocidade de propagação, usando a expressão:

$$
c_{s}=\frac{2 l_{s}}{\delta t_{23}}
$$

sendo $l_{s}$ o comprimento da câmara da amostra.

O comprimento da câmara da amostra é conhecido e poderia ser medido com paquímetro. Entretanto, para garantir a vedação da câmara é utilizado um anel o-ring. Assim, dependendo da força de aperto nos parafusos que unem o refletor ao restante da célula, a distância da câmara da amostra pode mudar sutilmente. Embora possa parecer insignificante uma variação de décimos de milímetro, a velocidade de propagação é bastante sensível (como é discutido no capítulo Resultados). Portanto, o mais prudente é calibrar a distância $l_{s}$ com um ensaio feito com água destilada, cuja velocidade de propagação $\left(c_{w}\right)$ é conhecida da literatura.

$$
l_{s}=\frac{c_{w} \delta t_{23, w}}{2}
$$

sendo $\delta t_{23, w} \mathrm{o}$ atraso entre os ecos $a_{2}$ e $a_{3,1}$ do ensaio realizado com água.

A velocidade de propagação do vidro deve ser conhecida a priori para seu posterior uso na determinação da impedância acústica da amostra (seção 3.2.3). Esta é determinada realizando um procedimento análogo ao mencionado acima, a partir do 
atraso temporal $\left(\delta_{12}\right)$ entre os ecos provenientes da primeira e da segunda linha de retardo, $a_{1}$ e $a_{2}$, respectivamente. Para calcular a velocidade é substituída a equação 3.5, usando $\delta_{12}$ e o comprimento da segunda linha de retardo $\left(l_{2}=25,6 \mathrm{~mm}\right)$. Nesse caso, a calibração não é necessária, pois o comprimento da camada de vidro não apresenta variações.

\subsubsection{Coeficiente de reflexão}

Na seção 2.2.7, foi visto que o coeficiente de reflexão numa interface é calculado a partir das impedâncias acústicas dos dois meios (eq. 2.19), sendo a impedância acústica do meio definida pelo produto entre a densidade e a velocidade de propagação (eq. 2.14). A razão entre as amplitudes de pressão das ondas refletida e incidente resulta no coeficiente de reflexão. O sinal de menos indica que houve uma inversão de fase entre as ondas incidente e refletida. A partir da relação entre as amplitudes dos ecos, é possível determinar o coeficiente de reflexão $\left(R_{23}\right)$, como mostrado nesta seção.

O sinal emitido $a_{0}(t)$, considerando a atenuação acústica, está dada pela eq. 3.7a, válida apenas para ondas monocromáticas. Como os pulsos emitidos experimentalmente estão constituídos por uma banda de frequência, faz-se uma análise das propriedades na banda do sinal em $-6 \mathrm{~dB}$ ou $-12 \mathrm{~dB}$. Este estudo é conhecido como análise espectral de frequências, onde é calculada a transformada de Fourier dos sinais temporais e as propriedades são determinadas no domínio da frequência. Logo, a eq. 3.7b representa a transformada de Fourier do sinal emitido (considerando-o monocromático).

$$
\begin{aligned}
a_{0}(t, x) & =P_{0} e^{i\left(\omega_{0} t-k x\right)} e^{-\alpha_{1} x} \\
A_{0}(\omega, x) & =2 \pi P_{0} \delta\left(\omega-\omega_{0}\right) e^{-i \omega_{0} \delta t_{x}} e^{-\alpha_{1} x}
\end{aligned}
$$

sendo $P_{0}$ a amplitude do sinal, $\omega_{0}$ a frequência angular de operação do transdutor, $k$ o número de onda, $\delta t_{x}$ o tempo transcorrido desde que o sinal é emitido até atingir a posição $x$, e $\alpha_{1}$ a atenuação acústica do meio de propagação (da primeira linha de retardo).

Considerando apenas a magnitude na eq. $3.7 \mathrm{~b}$, e sabendo que $\omega=2 \pi f$, tem-se 
que:

$$
A_{0}(f, x)=2 \pi P_{0} \delta\left(2 \pi f-2 \pi f_{0}\right) e^{-\alpha_{1} x}=P_{0} \delta\left(f-f_{0}\right) e^{-\alpha_{1} x}
$$

Como foi mencionado, a eq. 3.8 corresponde à transformada de Fourier de um sinal monocromático, que pode ser representada por um ponto na coordenada $\left(f_{0}, P_{0} e^{-\alpha_{1} x}\right)$. Considerando que um sinal temporal pode ser representado por meio da somatória de várias funções senoidais e que a transformada de Fourier tem a propriedade de linearidade, a transformada de um pulso qualquer emitido é uma função discreta no domínio da frequência, dada pelos pontos $\left(f_{n}, P_{n} e^{-\alpha_{1} x}\right)$.

Substituindo $x$ segundo à distância percorrida, as expressões para os ecos provenientes das diferentes interfaces, água-vidro $\left(A_{1}\right)$, vidro-amostra $\left(A_{2}\right)$ e amostra-refletor $\left(A_{3}\right)$, em termos da amplitude do sinal emitido $\left(A_{0}\right)$, são:

$$
\begin{aligned}
& A_{1}(f)=A_{0}(f) e^{-2 \alpha_{1} l_{1}} R_{12} \\
& A_{2}(f)=A_{0}(f) e^{-2 \alpha_{1} l_{1}} T_{12} T_{21} e^{-2 \alpha_{2} l_{2}} R_{23} \\
& A_{3}(f)=A_{0}(f) e^{-2 \alpha_{1} l_{1}} T_{12} T_{21} e^{-2 \alpha_{2} l_{2}} T_{23} T_{32} e^{-2 \alpha_{s} l_{s}} R_{34}
\end{aligned}
$$

sendo $\alpha_{n}$ e $l_{n}$ a atenuação acústica e o comprimento da camada de material que indica o subíndice $n$, respectivamente; e, $R_{i j}$ e $T_{i j}$ os coeficientes de reflexão e transmissão, respectivamente, do sinal propagando-se do meio $i$ para o meio $j$. O termo $l_{s}$ refere-se ao comprimento da câmara da amostra, que também poderia ser $l_{3}$.

Dividindo a eq. $3.9 \mathrm{~b}$ pela eq. $3.9 \mathrm{a}$ obtém-se:

$$
\frac{A_{2}(f)}{A_{1}(f)}=\frac{T_{12} T_{21}}{R_{12}} e^{-2 \alpha_{2} l_{2}} R_{23}
$$

as incógnitas da eq. $3.10\left(\alpha_{2}\right.$ e $\left.R_{23}\right)$ podem ser resolvidas realizando um ensaio com ar na câmara da amostra, porque o coeficiente de reflexão vidro-ar é aproximadamente igual a -1. Desta forma:

$$
\frac{A_{2}^{a r}(f)}{A_{1}^{a r}(f)}=-\frac{T_{12} T_{21}}{R_{12}} e^{-2 \alpha_{2} l_{2}}
$$

Combinando as eq. 3.10 e 3.11 , e colocando em evidência o termo $R_{23}$, tem-se 
que:

$$
R_{23}(f)=-\frac{A_{2}(f) / A_{1}(f)}{A_{2}^{a r}(f) / A_{1}^{a r}(f)}
$$

Cabe destacar que as transformadas discretas de Fourier (DFT) foram computadas usando um código baseado no algoritmo de Goertzel (ver seção 2.3.3), aplicado na faixa de frequências de $-6 \mathrm{~dB}$ com uma resolução de 500 pontos.

\subsubsection{Impedância acústica}

Uma vez determinado o coeficiente de reflexão na interface vidro-amostra (subseção anterior) e conhecendo as propriedades do vidro (Tabela 1), calcula-se a impedância acústica da amostra $Z_{s}$ a partir da eq. 2.19. Colocando em evidência o termo de interesse, tem-se que:

$$
Z_{s}(f)=\frac{1+R_{23}}{1-R_{23}} Z_{2}
$$

A impedância acústica do vidro $\left(Z_{2}\right)$ também pode ser calibrada a partir do valor reportado na literatura para a impedância acústica da água $\left(Z_{w}\right)$; e de fato sua calibração pode ser útil para verificar os valores medidos de densidade e velocidade de propagação do vidro.

$$
Z_{2}=\frac{1-R_{23}}{1+R_{23}} Z_{w}
$$

\subsubsection{Densidade}

A impedância acústica da amostra é calculada como o produto da densidade e da velocidade de propagação (eq. 2.14). Determinada a impedância acústica da amostra (ver seção 3.2.3) e a sua velocidade de propagação (ver seção 3.2.1), é possível encontrar a densidade como:

$$
\rho_{s}(f)=\frac{Z_{s}}{c_{s}}
$$




\subsubsection{Atenuação acústica}

Parte-se do conjunto de equações 3.9 para encontrar a atenuação acústica da amostra. A eq. 3.9c é dividida pela eq. 3.9b obtendo:

$$
\frac{A_{3}(f)}{A_{2}(f)}=\frac{T_{23} T_{32} R_{34}}{R_{23}} e^{-2 \alpha_{s} l_{s}}
$$

Sabendo que $T_{i j}=1+R_{i j}$ e que $R_{i j}=-R_{j i}$, deixando em evidência o termo de interesse $\alpha_{s}$ e aplicando a propriedade de soma dos logaritmos, tem-se que:

$$
\alpha_{s}(f)=\frac{\ln \left[\frac{A_{2}(f)}{A_{3}(f)}\right]+\ln \left[\frac{1-R_{23}^{2}}{R_{23}}\right]+\ln \left[R_{34}\right]}{2 l_{s}}
$$

\subsubsection{Comparação com o modelo teórico de misturas de Urick}

Como foram feitos vários ensaios por amostra obtiveram-se múltiplos valores das propriedades para cada concentração. Para encontrar um único valor por amostra, determinou-se a média dos valores, calculando posteriormente seu desvio padrão. Para as propriedades que variavam com a frequência $\left(R_{23}(f) ; Z_{s}(f) ; \rho_{s}(f)\right.$ e $\left.\alpha_{s}(f)\right)$, foi necessário reduzir a função a um valor só, previamente; para isso utilizou-se o valor associado à frequência central do transdutor, e também seu valor médio, calculado com a eq. 3.18. A frequência central do transdutor foi estabelecida como o valor de frequência associado ao máximo absoluto do primeiro eco $A_{1}(f)$, ou seja, $f_{c}=$ $f_{@ \max \left(A_{1}\right)}$, dado que seu espectro de frequências era o menos distorcido, ao ter viajado a menor distância e ter incidido em apenas uma interface.

$$
\bar{\psi}=\frac{1}{f_{b}-f_{a}} \int_{f_{a}}^{f_{b}} \psi(f) d f
$$

sendo $\psi$ a propriedade de interesse em cada caso, e $f_{a}$ e $f_{b}$ as frequências que definem a janela de análise.

O modelo teórico de misturas de Urick sugere que a densidade $(\rho)$ e a compressibilidade adiabática $(\beta)$ das misturas têm um comportamento linear e proporcional à 
concentração da fase dispersa (URICK, 1947), como:

$$
\begin{aligned}
& \rho=\rho_{w} \phi+\rho_{o}(1-\phi) \\
& \beta=\beta_{w} \phi+\beta_{o}(1-\phi)
\end{aligned}
$$

onde $\phi$ é a concentração volumétrica da fase dispersa, que, neste trabalho, é a água, e os subscritos $w$ e $o$ indicam, respectivamente, água e óleo.

A velocidade de propagação da mistura é calculada com a seguinte expressão:

$$
c^{2}=\frac{1}{\rho \beta}
$$

Como resulta um pouco difícil determinar a compressibilidade adiabática $(\beta)$ experimentalmente, costuma-se calcular $\beta_{w}$ e $\beta_{o}$ utilizando a densidade e a velocidade de propagação das substâncias puras que compõem a emulsão estudada, usando a expressão acima. Com a densidade e a velocidade de propagação do modelo, podem ser extrapolados outros parâmetros, como a impedância acústica ou, posteriormente, os coeficientes de reflexão e transmissão.

É importante ressaltar que este modelo é válido quando a dispersão acústica é baixa, ou seja, quando o raio das gotículas da fase dispersa é muito menor que um comprimento de onda.

\subsubsection{Análise da propagação da incerteza de medição na determi- nação das propriedades}

Nos experimentos, utilizam-se diversos equipamentos para medir: paquímetro, balança, osciloscópio, etc. Estes equipamentos têm incertezas associadas chamadas de $\Delta \Theta$, sendo $\Theta$ a quantidade física que eles medem. A incerteza do paquímetro (comprimento) é $\Delta l=0,05 \mathrm{~mm}$ e a da balança (massa) é $\Delta m=0,01 \mathrm{~g}$. Nas medições realizadas com o osciloscópio, utilizou-se uma frequência de amostragem de $200 \mathrm{MHz}$, portanto $T_{s}$ seria a incerteza relacionada ao tempo, $\Delta t=5 \mathrm{~ns}$. A placa de aquisição do osciloscópio é de 8-bit, e a escala total na qual realizaram-se as medições foi de $\pm 20 \mathrm{mV}$, portanto a resolução vertical (tensão elétrica) seria $\Delta V=40 /\left(2^{8}\right) \mathrm{mV}$.

Quando os valores medidos interatuam através das equações, as incertezas se pro- 
pagam afetando o resultado final; por exemplo, quando pretende-se medir a densidade de um objeto usando uma balança para conhecer sua massa e um paquímetro para determinar seu volume. A eq. 3.21 permite determinar a incerteza propagada devido às incertezas dos equipamentos, somando as taxas de variação entre a propriedade a calcular $\psi$ e as quantidades físicas $\Theta_{n}$ das quais depende, cada uma multiplicada pela incerteza associada $\Delta \Theta_{n}$.

$$
\Delta \psi\left(\Theta_{1}, \Theta_{2}, \ldots, \Theta_{n}\right)=\left|\frac{\partial \psi}{\partial \Theta_{1}}\right| \Delta \Theta_{1}+\left|\frac{\partial \psi}{\partial \Theta_{2}}\right| \Delta \Theta_{2}+\cdots+\left|\frac{\partial \psi}{\partial \Theta_{n}}\right| \Delta \Theta_{n}
$$

Na seção 3.2.1 a velocidade de propagação foi calculada com a eq. 3.5. Esta depende do atraso entre os ecos $a_{2}$ e $a_{3}$ ( $\delta t_{23}$ ), e do comprimento da câmara da amostra $\left(l_{s}\right)$. Aplicando a eq. 3.21, a incerteza na velocidade de propagação é:

$$
\Delta c_{s}=\left|\frac{2}{\delta t_{23}}\right| \Delta l+\left|\frac{2 l_{s}}{\delta t_{23}^{2}}\right| \Delta t
$$

Na seção 3.2.2 o coeficiente de reflexão foi calculado usando a eq. 3.12, porém esta equação utiliza o espectro de frequências e não o sinal temporal, impedindo a utilização direta da incerteza da tensão elétrica $(\Delta V)$ e, consequentemente, esta situação sugere que deva ser usada a incerteza da DFT. A continuação é proposto um procedimento para estimá-la. A transformada de Fourier do sinal discreto, considerando sua incerteza, está dada por:

$$
F(n) \pm \Delta F(n)=\sum_{k=0}^{N-1}\left(V_{k} \pm \Delta V\right) e^{-i 2 \pi n k / N}
$$

sendo $N$ o número de pontos do sinal temporal; $n$ o índice associado a uma frequência desejada $f_{x}$, calculado como $n=\frac{f_{x}}{f_{s}} \cdot N$ (sendo $f_{s}$ a frequência de amostragem); $V_{k}$ os valores discretos do sinal temporal (tensão elétrica) e $\Delta V$ a incerteza destes valores.

A partir da propriedade de linearidade, que considera que a transformada de Fourier de uma soma é a soma das transformadas, tem-se como resultado a transformada do sinal discreto e a transformada da incerteza (aqui tratada como uma constante). Assim, a incerteza da DFT está dada pela eq. 3.24, cujo valor é não nulo unicamente para $n=0$, sendo este $\Delta F(0)=N \Delta V$. Esta expressão é equivalente com o resultado da 
transformada de Fourier para sinais contínuos: $\Delta F(\omega)=2 \pi \Delta V \delta(\omega)$.

$$
\Delta F(n)=\Delta V \sum_{k=0}^{N-1} e^{-i 2 \pi n k / N}
$$

O resultado anterior sugere que, teoricamente, o coeficiente de reflexão não tem uma incerteza associada, embora na prática sabe-se que existem não linearidades no pulsador que podem introduzir erros, além das variações nos equipamentos eletrônicos com a temperatura (aquecimento). Para não desprezar estes fatores, desenvolveu-se um procedimento para resolver a equação 3.24 de forma analítica por aproximação. A somatória foi resolvida como uma série geométrica, no resultado foi aplicada a fórmula de Euler para números complexos e, finalmente, considerou-se que $N \gg 1$, obtendo:

$$
\begin{aligned}
& \Delta F \approx \frac{\Delta V}{2}\left|1+i \cdot \operatorname{cotg}\left(-\pi f_{x} / f_{s}\right)\right| \\
& \Delta F \approx \frac{\Delta V}{2}\left|\operatorname{cosec}\left(-\pi f_{x} / f_{s}\right)\right|
\end{aligned}
$$

A incerteza na determinação do coeficiente de reflexão (calculado com a equação 3.12), é dado por:

$$
\Delta R_{23}=\frac{A_{1} A_{2}^{a r}\left(A_{1}^{a r}+A_{2}\right)+A_{1}^{a r} A_{2}\left(A_{1}+A_{2}^{a r}\right)}{\left(A_{1} A_{2}^{a r}\right)^{2}} \Delta F
$$

sendo $A_{1}, A_{2}, A_{1}^{a r}$ e $A_{2}^{a r}$ o valor absoluto das transformadas de Fourier dos ecos indicados pelos subíndices.

$\mathrm{Na}$ expressão anterior, considera-se que a incerteza para a transformada de Fourier de cada eco é a mesma $(\Delta F)$, no entanto, na pratica, a incerteza dos ecos de menor amplitude pode ser maior devido à menor relação entre sinal e ruido. Outra abordagem para determinar a incerteza $\operatorname{dos} \operatorname{ecos} A_{i}^{x x}$, consiste em adquirir $M$ sinais, calcular o seu espectro de frequências na banda de frequências desejada e calcular o desvio padrão, ou a diferença entre o máximo e o mínimo, destas $M$ curvas (BUIOCHI, 1994). Esta última abordagem foi implementada para encontrar $\Delta R_{23}$, obtendo os mesmos resultados que pela metodologia aqui proposta.

Na seção 3.2.3, a impedância acústica da amostra foi calculada com a eq. 3.13; esta depende do coeficiente de reflexão e da impedância acústica do vidro. Esta última 
depende ao mesmo tempo da densidade e da velocidade de propagação, propriedades que implicitamente dependem de outras quantidades físicas como: massa, volume, comprimento e tempo. Assim, a incerteza na determinação da impedância acústica é dada por:

$$
\Delta Z_{s}=\frac{2 Z_{2} \Delta R_{23}}{\left(1-R_{23}\right)^{2}}+\left[\frac{1+R_{23}}{1-R_{23}}\right] \frac{2}{\pi r_{2}^{2} \delta t_{12}}\left[\Delta m+\frac{m \Delta t}{\delta t_{12}}+\frac{2 m\left(r_{2}+l_{2}\right) \Delta l}{r_{2} l_{2}}\right]
$$

Como todas as quantidades físicas são positivas, não foi necessário utilizar o indicador de valor absoluto. Somente o termo $R_{23}$ pode ser negativo, porém seu valor está na faixa $[-1,1]$.

Na seção 3.2.4, a densidade da amostra foi calculada com a eq. 3.15; esta depende da impedância acústica da amostra $\left(Z_{s}\right)$ e da sua velocidade de propagação $\left(c_{s}\right)$; por conseguinte, sua incerteza está dada por:

$$
\Delta \rho_{s}=\frac{Z_{s} \Delta c_{s}}{c_{s}^{2}}+\frac{\Delta Z_{s}}{c_{s}}
$$

sendo $\Delta c_{s}$ e $\Delta Z_{s}$ as incertezas calculadas com as eq. 3.22 e 3.27 , respectivamente.

A atenuação acústica, calculada na seção 3.2 .5 com a eq. 3.17, depende dos ecos $a_{2}$ e $a_{3}$ no domínio da frequência, do coeficiente de reflexão $\left(R_{23}\right)$, do comprimento da câmara da amostra $\left(l_{s}\right)$, e, de forma implícita, da impedância acústica da amostra $\left(Z_{s}\right)$. Logo, sua incerteza está dada por:

$$
\begin{gathered}
\Delta \alpha_{s}=\frac{\left(A_{2}+A_{3}\right) \Delta F}{2 l_{s} A_{2} A_{3}}+\frac{\left(1+R_{23}{ }^{2}\right) \Delta R_{23}}{2 l_{s}\left(1-R_{23}{ }^{2}\right)\left|R_{23}\right|}+\frac{Z_{4} \Delta Z_{s}}{\left(Z_{4}^{2}-Z_{s}^{2}\right) l_{s}} \\
+\frac{\ln \left[\frac{A_{2}(f)}{A_{3}(f)}\right]+\ln \left[\frac{1-R_{23}^{2}}{R_{23}}\right]+\ln \left[R_{34}\right]}{2 l_{s}{ }^{2}} \Delta l
\end{gathered}
$$

As incertezas apresentadas nesta seção geram uma faixa ao redor da média da propriedade encontrada experimentalmente $(\bar{\psi} \pm \Delta \psi)$. Logo, o erro relativo, devido às incertezas dos equipamentos, pode ser calculado como:

$$
\varepsilon_{\text {med }}(\%)=100 \frac{\Delta \psi}{\bar{\psi}}
$$


Finalmente, foi determinada a diferença relativa entre o valor médio das propriedades encontradas experimentalmente (sem realizar calibração) e o modelo teórico de misturas de Urick $\left(\psi_{t e o}\right)$.

$$
\varepsilon_{\text {teo }}(\%)=100 \frac{\left|\bar{\psi}-\psi_{\text {teo }}\right|}{\psi_{\text {teo }}}
$$

A curva do modelo teórico e a da média experimental com sua faixa de incerteza, são apresentadas na Figura 23 da seção 4.1.6.

\subsection{Procedimento experimental para a aquisição de da- dos usando a célula com linhas de retardo}

Foram preparadas emulsões de água em óleo, cujas concentrações variavam entre $0 \%$ e $45 \%$ de água, em volume. Nesses experimentos foi utilizado o óleo Deiton Hidra 68. As duas fases eram vertidas em um béquer de vidro e logo agitadas com um mixer (Ika Labortechnik, 8000-24000 rpm), até conseguir sua homogeneização. Cada amostra foi agitada durante 2 minutos a $8000 \mathrm{rpm}$, e logo deixada em repouso por 15 minutos para eliminar as bolhas de ar introduzidas durante a mistura. Do béquer, eram extraídos $8 \mathrm{ml}$ da amostra com uma seringa de plástico. Esta era conectada a uma das mangueiras da célula, e o conjunto seringa-célula era introduzido no banho termostático a $20^{\circ} \mathrm{C}$ (com precisão de $0,01^{\circ} \mathrm{C}$ ). A outra mangueira da célula era deixada para fora (para evitar a entrada de água). A célula, junto à seringa, era deixada dentro do banho durante 15 minutos para conseguir o equilíbrio térmico. A amostra permanecia na seringa sem ser injetada porque, primeiramente, era necessário fazer uma aquisição de referência com ar, como comentado na seção 3.2.2. Após a aquisição dos dados de referência, a amostra era injetada na célula (que continuava imersa no banho termostático) até que saísse pela mangueira livre à superfície. Imediatamente depois eram feitas as aquisições dos sinais com a emulsão na câmara da amostra. Foram adquiridos 10 sinais por amostra durante 6 minutos. Fotos do processo experimental são mostradas na Figura 6.

No experimento, as concentrações foram obtidas adicionando água a $50 \mathrm{ml}$ da emulsão previamente preparada. O experimento começou com $50 \mathrm{ml}$ de óleo puro, ao qual foram adicionados $8 \mathrm{ml}$ de água. No momento de extrair a amostra do béquer, garantia-se que ficassem $50 \mathrm{ml}$ nele para continuar com o processo de forma sucessiva, 
Figura 6: Fotos do processo experimental utilizando a célula com linhas de retardo.
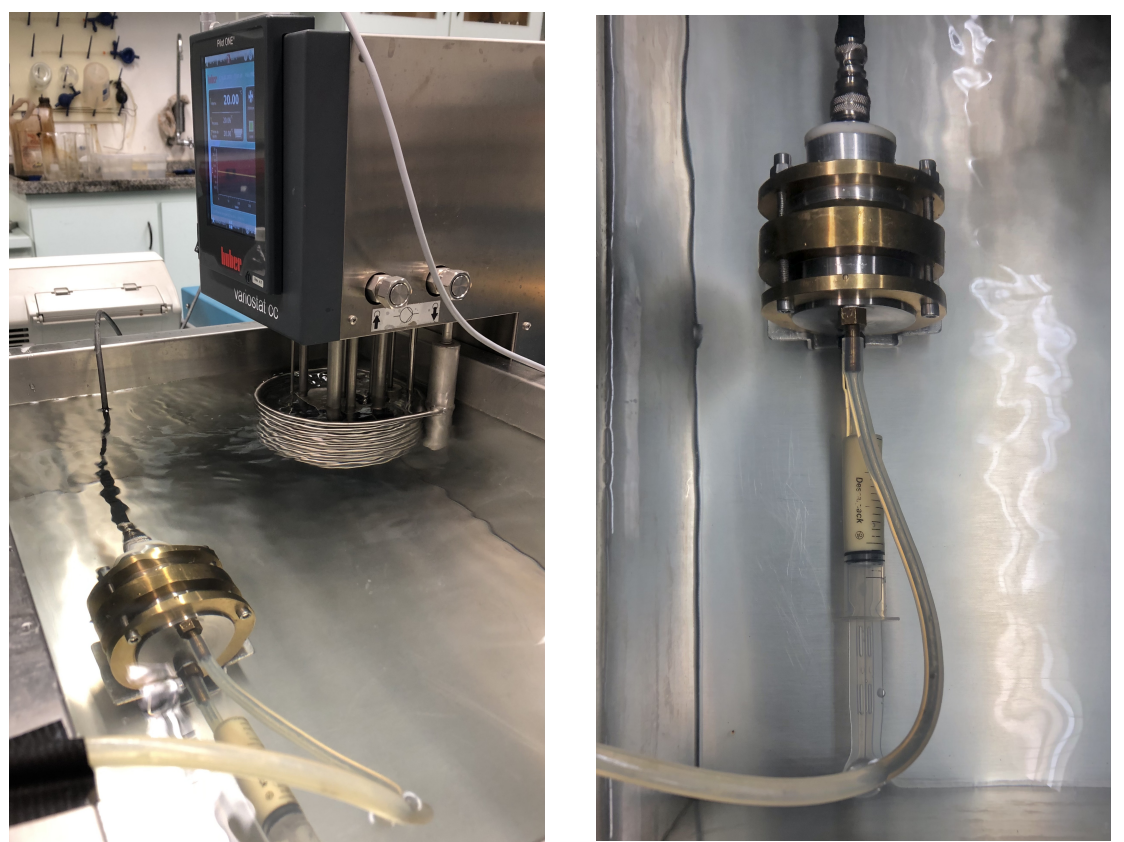

Fonte: Autor.

como modela a eq. 3.32 :

$$
\phi_{n+1}=\frac{50 \phi_{n}+8}{50+8}
$$

sendo $\phi$ a concentração de água da emulsão.

Após cada medição, o conjunto célula-seringa era retirado do banho termostático com cuidado para não contaminar sua água. O transdutor era desconectado do pulsador e eram retirados os parafusos para abrir a câmara da amostra. A célula era deixada com a abertura para baixo por alguns minutos para escorrer a amostra sobre um recipiente destinado a descarte de líquidos. Finalmente, a câmara da amostra era limpa com papel toalha e fechada novamente.

Utilizou-se um pulsador-receptor ultrassônico (Olympus Panametrics 5072PR) para acionar um transdutor ultrassônico de 3,50 MHz (Olympus Panametrics V381), operando no modo pulso-eco (para emitir e receber os sinais ultrassônicos). Um pulso de alta tensão e curta duração excitou o transdutor gerando uma onda acústica. $\mathrm{O}$ pulsador-receptor, conectado a um osciloscópio, recebeu e amplificou os ecos recebidos pelo mesmo transdutor. O osciloscópio (Keysight DSO 5032A) permitiu a visualização e aquisição dos sinais. Os dados foram transferidos para um computador por meio da rede local LAN para seu posterior armazenamento, análise e processamento. 
Um esquema da montagem experimental é mostrado na Figura 7.

Figura 7: Esquema da montagem experimental para a utilização da célula com linhas de retardo.

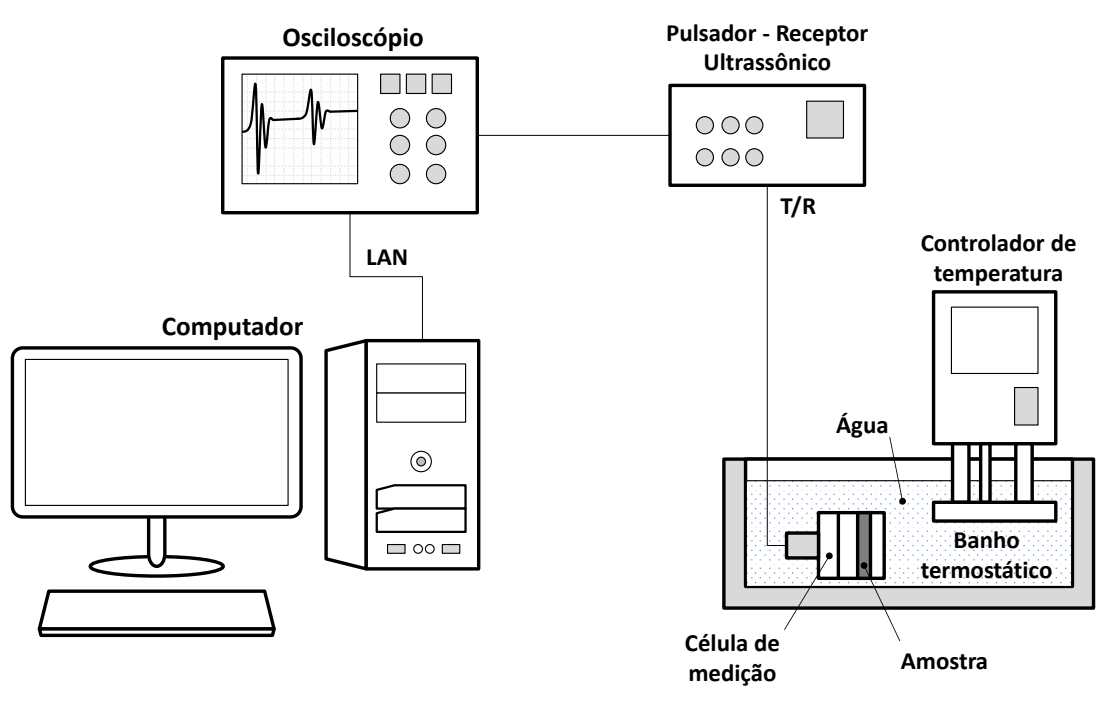

Fonte: Autor.

\subsection{Célula de espalhamento}

A Figura 8 mostra a célula de espalhamento projetada e construída para este trabalho: a) uma fotografia e b) um esquema com a distribuição dos dispersores. A célula consiste em um transdutor ultrassônico comercial de 3,50 MHz e diâmetro de 19 mm (Panametrics V381-SU), e um conjunto de dispersores cilíndricos localizados no campo próximo. Os dispersores são porções de varetas de aço inoxidável com diâmetro de 1,60 mm, que foram soldadas formando seis filas dentro de um tubo de aço inoxidável de seção transversal quadrada, com dimensões $W=H=60 \mathrm{~mm}$ e $L=65$ mm. A separação entre a face do transdutor e a primeira fila de dispersores é $e=5,2$ $\mathrm{mm}$, a separação entre filas consecutivas de dispersores é $l_{z}=6,3 \mathrm{~mm}$ e a separação entre dispersores de uma mesma fila é $l_{x}=4 \mathrm{~mm}$. Cada fila de dispersores está defasada horizontalmente com relação às filas vizinhas por um terço da separação entre dispersores de uma mesma fila $\left(l_{x} / 3\right)$, de tal forma que a quarta fila coincide com a primeira. Um adaptador polimérico suporta o transdutor ultrassônico. 
Figura 8: Fotografia da célula de espalhamento e esquema com a configuração dos dispersores.

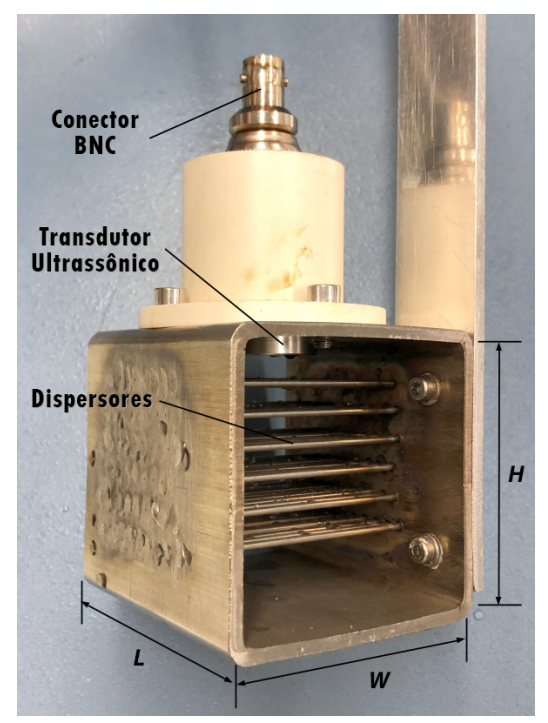

a) Fotografia da célula de espalhamento

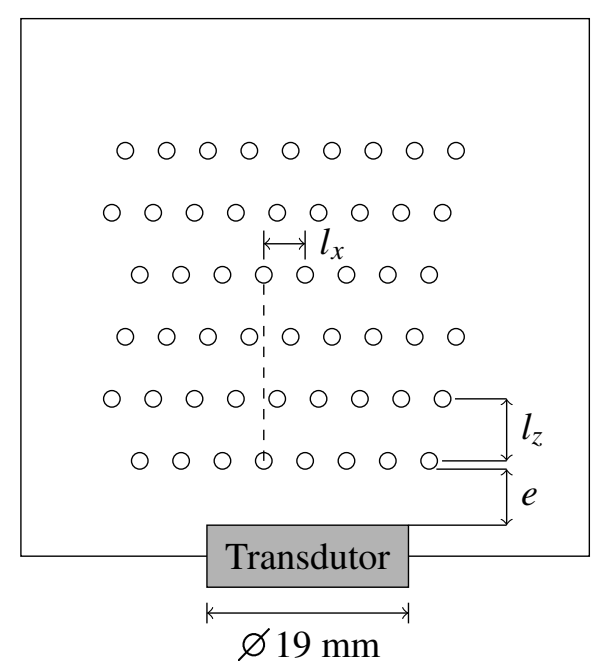

b) Distribuição dos dispersores na célula

Fonte: Autor.

\subsection{Detecção de variações nas amostras usando a célula de espalhamento}

A Figura 9 mostra um sinal de dispersão e sua transformada discreta de Fourier, este sinal foi obtido com a célula de espalhamento do ensaio com $10 \%$ de água. O espectro de frequências foi bastante afetado por causa do espalhamento e da superposição dos ecos provenientes dos espalhadores (note as diferenças com relação ao espectro de frequências da Figura 5, obtido com o mesmo transdutor).

As variações nas amostras foram analisadas considerando as medidas relativas de correlação cruzada $\left(R_{x y}\right)$, energia de onda $(E)$ e correlação cruzada com os sinais normalizados $\left(\hat{R}_{x y}\right)$. Diz-se medidas relativas porque estes parâmetros foram comparados com os associados a um sinal de referência (obtido de uma amostra de petróleo puro). Este procedimento foi aplicado para todas as amostras de cada concentração de água em petróleo. Com a correlação cruzada verifica-se o grau de similaridade entre os sinais comparados; com a energia de onda, os efeitos devidos à atenuação produzida pela fase dispersa; e com a correlação cruzada com os sinais normalizados, a similaridade entre os sinais comparados, descontando os efeitos da amplitude e se baseando, principalmente, na fase dos sinais. 
Figura 9: a) Sinal experimental obtido com a célula de espalhamento, extraído do ensaio com $10 \%$ de água. O sinal foi segmentado em três partes $a_{n}(t)$ como indicado na seção 3.6. b) Transformada discreta de Fourier do sinal de espalhamento na banda de frequência 1-5 MHz.

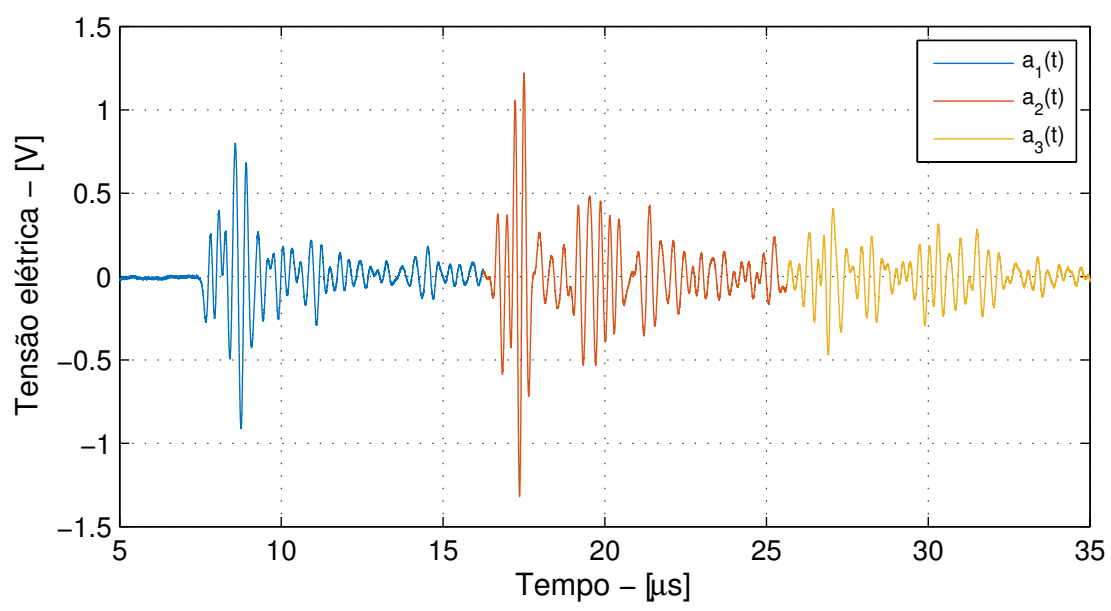

a)

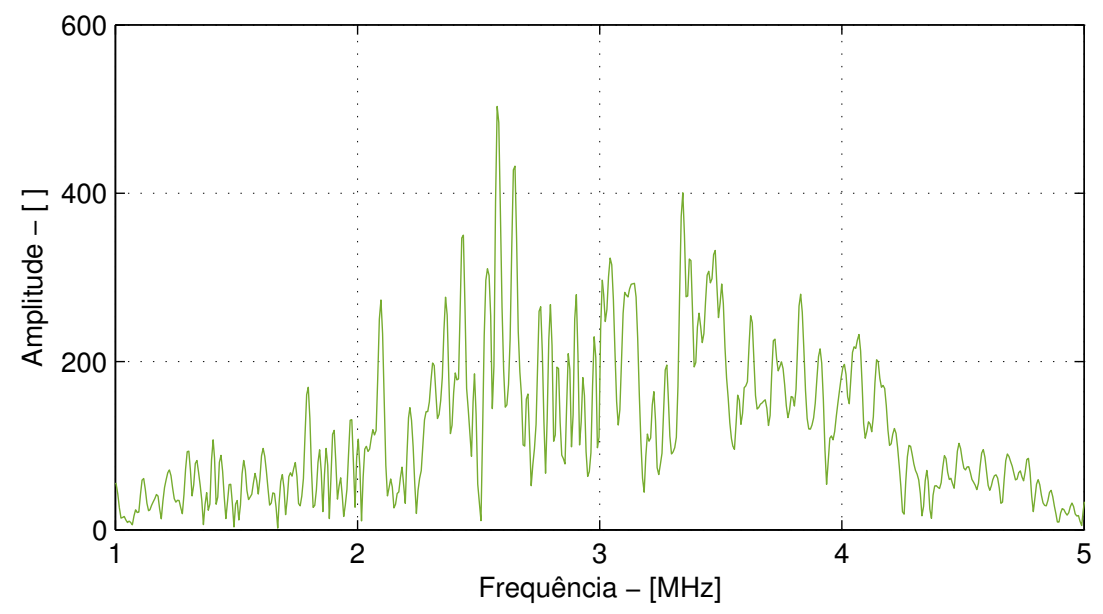

b)

Fonte: Autor.

A correlação cruzada foi calculada mediante:

$$
R_{x y}=\int_{-\infty}^{+\infty} a_{r e f}(\tau) a(\tau+t) d \tau,
$$

sendo $a(t)$ um sinal de qualquer concentração e $a_{r e f}(t)$ o sinal de referência (obtido de um amostra de petróleo puro).

A energia de onda foi calculada mediante:

$$
E=\int_{t_{a}}^{t_{b}}|a(t)|^{2} d t
$$


sendo $t_{a}$ e $t_{b}$ os tempos que definem a janela temporal que cobre as reflexões de todos os dispersores.

Os sinais foram normalizados usando a energia de onda e, posteriormente, estes foram introduzidos na eq. 3.33 para recalcular a correlação cruzada $\left(\hat{R}_{x y}\right)$.

$$
\hat{a}(t)=\frac{a(t)}{\sqrt{E}}
$$

sendo $\hat{a}(t)$ o sinal normalizado.

A correlação cruzada relativa foi calculada dividindo o máximo absoluto da correlação cruzada $\left(R_{x y}\right)$, pelo máximo absoluto da autocorrelação do sinal de referência $\left(R_{x x}\right)$ :

$$
\chi=\frac{\max \left(\left|R_{x y}\right|\right)}{\max \left(\left|R_{x x}\right|\right)}
$$

A correlação cruzada relativa com os sinais normalizados foi calculada dividindo o máximo absoluto da correlação cruzada $\left(\hat{R}_{x y}\right)$, pelo máximo absoluto da autocorrelação do sinal de referência $\left(\hat{R}_{x x}\right)$, ambas previamente calculadas com os sinais normalizados:

$$
\hat{\chi}=\frac{\max \left(\left|\hat{R}_{x y}\right|\right)}{\max \left(\left|\hat{R}_{x x}\right|\right)}
$$

Finalmente, a energia de onda relativa foi calculada dividindo a energia de onda de um sinal qualquer $(E)$, pela energia de onda do sinal de referência $\left(E_{r e f}\right)$ :

$$
\xi=\frac{E}{E_{r e f}}
$$

A Tabela 2 mostra o fluxo de cálculo utilizado para a determinação das variações relativas. Os resultados destas operações são dados em função do tempo de medição. Pelo que, posteriormente, para verificar a dependência destes com a quantidade de água nas emulsões, foi calculado o valor médio e o desvio padrão dos ensaios para cada concentração. 
Tabela 2: Fluxo de cálculo utilizado para a determinação das variações relativas com a célula de espalhamento.

\begin{tabular}{|}
$\begin{array}{l}\text { Correlação cruzada relativa: } \\
a(t) \longrightarrow R_{x y}=\int_{-\infty}^{+\infty} a_{r e f}(\tau) a(\tau+t) d \tau \longrightarrow \chi=\frac{\max \left(\left|R_{x y}\right|\right)}{\max \left(\left|R_{x x}\right|\right)}\end{array}$ \\
Correlação cruzada relativa com os sinais normalizados: \\
$\hat{a}(t)=\frac{a(t)}{\sqrt{E}} \longrightarrow \hat{R}_{x y}=\int_{-\infty}^{+\infty} \hat{a}_{r e f}(\tau) \hat{a}(\tau+t) d \tau \longrightarrow \hat{\chi}=\frac{\max \left(\left|\hat{R}_{x y}\right|\right)}{\max \left(\left|\hat{R}_{x x}\right|\right)}$ \\
Energia de onda relativa: \\
$\qquad a(t) \longrightarrow E=\int_{t_{a}}^{t_{b}}|a(t)|^{2} d t \longrightarrow \xi=\frac{E}{E_{r e f}}$
\end{tabular}

\subsection{Determinação da velocidade de propagação com a célula de espalhamento}

Para esta análise o sinal de dispersão foi segmentado em três partes (ver Figura 9). Os segmentos $a_{1}(t), a_{2}(t)$ e $a_{3}(t)$ foram definidos a partir do tempo de chegada teórico das reflexões provenientes da primeira, segunda e terceira fila de dispersores, respectivamente. $\mathrm{O}$ início destas janelas temporais $\left(t_{i, n}\right)$ foi determinado usando a separação entre a face do transdutor e a primeira fila de dispersores $(e)$, a separação entre filas consecutivas de dispersores $\left(l_{z}\right)$ e a velocidade de propagação da água a $25^{\circ} \mathrm{C}\left(c_{w}\right)$, considerando, além, uma tolerância de $-3 \%$. Assim, o início de cada janela (indicada $\operatorname{com} n$ ), foi calculado segundo a expressão:

$$
t_{i, n}=\frac{2\left[e+(n-1) l_{z}\right]}{c_{w}} \cdot 0,97 ; \quad n=\{1,2,3\}
$$

Logo, o fim das janelas temporais $\left(t_{f, n}\right)$ foi definido como:

$$
t_{f, n}=t_{i, n}+\frac{2 l_{z}}{c_{w}} \cdot 0,97
$$

A velocidade de propagação da amostra foi calculada por meio de duas metodologias. A primeira, aqui chamada de absoluta (por utilizar apenas o primeiro segmento do sinal de dispersão $a_{1}(t)$ ), consistia em calcular a diferença temporal entre o tempo zero (em que o sinal é emitido) e, o tempo associado aos valores máximo e mínimo do segmento, o tempo associado ao valor máximo da envoltória do segmento (calculada com a transformada de Hilbert), ou o tempo em que $a_{1}(t)$ ultrapassa pela primeira vez 
um limiar de tensão acima do nível de ruido (threshold method). A segunda metodologia, aqui chamada de relativa (por utilizar os dois primeiros segmentos do sinal de dispersão $a_{1}(t)$ e $a_{2}(t)$ ), consistia em calcular a diferença temporal entre os valores máximos de cada segmento, a diferença temporal entre os valores mínimos de cada segmento, ou o atraso associado ao máximo absoluto da correlação cruzada entre os dois segmentos.

De cada método obteve-se um valor temporal $\delta t_{s}$ utilizado para calcular a velocidade de propagação da amostra $\left(c_{s}\right)$ segundo a expressão:

$$
c_{s}=\frac{2 l_{s}}{\delta t_{s}}
$$

sendo $l_{s}$ uma distância característica.

Como do sinal de dispersão, infere-se que o máximo de cada segmento resulta da superposição construtiva dos ecos provenientes dos dispersores de uma mesma fila, espera-se que, nos métodos absolutos que usam o máximo e mínimo do segmento $a_{1}(t)$, $l_{s}$ seja um pouco maior que a distância entre a face do transdutor e a primeira fila de dispersores $e$, e que, nos métodos relativos, $l_{s}$ seja aproximadamente a distância entre duas fileiras consecutivas de dispersores $l_{z}$ (no método threshold, $l_{s}$ seria aproximadamente o valor de $e$ ). No entanto, como o fenômeno de superposição é complexo, devido à dispersão e à distribuição não simétrica dos dispersores na célula em relação ao transdutor, em ambos os métodos (absolutos e relativos) a distância característica $l_{s}$ deve ser tratada como desconhecida, e estimada a partir do ensaio realizado com água pura, onde a velocidade de propagação é conhecida $\left(c_{w}\right)$.

Para estimar $l_{s}$ deve-se escolher um valor temporal do ensaio com água pura $\left(\hat{\delta} t_{w}\right)$, para substituir na expressão:

$$
l_{s}=\frac{c_{w} \hat{\delta} t_{w}}{2}
$$

O valor temporal, $\hat{\delta} t_{w}$, foi determinado aplicando a metodologia $k$-medoids aos valores temporais obtidos do ensaio com água pura. Do método foi extraído o centroide com o maior número de elementos associados ao seu grupo, depois de ter otimizado a quantidade de grupos (ver informação detalhada do método na seção 2.3.9).

Igual à análise de variações relativas da seção 3.5, primeiro foi calculada a veloci- 
dade de propagação em função do tempo de medição e, posteriormente, para verificar sua dependência com a quantidade de água nas emulsões, foram calculados o valor médio e o desvio padrão dos ensaios para cada concentração. Finalmente, os resultados obtidos para a velocidade de propagação foram comparados com o modelo teórico de misturas de Urick, enunciado na seção 3.2.6.

\subsection{Procedimento experimental para a aquisição de da- dos com a célula de espalhamento}

Para utilizar a célula de espalhamento foram preparadas emulsões de água em petróleo, cujas concentrações volumétricas variaram entre $0 \%$ e $50 \%$. O petróleo era leve e foi fornecido pela companhia brasileira Petrobras (30.5 API). As duas fases eram vertidas num béquer de vidro e agitadas com um mixer (Ika Labortechnik, 8000-24000 rpm) para conseguir sua homogeneização. Cada amostra foi agitada durante 2 minutos a 8000 rpm, e logo deixada em repouso de 3 a 5 minutos para eliminar as bolhas de ar introduzidas no processo de mistura. O béquer, no qual eram agitadas as emulsões, era colocado dentro de um banho termostático com a temperatura controlada a $25^{\circ} \mathrm{C}$; com precisão de $0,01^{\circ} \mathrm{C}$. O sensor ficava imerso na emulsão, dentro do béquer, com uma pequena inclinação para evitar que as bolhas de ar, que ainda estavam presentes na emulsão, ficassem confinadas em frente ao transdutor (o qual estava com a face orientada para baixo). Logo era feita a aquisição dos dados. Foram realizados dois experimentos. O Teste 1 tomou vários dias, porque, para cada concentração, foram adquiridos vários sinais durante longos períodos de tempo, mostrados na Tabela 3. O Teste 2 foi mais rápido, adquirindo 25 sinais em 15 minutos, para cada concentração. Nesse segundo teste, foi possível medir um maior número de concentrações. Cabe mencionar que além de garantir a temperatura com o banho termostático, a temperatura da amostra foi monitorada durante os testes utilizando um termômetro digital Delta Ohm HD2127.1.

Tabela 3: Informações do Teste 1. Número de sinais adquiridos e duração do ensaio para cada concentração.

\begin{tabular}{|c|r|r|r|}
\hline Concentração (\%) & No. sinais & Duração (horas) & Sinais/hora \\
\hline 10 & 840 & 12,90 & 65 \\
\hline 20 & 200 & 1,96 & 102 \\
\hline 27 & 900 & 13,86 & 65 \\
\hline 50 & 400 & 3,94 & 102 \\
\hline
\end{tabular}


Nos experimentos, as concentrações sucessivas foram obtidas adicionando água a $25^{\circ} \mathrm{C}$ à emulsão previamente preparada, até atingir uma concentração de $50 \%$. O Teste 1 começou com $800 \mathrm{ml}$ de petróleo puro e, nessa mesma amostra inicial, foi sendo adicionado água para formar as concentrações de: 10, 20, 27 e 50\%. O Teste 2 começou com $600 \mathrm{ml}$ de petróleo puro, ao qual ia sendo adicionado água para formar as concentrações de: $8,14,20,25,31,37,41,45$ e $50 \%$.

Após cada medição, o conjunto béquer-célula era retirado do banho termostático com cuidado para não contaminar sua água. O transdutor era desconectado do pulsador e a célula era deixada sobre um recipiente para escorrer a emulsão velha, enquanto preparava-se a nova amostra. Finalizado o experimento, os excessos de petróleo, na célula, no béquer e nos recipientes utilizados, eram lavados com uma escova e uma esponja, ambos ensopados em gasolina já que a água e o detergente não os removiam.

Foram utilizados os mesmos equipamentos descritos no último parágrafo da seção 3.3. Um esquema da montagem experimental é mostrado na Figura 10.

Figura 10: Esquema da montagem experimental para a utilização da célula de espalhamento.

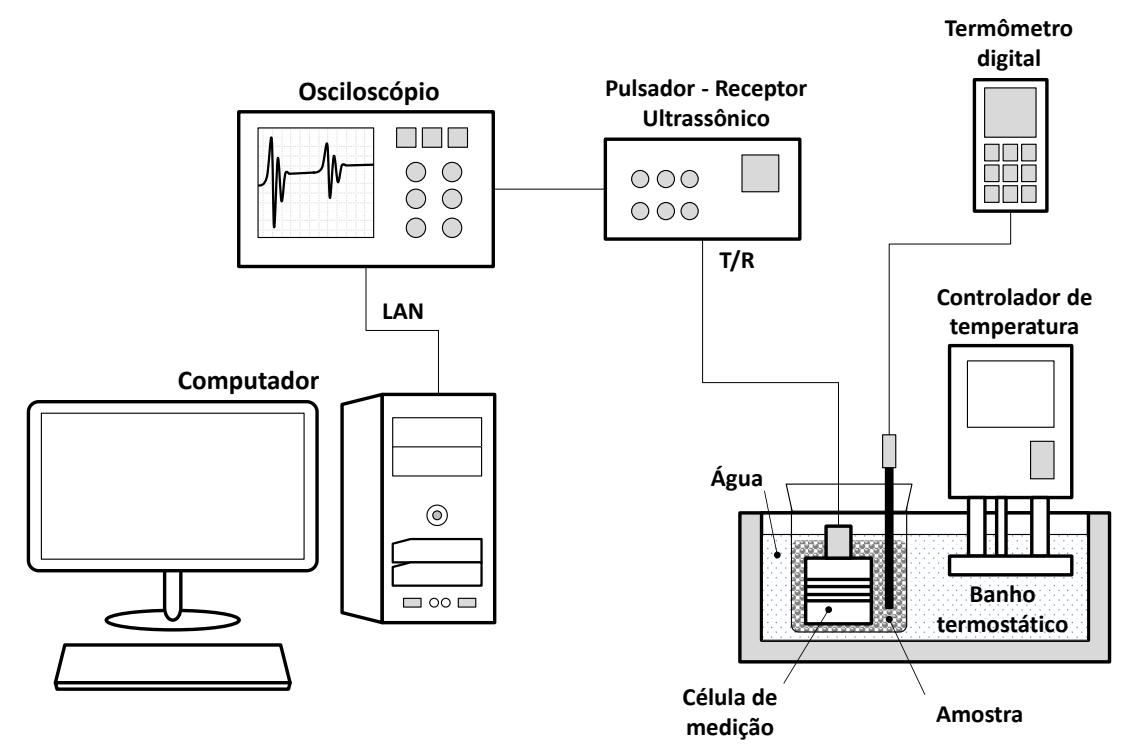

Fonte: Autor.

\subsection{Célula de espalhamento modificada}

Analisando o sinal obtido com a célula de espalhamento, mostrado na Figura 9, verifica-se que a amplitude da reflexão proveniente da segunda fileira de dispersores 
é maior que a proveniente da primeira, e, devido à atenuação, era esperado que fosse ao contrário. Inferiu-se que este incremento podia ser produto de uma superposição construtiva, originada por uma segunda reflexão proveniente da primeira fileira de dispersores, já que a separação entre a face do transdutor e a primeira fileira ( $e=5,2$ $\mathrm{mm})$ era muito próxima da separação entre fileiras consecutivas $\left(l_{z}=6,3 \mathrm{~mm}\right)$. Sob esta premissa, resolveu-se cortar os dispersores da primeira fileira, aumentando o valor de $e$ para $11,5 \mathrm{~mm}$. Com a célula modificada foram realizados um par de testes preliminares evidenciando pequenos deslocamentos do transdutor. Essa movimentação do transdutor, mesmo sendo pequena, trazia consequências negativas para a medição, principalmente na determinação da velocidade de propagação. Assim, para evitá-la, também foram realizadas duas perfurações roscadas na direção radial do suporte polimérico, garantindo a fixação do transdutor. A Figura 11a mostra a célula de espalhamento modificada, e a Figura 11 b a nova configuração para os dispersores.

Figura 11: Fotografia da célula de espalhamento modificada e esquema com a nova configuração para os dispersores.

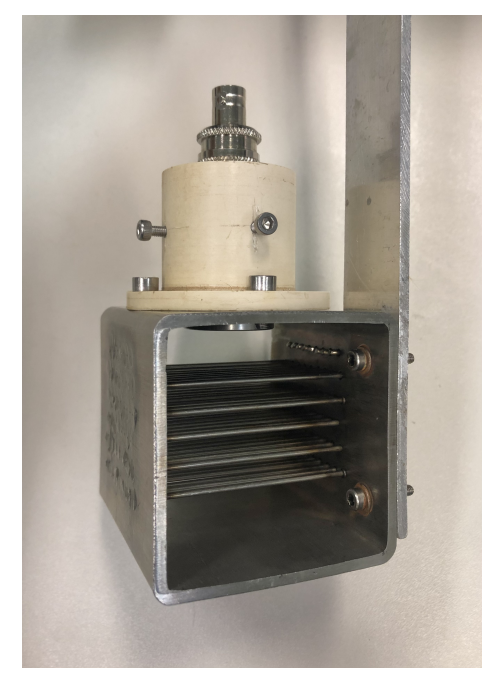

a) Fotografia da célula de espalhamento modificada

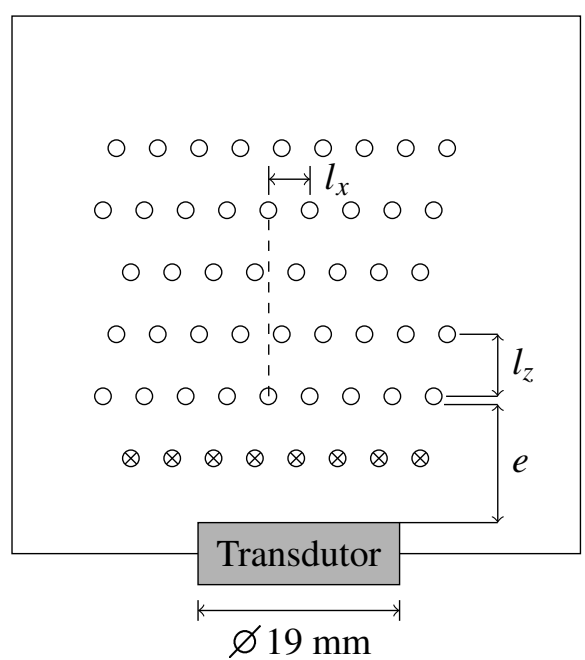

b) Distribuição dos dispersores na célula

Fonte: Autor.

A Figura 12 mostra a comparação entre dois sinais de dispersão obtidos com a célula de espalhamento: em a) antes de realizar as modificações, e em b) após. Cortando os dispersores da primeira fileira, o tempo de chegada da primeira reflexão passa de 7,5 $\mu \mathrm{s}$ a $16,2 \mu \mathrm{s}$, aproximadamente, e evita-se a superposição entre os ecos das duas primeiras fileiras. O sinal em b), encontra-se mais atenuado devido ao decaimento exponencial da amplitude com a distância e à ausência de superposição. 
Figura 12: Comparação entre dois sinais de dispersão obtidos com a célula de espalhamento em experimentos a $25^{\circ} \mathrm{C}$. Em a) prévio às modificações da célula, usando uma concentração de água de $10 \%$, e em b) após às modificações, usando uma concentração de água de $11 \%$.

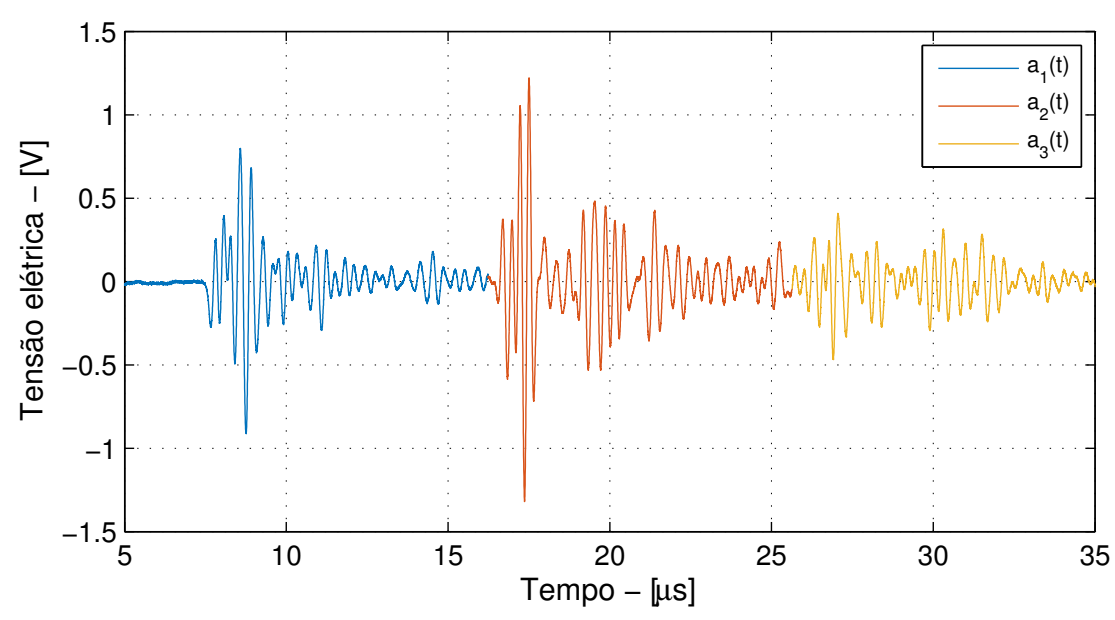

a)

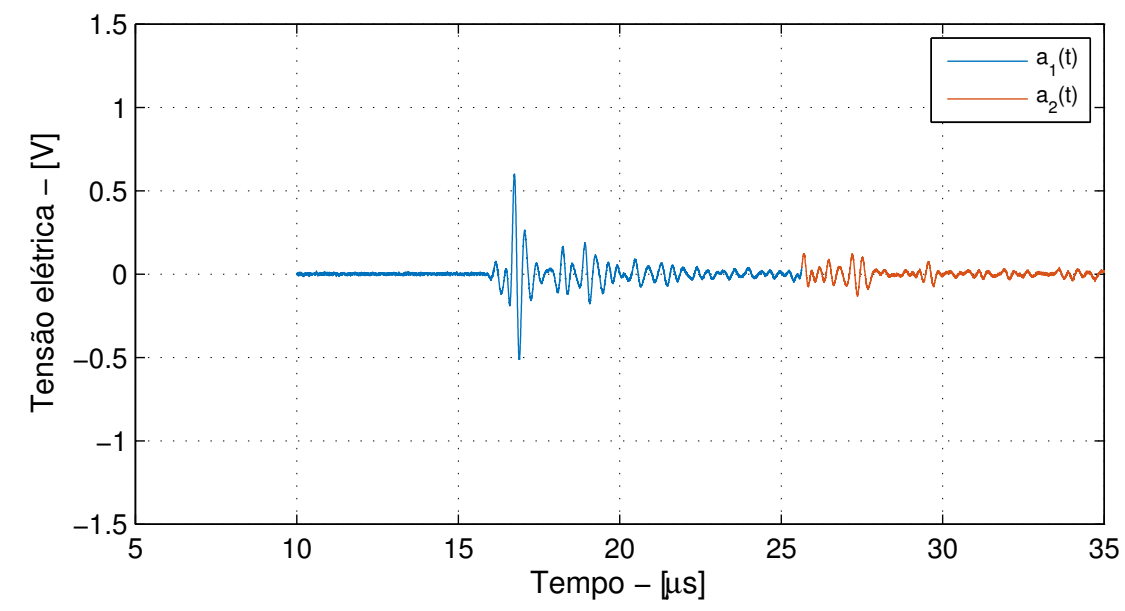

b)

Fonte: Autor.

A detecção de variações nas emulsões se realizou seguindo a metodologia descrita na seção 3.5, mediante os parâmetros de correlação cruzada, energia de onda e correlação cruzada com os sinais normalizados. Nessa seção, foi comentado que os sinais foram utilizados na extensão da janela temporal definida pelas reflexões de todos os espalhadores mas, desta vez, além de utilizar aquela janela, foram verificados os resultados usando apenas o primeiro segmento do sinal.

A velocidade de propagação das emulsões foi determinada mediante algumas das metodologias descritas na seção 3.6. Com a metodologia absoluta foi utilizado, unicamente, o primeiro segmento do sinal, localizando o tempo associado aos valores máximo e mínimo. Com a metodologia relativa foram utilizados os dois primeiros 
segmentos, $a_{1}(t)$ e $a_{2}(t)$, calculando a diferença temporal entre os valores máximos de cada segmento, a diferença temporal entre os valores mínimos de cada segmento, e o atraso associado ao máximo absoluto da correlação cruzada entre os dois segmentos.

\subsection{Procedimento experimental para a aquisição de da- dos com a célula de espalhamento modificada}

Para utilizar a célula de espalhamento modificada foram implementados cinco experimentos: dois à temperatura de $20^{\circ} \mathrm{C}$, dois à temperatura de $25^{\circ} \mathrm{C}$ e um à temperatura de $30^{\circ} \mathrm{C}$. Prepararam-se emulsões de água em petróleo cujas concentrações volumétricas variavam entre $0 \%$ e $50 \%$. O petróleo era leve e foi fornecido pela companhia brasileira Petrobras $\left(30.5^{\circ} \mathrm{API}\right)$.

Cada emulsão foi preparada adicionando água, à temperatura do experimento, ao béquer com a amostra previamente medida, para logo agitar durante 2 minutos a 8000 rpm. O agitador (Ika Labortechnik) era introduzido na amostra até encostar no fundo do recipiente e, já no fluido, era ligado (para evitar a introdução de ar na amostra). Com o agitador, era realizado um movimento de pêndulo cônico durante 40 segundos, logo, o agitador era fixo e o béquer era inclinado a aproximadamente $30^{\circ}$. Ao béquer, era aplicado um movimento de precessão durante 20 segundos. Depois, a haste do agitador era levantada até a ponta alcançar o centro da coluna de fluido (processo que tardava 10 segundos aproximadamente), a esta altura repetia-se o movimento de pêndulo cônico durante 20 segundos, e logo, o de precessão durante outros 20 segundos. Chegado a este ponto, o agitador era desligado e removido totalmente da amostra.

O béquer, no qual eram agitadas as emulsões, era colocado dentro do banho termostático com a temperatura controlada; com precisão de $0,01^{\circ} \mathrm{C}$. O sensor ficava imerso na emulsão, dentro do béquer, com uma pequena inclinação para evitar que as bolhas de ar, que ainda estavam presentes na emulsão, ficassem confinadas em frente ao transdutor (o qual estava com a face orientada para baixo). Logo era feita a aquisição dos dados. Fotos do processo experimental são mostradas na Figura 13.

A duração de cada experimento foi de 17 a 19 horas (a Figura 14 mostra a hora do dia em que cada sinal foi adquirido). Cada experimento consistia de onze ensaios: a água pura, o petróleo puro e nove emulsões variando a concentração de água. Em cada ensaio realizava-se a aquisição de 55 sinais durante 32 minutos. A temperatura 
Figura 13: Fotos do processo experimental utilizando a célula de espalhamento modificada. Ensaio realizado a $30^{\circ} \mathrm{C}$.
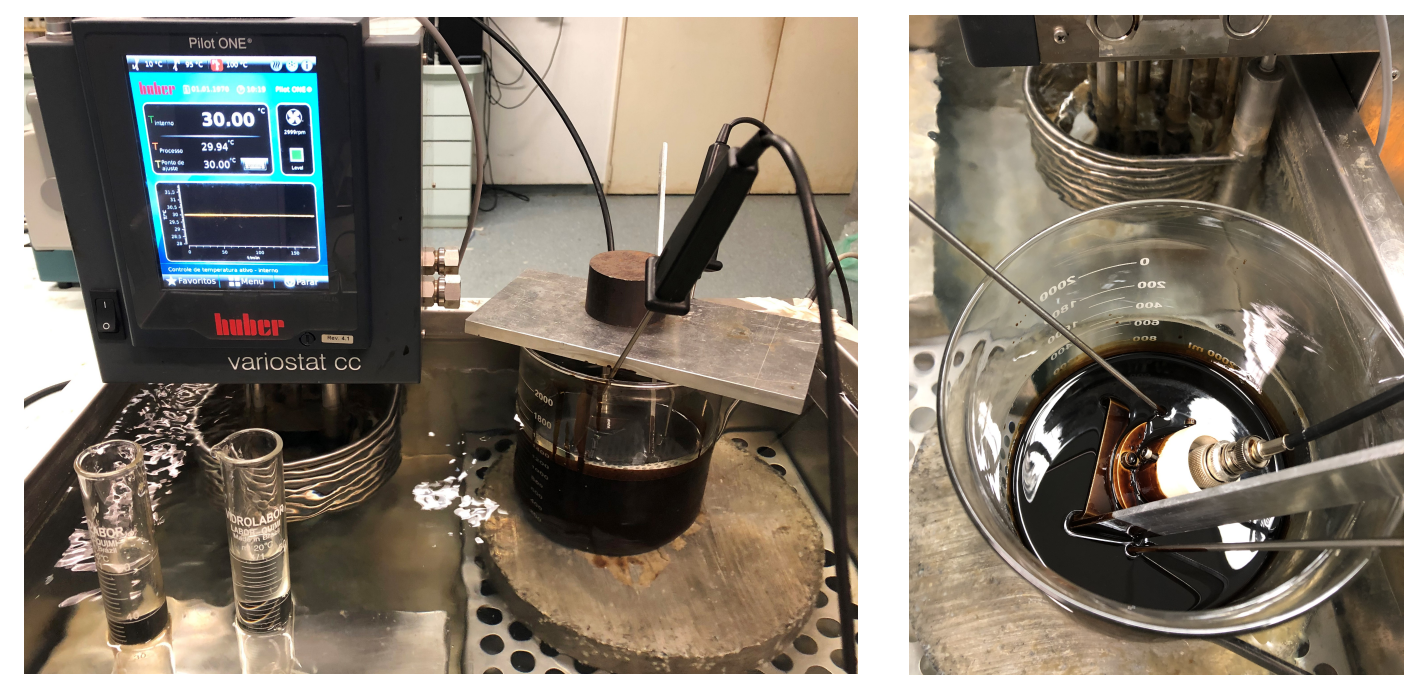

Fonte: Autor.

das amostras foi monitorada e adquirida utilizando um termômetro digital Delta Ohm HD2127.1 com dois termopares. Como neste conjunto de experimentos pretendia-se verificar a influência da temperatura na medição, as aquisições dos sinais eram iniciadas só após a estabilização térmica. Assim, o tempo de espera para iniciar a medição, que também permitia liberar o excesso de ar introduzido no processo de mistura, podia variar um pouco de uma concentração para outra.

Figura 14: Hora do dia em que cada sinal foi adquirido segundo o experimento.

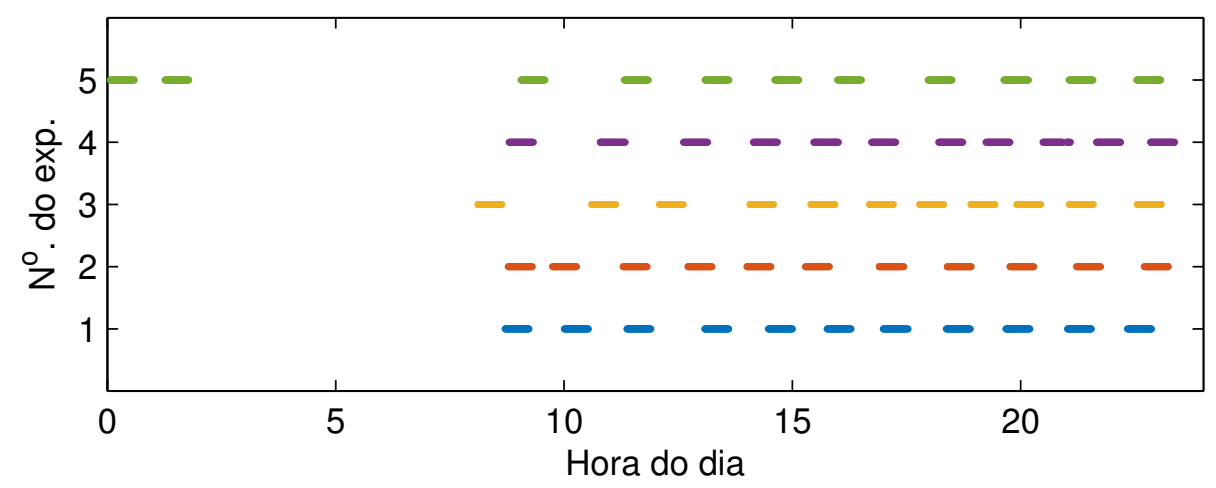

Fonte: Autor.

Cada experimento começou com $850 \mathrm{ml}$ de petróleo puro, já que era o volume mínimo que cobria o transdutor. Nessa mesma amostra, foi sendo adicionado água de forma recursiva (como comentado) para formar as concentrações de: 6, 11, 15, 19, 26, $32,37,41$ e $48 \%$.

Após cada medição, o conjunto béquer-célula era retirado do banho termostático 
com cuidado para não contaminar a água. A célula era deixada sobre um recipiente para escorrer a emulsão velha, enquanto preparava-se a nova amostra. Finalizado cada experimento, os excessos de petróleo, na célula, no béquer e nos recipientes utilizados, eram lavados com uma escova e uma esponja ensopadas em gasolina, pois a água e o detergente não os removiam.

Foram utilizados os mesmos equipamentos descritos no último parágrafo da seção 3.3. Um esquema da montagem experimental é mostrado na Figura 15.

Figura 15: Esquema da montagem experimental para a utilização da célula de espalhamento modificada.

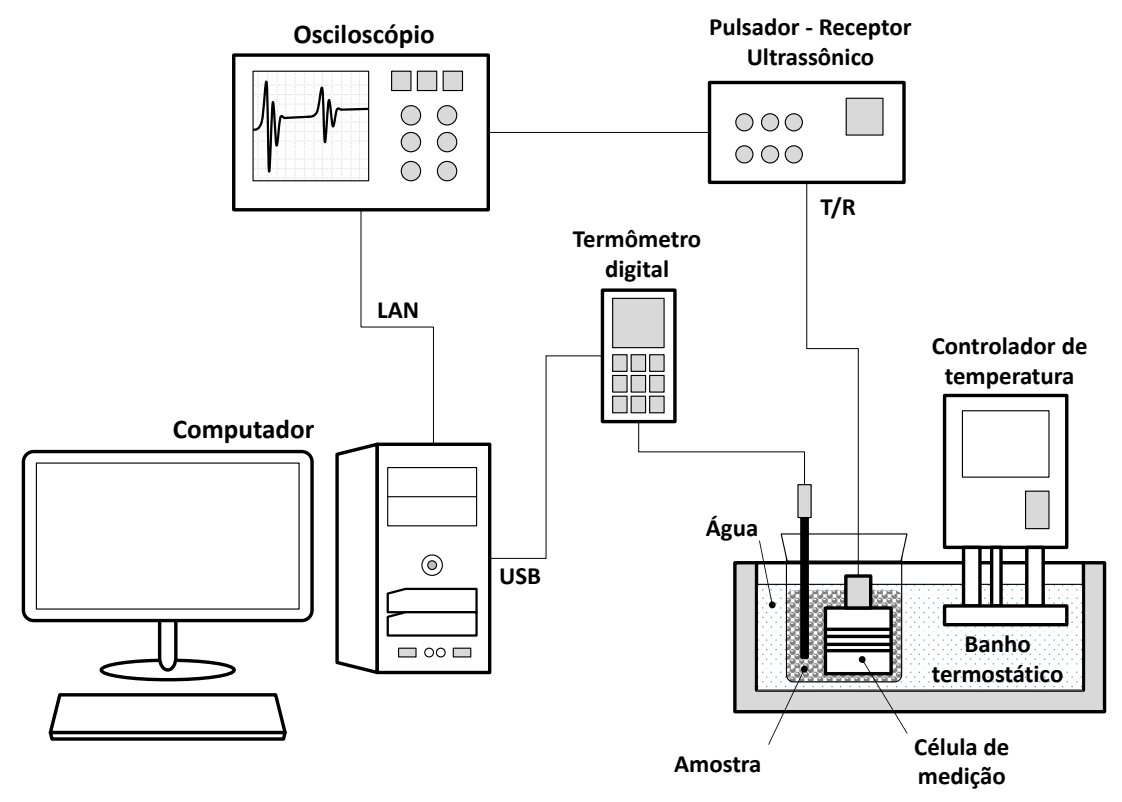

Fonte: Autor. 


\section{RESULTADOS E DISCUSSÃO}

Neste capítulo, são apresentados os resultados obtidos com as duas células de medição utilizadas. Primeiro são apresentados os resultados (propriedades acústicas) obtidos usando a célula com linhas de retardo, estes valores são comparados com o modelo teórico de misturas de Urick, e, posteriormente, são mostrados os resultados da análise de propagação das incertezas de medição dos equipamentos. Depois, são mostrados os resultados obtidos com a célula de espalhamento: as variações relativas das correlações cruzadas e da energia de onda das emulsões em função do tempo de medição, da concentração de água e da temperatura, usando como referência o petróleo puro; e a velocidade de propagação a partir do sinal de dispersão, usando as metodologias propostas (absolutas e relativas).

Os resultados são analisados e discutidos neste mesmo capítulo, na medida em que vão sendo apresentados.

\subsection{Resultados obtidos usando a célula com linhas de retardo}

Foi realizado o procedimento experimental descrito na seção 3.3. Terminados os ensaios, os sinais adquiridos apresentavam a forma mostrada na Figura 5. Nas subseções a seguir, são apresentados os resultados obtidos determinando as propriedades acústicas das emulsões em função da concentração de água. Em azul o valor médio da propriedade na banda de frequência estudada, em verde o valor da propriedade à frequência central do transdutor, e em vermelho o modelo teórico de misturas de Urick (mencionado na seção 3.2.6). A velocidade de propagação não foi determinada por espectroscopia, consequentemente, não se conta com valores à frequência central do transdutor nem calculou-se um valor médio em uma banda de frequência. Finalmente, é calculada a diferença relativa entre as propriedades e o modelo teórico. 
No final da seção, são apresentados os resultados obtidos usando a análise da propagação das incertezas de medição. Apresentam-se o valor médio das propriedades obtidas de forma experimental (sem realizar calibração), a sua faixa de incerteza e a curva do modelo teórico de Urick. Todos esses resultados em função da concentração de água.

\subsubsection{Velocidade de propagação da amostra}

A Figura 16 mostra os resultados obtidos para a velocidade de propagação da emulsão em função da concentração de água. Pode-se observar que quanto maior é a concentração de água da emulsão, maior é a velocidade de propagação, e este comportamento coincide com o modelo teórico de Urick. Obteve-se uma velocidade de propagação para o óleo puro de $1454 \mathrm{~m} / \mathrm{s}$. As velocidades de propagação do óleo e da água pura, junto as suas densidades, foram utilizadas para alimentar o modelo teórico, portanto, os resultados coincidem para as concentrações de $0 \%$ e $100 \%$. A máxima diferença relativa entre as curvas foi inferior a $0,50 \%$.

Figura 16: Velocidade de propagação na emulsão em função da concentração de água, medida com a célula com linhas de retardo.

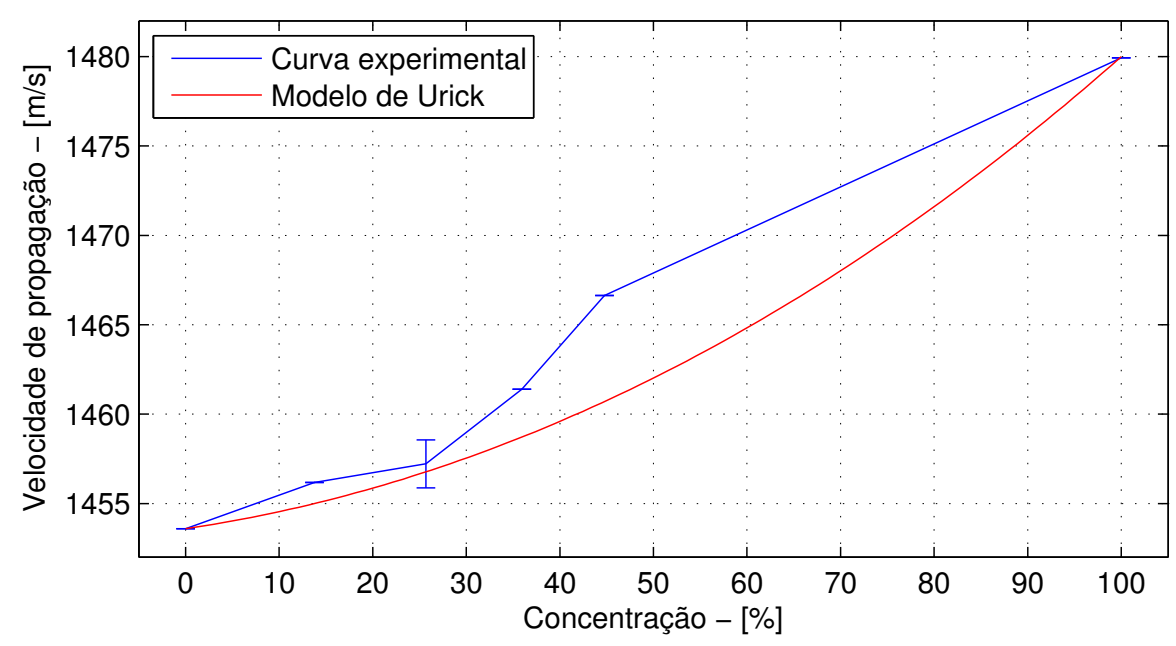

Fonte: Autor.

Observou-se que a velocidade de propagação é muito sensível a mudanças no comprimento da câmara da amostra $\left(l_{s}\right)$, de tal forma que o valor para a água pura, usando um comprimento de 2,00 mm (valor medido com paquímetro), era de $1450 \mathrm{~m} / \mathrm{s}$ e, usando 2,042 mm (valor obtido na calibração), era de $1480 \mathrm{~m} / \mathrm{s}$ (valor encontrado na literatura para $20^{\circ} \mathrm{C}$ ). Verifica-se então, que uma diferença de $0,042 \mathrm{~mm}$ pode gerar 
uma divergência de $30 \mathrm{~m} / \mathrm{s}$ na velocidade de propagação, que corresponde a 2,03\% de erro relativo teórico. Por esse motivo, é essencial calibrar o comprimento da câmara da amostra.

Usando a mesma metodologia, calculou-se a velocidade de propagação do vidro. $\mathrm{O}$ atraso temporal entre os ecos provenientes da primeira e da segunda linha de retardo $\left(\delta t_{12}\right)$ foi igual a $9,065 \mu \mathrm{s}$ para todos os ensaios. Logo, usando este resultado e o comprimento da camada deste material $\left(l_{2}=25,6 \mathrm{~mm}\right)$, obteve-se uma velocidade de propagação igual a $5648 \mathrm{~m} / \mathrm{s}$, para a temperatura de $20^{\circ} \mathrm{C}$.

\subsubsection{Coeficiente de reflexão na interface vidro-amostra}

A Figura 17 mostra os resultados obtidos para o coeficiente de reflexão na interface vidro-amostra em função da concentração de água das emulsões. Pode-se observar que esta propriedade incrementa de forma linear com a concentração de água, e que seu sinal é negativo porque a impedância acústica da emulsão é menor que a do vidro. $\mathrm{O}$ comportamento das curvas experimentais é similar ao modelo teórico de Urick, com uma diferença relativa inferior a $0,18 \%$. O coeficiente de reflexão não precisou ser calibrado, visto que sua determinação dependia unicamente das transformadas de Fourier dos sinais temporais.

Figura 17: Coeficiente de reflexão na interface vidro-amostra em função da concentração de água, medido com a célula com linhas de retardo.

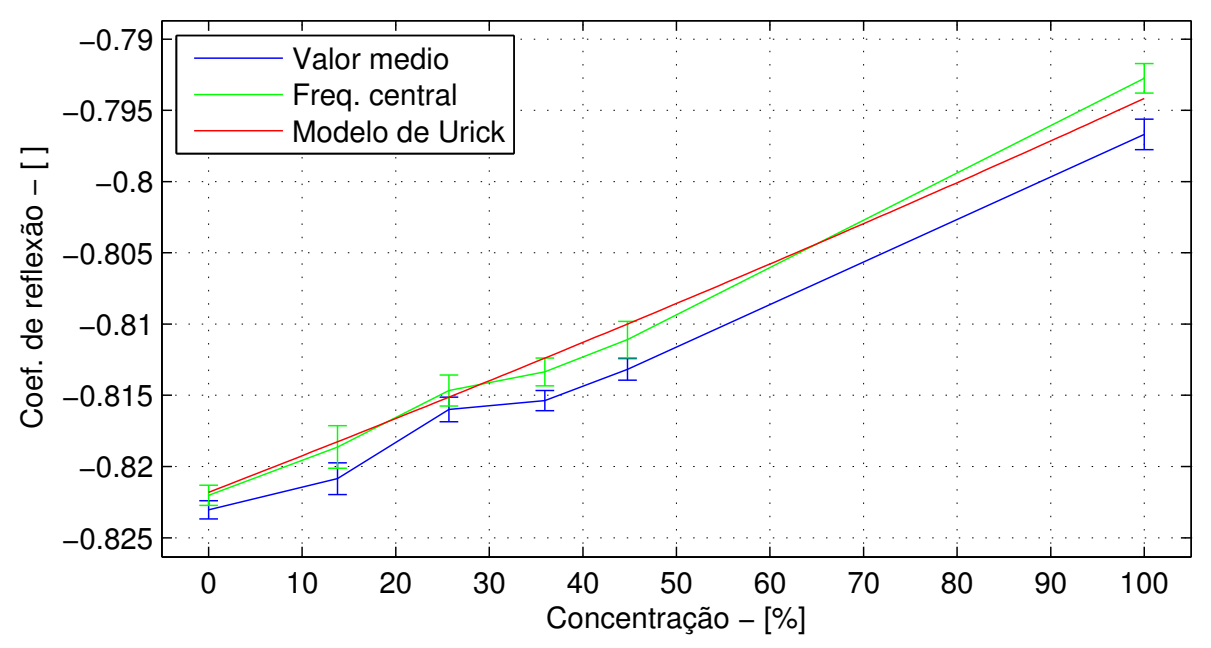

Fonte: Autor. 


\subsubsection{Impedância acústica da amostra}

A Figura 18 mostra os resultados obtidos para a impedância acústica da emulsão em função da concentração de água. Esta propriedade também apresenta um comportamento aproximadamente linear, aumentando proporcionalmente com a concentração de água das amostras. Obteve-se uma impedância acústica de 1,26 Mrayl para o óleo puro. Logo, comparando os resultados com o modelo teórico de Urick obteve-se uma diferença relativa inferior a $0,75 \%$.

Figura 18: Impedância acústica da emulsão em função da concentração de água, medida com a célula com linhas de retardo.

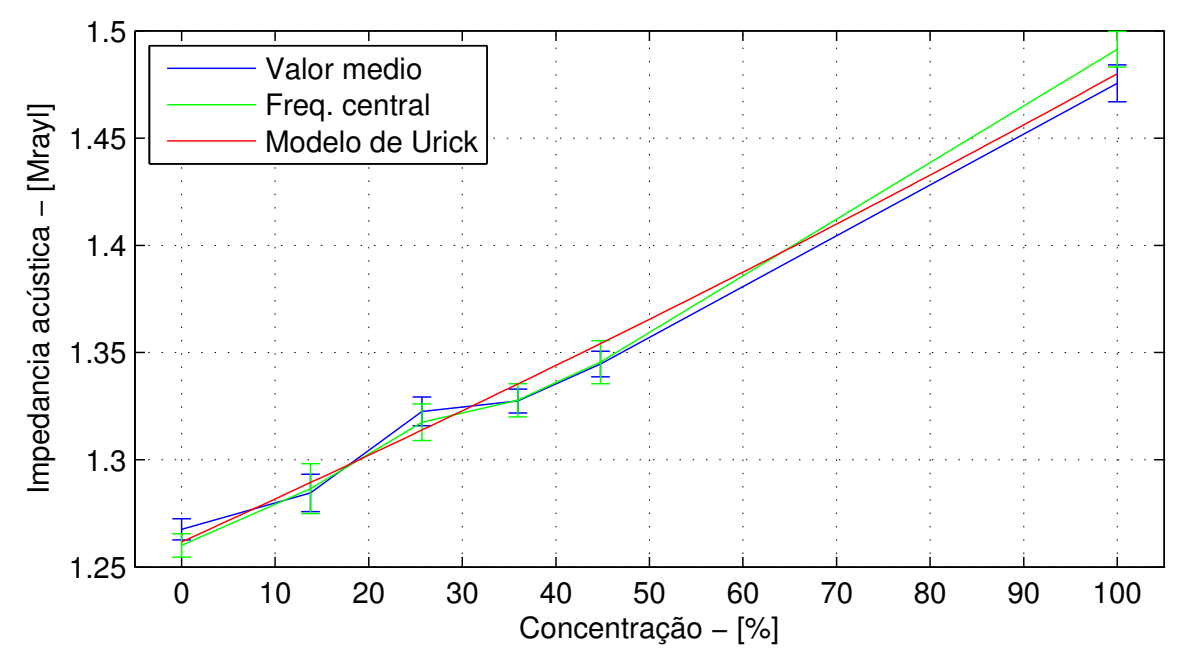

Fonte: Autor.

Na determinação desta propriedade foi necessário utilizar parâmetros físicos do vidro tais como seu diâmetro, espessura, peso e velocidade de propagação. A velocidade de propagação foi determinada na seção 4.1.1 e os parâmetros dimensionais foram medidos com paquímetro, porém houve dificuldade para determinar o peso com precisão, dado que o vidro estava embutido em um aro de bronze, fixo com uma fina camada de resina. Em vista disso, realizou-se um procedimento para determinar apenas o peso do vidro. Calculou-se a densidade do aro a partir do tarugo de onde foi extraído e com sua geometria, aproximou-se a massa para ser descontada do conjunto aro-vidro. Assim, o peso e a densidade do vidro resultaram em $188,3 \mathrm{~g}$ e $2359 \mathrm{Kg} / \mathrm{m}^{3}$, respectivamente. Não obstante, utilizando estes valores, a impedância acústica da água pura resultou em 1,532 Mrayl, e sabe-se da literatura que seu valor é 1,483 Mrayl (a $\left.20^{\circ} \mathrm{C}\right)$. Com este resultado, decidiu-se estimar o erro associado à medição do peso do vidro, sendo este de $3 \%$, pois obteve-se uma massa igual a 182,3 g. A curva apresentada na Figura 18 
está calibrada com o valor da impedância acústica da água medida a $20^{\circ} \mathrm{C}$, análogo ao procedimento realizado para a velocidade de propagação na seção 4.1.1. Variações na impedância acústica do vidro também resultam em erros na propriedade medida. Verifica-se que uma discrepância de $6 \mathrm{~g}$ na massa do vidro implica em uma diferença de 0,049 Mrayl.

\subsubsection{Densidade da amostra}

A Figura 19 mostra os resultados obtidos para a densidade da emulsão em função da concentração de água. Observa-se que essa propriedade aumenta de forma linear com a concentração, comportamento que coincide com o modelo teórico de Urick. As densidades das substâncias puras (0\% e 100\%) foram utilizadas para alimentar o modelo teórico. A máxima diferença relativa entre o modelo de Urick e os valores experimentais foi de $1,15 \%$.

Figura 19: Densidade da emulsão em função da concentração de água, medida com a célula com linhas de retardo.

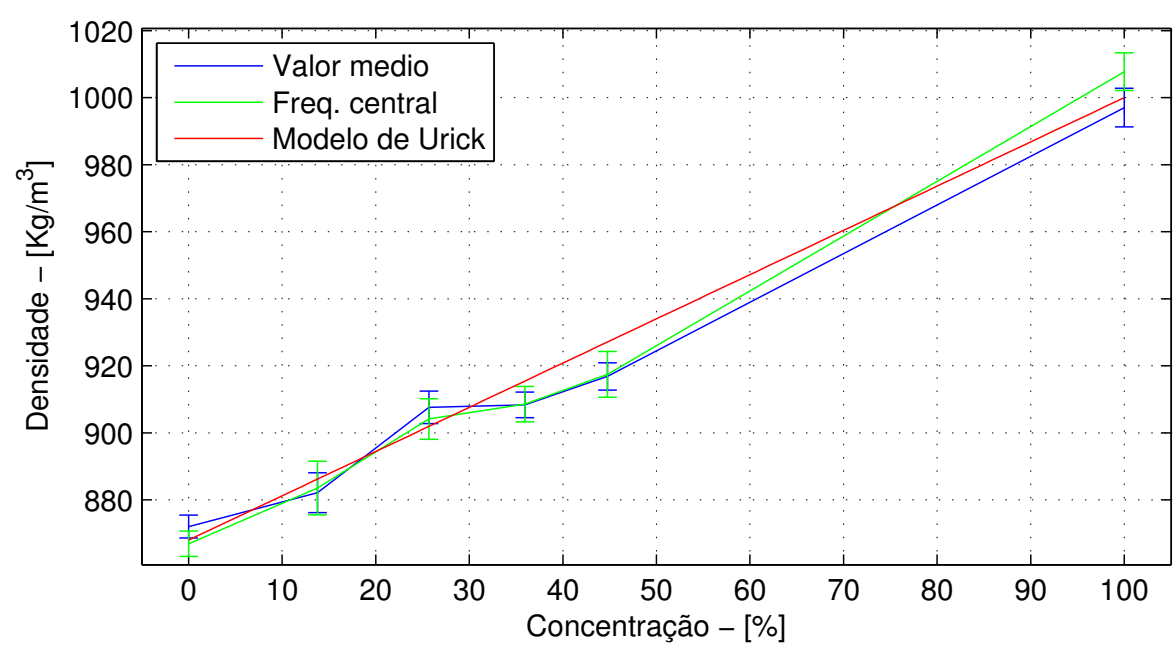

Fonte: Autor.

O valor obtido para a densidade no ensaio com óleo puro foi de aproximadamente $868 \mathrm{Kg} / \mathrm{m}^{3}$. Esse valor foi comparado com o reportado na Ficha de Informações de Segurança de Produtos Químicos da Lucheti Lubrificantes, fabricante do óleo Deiton Hidra 68 , observando que o valor medido está dentro da faixa $860-920 \mathrm{Kg} / \mathrm{m}^{3}$. Da mesma forma, o resultado experimental foi comparado com um óleo ISO 68 produzido pela companhia Petrobras, obtendo um erro de $1,70 \%$ (sendo $883 \mathrm{Kg} / \mathrm{m}^{3}$ o valor de referência). 


\subsubsection{Atenuação acústica da amostra}

A Figura 20 mostra os resultados obtidos para a atenuação acústica em função da concentração de água das emulsões. Observa-se que essa propriedade aumenta com a concentração de água da emulsão. O máximo valor de atenuação encontrado foi de $65,23 \mathrm{~Np} / \mathrm{m}$, e foi obtido para a maior concentração testada (45\%). O mínimo foi de $4,84 \mathrm{~Np} / \mathrm{m}$, para o ensaio realizado com água pura. Na literatura, a expressão para calcular a atenuação acústica da água $\left(\alpha_{w}\right)$ em função da frequência, para $20^{\circ} \mathrm{C}$, é da forma:

$$
\alpha_{w}=k f^{2}
$$

sendo $k=22 \cdot 10^{-15}$ em (KINO, 1987) e $k=25 \cdot 10^{-15}$ em (KINSLER et al., 2000).

Figura 20: Atenuação acústica da emulsão em função da concentração de água, medida com a célula com linhas de retardo.

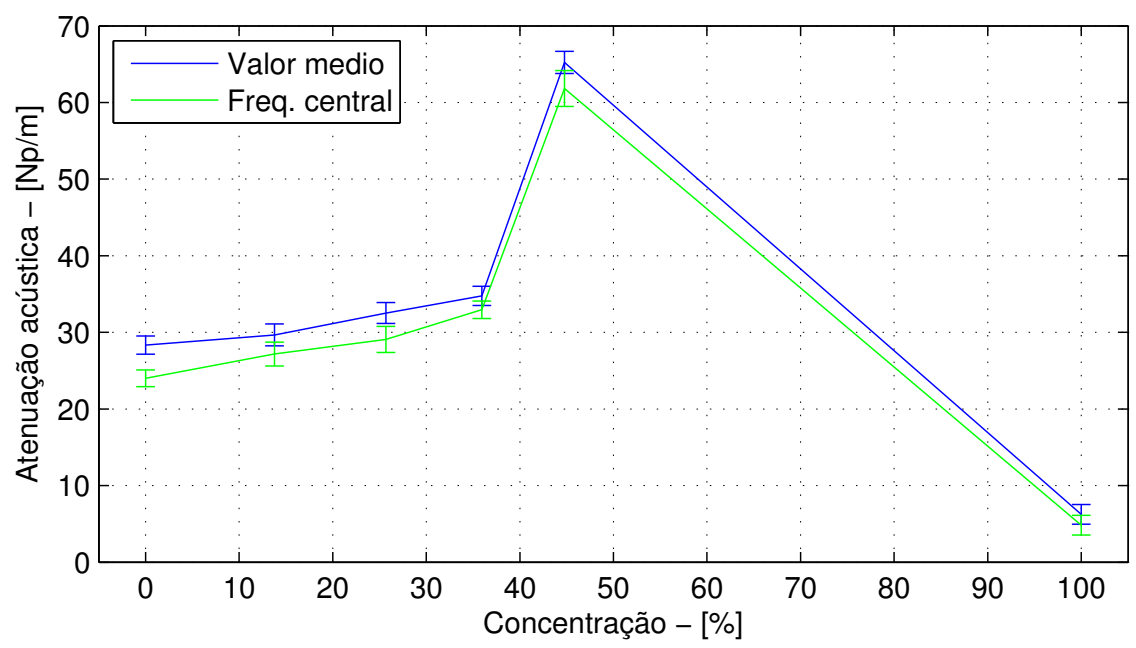

Fonte: Autor.

Para a frequência central do transdutor, $\left(f_{@ \max \left(A_{1}\right)}=3,17 \mathrm{MHz}\right)$, a atenuação acústica da água deveria ser de aproximadamente 0,237 Np/m (KINSLER et al., 2000; KINO, 1987) e, comparado com o valor experimental, o erro é demasiado grande (1900\%). Como as outras propriedades apresentaram uma diferença relativa, ao modelo de misturas, consideravelmente baixa (menor a 1,15\%), provavelmente o erro na medição da atenuação seja devido ao sinal $a_{3}(t)$ ou devido ao valor da impedância acústica do aço inoxidável $\left(Z_{4}\right)$, que são parâmetros envolvidos na determinação da atenuação, eq. 3.17. Se analisada esta expressão, a impedância do aço encontra-se implícita no coe- 
ficiente de reflexão amostra-aço $\left(R_{34}\right)$ que, pela diferença na ordem de grandeza entre $Z_{3}$ e $Z_{4}$, é aproximadamente 1 . Desse modo, acredita-se que a maior contribuição de erro provém do sinal $a_{3}(t)$ que, após refletir em múltiplas interfaces e atravessar vários materiais, possa ter tido seu espectro de frequências afetado.

Figura 21: Transformada de Fourier experimental e teórica do terceiro eco, junto ao erro relativo entre as curvas. Calculado para o ensaio realizado com água pura.

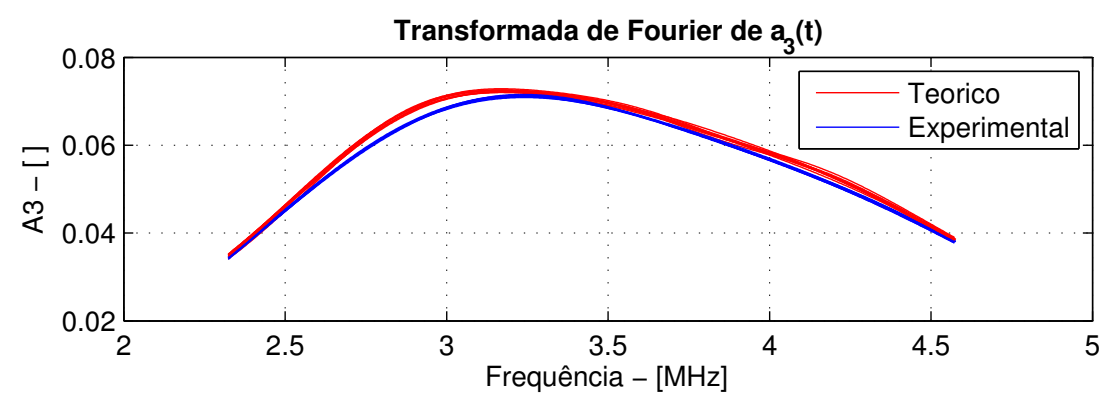

Erro relativo em $\mathrm{A}_{3}$

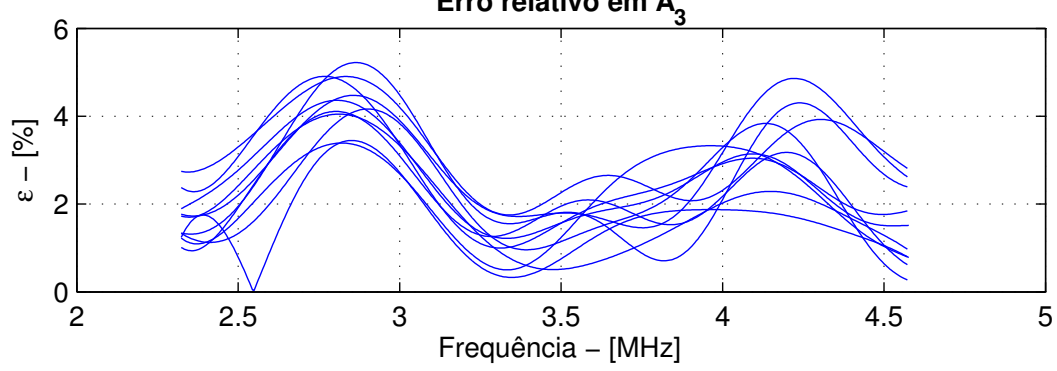

Fonte: Autor.

Para os ensaios realizados com água pura, foi calculado o valor teórico da transformada de Fourier do terceiro eco e o erro relativo experimental. Para isso, foi colocado em evidência o termo $A_{3}(f)$ da eq. 3.17, e na expressão resultante, foi substituída a eq. 4.1. Estes resultados são mostrados na Figura 21, onde as curvas experimentais e teóricas têm o mesmo comportamento, e seus valores são bastante próximos entre si. Logo, o erro relativo para valores próximos à frequência central do transdutor é de aproximadamente $2 \%$, dando a entender que trata-se de uma propriedade muito sensível, pois uma pequena diferença de $2 \%$ em $A_{3}(f)$ produziu um erro teórico de $1900 \%$ na atenuação acústica da água pura, o qual pode ser consequência de problemas de paralelismo nas linhas de retardo devido à manufatura.

As curvas experimentais de atenuação, do ensaio realizado com água pura, foram plotadas na Figura 22, acompanhadas das duas curvas teóricas mencionadas acima. Há uma diferença entre os valores teóricos e experimentais de uma a duas ordens de grandeza. 
Figura 22: Atenuação acústica experimental e teórica da água em função da frequência.

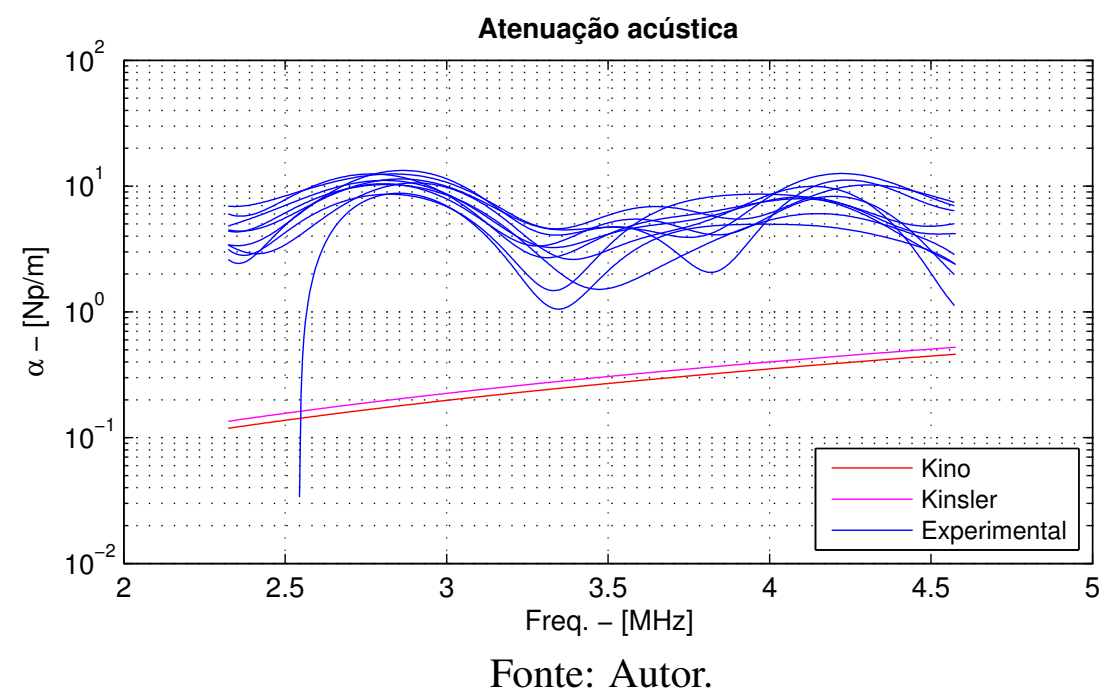

O modelo teórico de Urick não foi utilizado na determinação das curvas de atenuação acústica, porque a equação da atenuação acústica (eq. 3.17), além de precisar de outras propriedades, necessita do termo $A_{2}(f) / A_{3}(f)$, cujo valor "correto" é desconhecido para cada concentração.

\subsubsection{Análise da propagação das incertezas de medição}

Na Figura 23 é apresentado o resumo das propriedades obtidas com a célula, junto a suas respectivas incertezas. Em azul, a média dos dez ensaios para cada concentração, previamente obtidos a partir do valor da propriedade à frequência central do transdutor, e em vermelho o modelo teórico de misturas de Urick. As curvas experimentais apresentadas não estão calibradas e as linhas tracejadas representam a faixa de incerteza associada aos equipamentos de medição (calculadas com as eqs. da seção 3.2.7). O espaço compreendido entre as linhas tracejadas pode ser interpretado como os possíveis valores que uma propriedade pode ter após ser calculada com medidas tomadas pelos equipamentos e instrumentos à disposição. Assim, quanto mais baixa seja a incerteza dos instrumentos de medição, mais estreitas serão as faixas e, consequentemente, mais precisa será a medição.

Para as propriedades apresentadas, a curva teórica encontra-se dentro do desvio “permissível”, o que valida o procedimento realizado. Não obstante, como foi comentado no final da subseção anterior, não foi possível construir a curva teórica de atenuação dado que não se conhece o valor teórico do termo $A_{2}(f) / A_{3}(f)$ para cada 
Figura 23: Resumo das propriedades obtidas (linhas azuis), com seus desvios de medição sem realizar calibração (linhas tracejadas), e modelo teórico de Urick (linhas vermelhas).
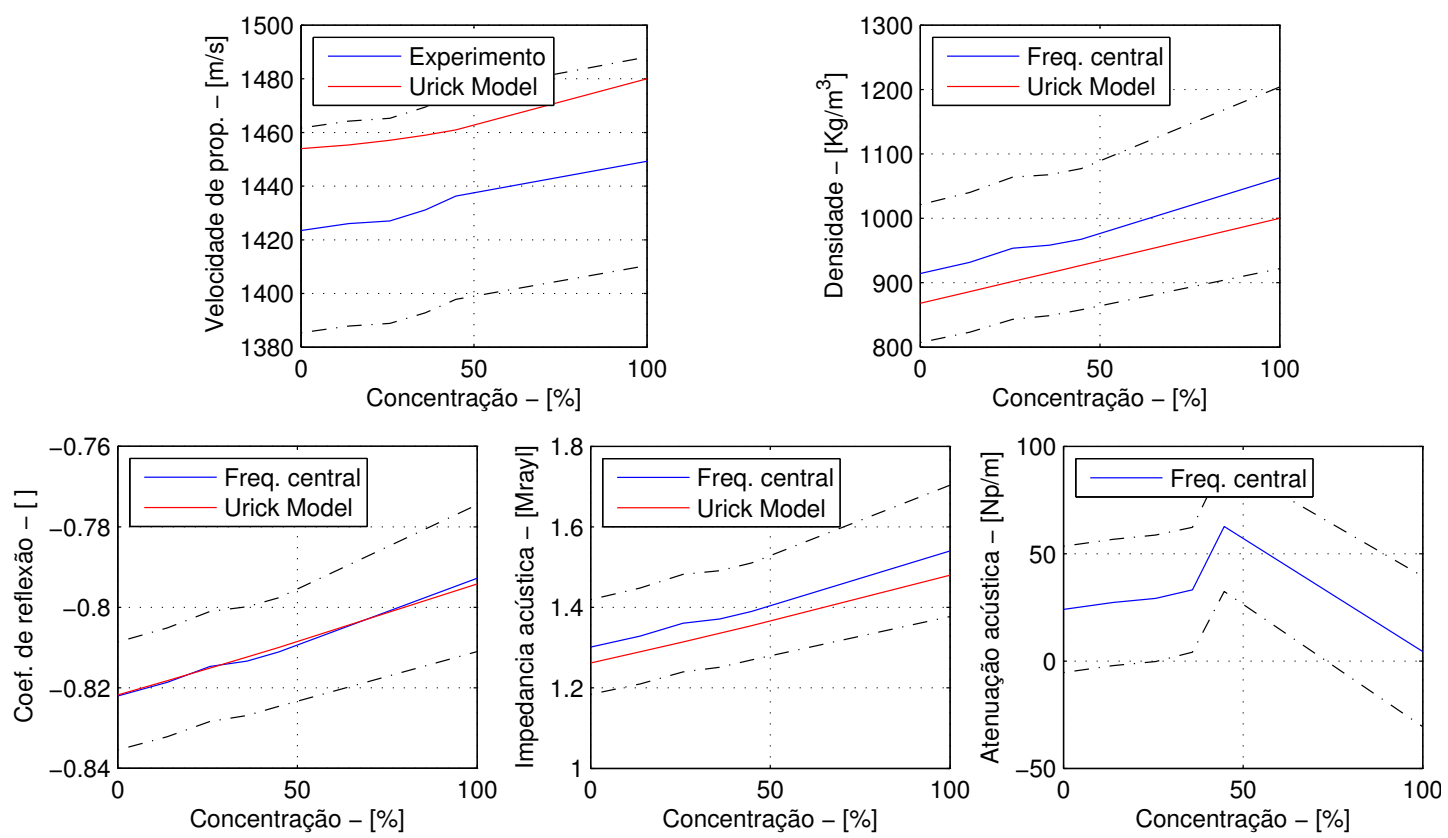

Fonte: Autor.

concentração de água. Na Tabela 4, são reportados os erros relativos máximos que podem ser cometidos devido às incertezas dos equipamentos de medição. Também são comparadas as máximas diferenças relativas entre o modelo teórico de misturas de Urick e as curvas experimentais, com calibração e sem calibração. Lembrando que as máximas diferenças relativas entre o modelo teórico e as curvas experimentais calibradas para cada propriedade (última coluna da Tabela 4) foram mencionados em suas respectivas seções.

Como as curvas teóricas encontram-se dentro da faixa de incerteza devido à me-

Tabela 4: Erro relativo devido às incertezas dos equipamentos de medição e, máxima diferença relativa entre o modelo teórico de misturas de Urick e as curvas experimentais, com e sem calibração.

\begin{tabular}{|l|r|r|r|}
\hline \multirow{2}{*}{ Propriedade } & \multicolumn{3}{|c|}{ Erro relativo } \\
\cline { 2 - 4 } & $\begin{array}{c}\text { Incerteza na } \\
\text { medição }\end{array}$ & $\begin{array}{c}\text { Urick vs Exp. } \\
\text { não calibrado }\end{array}$ & $\begin{array}{c}\text { Urick vs Exp. } \\
\text { calibrado }\end{array}$ \\
\hline Velocidade de prop. & $2,68 \%$ & $2,10 \%$ & $0,50 \%$ \\
\hline Densidade & $13,27 \%$ & $6,28 \%$ & $1,15 \%$ \\
\hline Coef. de reflexão & $2,30 \%$ & $0,18 \%$ & $0,18 \%$ \\
\hline Impedância acústica & $10,59 \%$ & $4,08 \%$ & $0,75 \%$ \\
\hline
\end{tabular}


dição, os erros experimentais são inferiores aos erros devidos à medição. Logo, ao comparar a diferença relativa entre o modelo teórico e as curvas experimentais, com e sem calibração, vê-se que a calibração é uma alternativa que permite reduzir a incerteza de medição; por exemplo, para a velocidade de propagação, ajustando o comprimento da câmara da amostra $\left(l_{s}\right)$ de $2,00 \mathrm{~mm}$ a $2,042 \mathrm{~mm}$, o erro diminuiu de 2,10\% a 0,50\%. Então, esta análise serve para discernir quando os erros são consequência dos instrumentos de medição (e pode realizar-se calibração) e quando são por causa de imprevistos nos procedimentos experimentais ou outros fatores.

\subsection{Resultados obtidos usando a célula de espalha- mento}

Foi realizado o procedimento experimental descrito na seção 3.7 e os sinais adquiridos foram da forma mostrada na Figura 9. Inicialmente foram estudadas as variações relativas das emulsões usando como referência o petróleo puro. Isto foi feito em função do tempo e da concentração de água, utilizando os parâmetros: correlação cruzada, correlação cruzada normalizada e energia de onda.

Além disso, os resultados da velocidade de propagação foram obtidos usando as metodologias propostas: absolutas e relativas. Por fim, as curvas de velocidade foram comparadas com o modelo teórico de misturas de Urick.

\subsubsection{Variações na amostra usando a célula de espalhamento}

A Figura 24 mostra as variações relativas das amostras em função do tempo de medição, usando como referência uma amostra de petróleo puro. Estas variações foram medidas através dos seguintes parâmetros: correlação cruzada, correlação cruzada com os sinais normalizados, e energia de onda. No Teste 1 , as concentrações de $0 \%$ (óleo puro) e $100 \%$ (água) foram testadas por poucos minutos por tratar-se de substâncias puras que não mudam no tempo. Em ambos testes, os valores dos parâmetros relativos associados ao petróleo puro são iguais a 1, pois foram comparados consigo mesmos. A tendência geral das curvas nos dois testes, para todas as análises, é alcançar um valor estável após um período de tempo. Não obstante, os ensaios de $10 \%$ no Teste 1 e de $8 \%$ no Teste 2, aparentam ter um comportamento um pouco mais dependente do tempo devido à presença de variações maiores nas propriedades medidas. Este 
Figura 24: Variações relativas das amostras em função do tempo de medição, obtidas através da correlação cruzada, correlação cruzada normalizada e energia de onda.

Teste 1
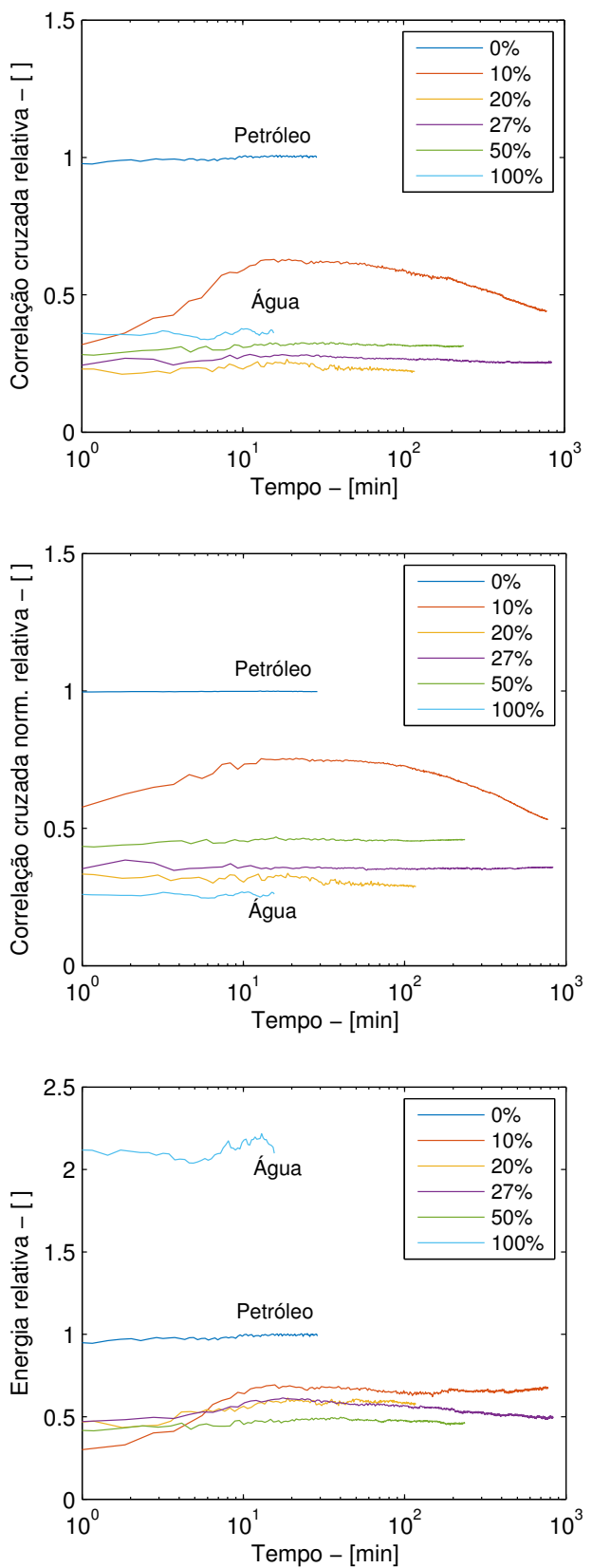

Teste 2
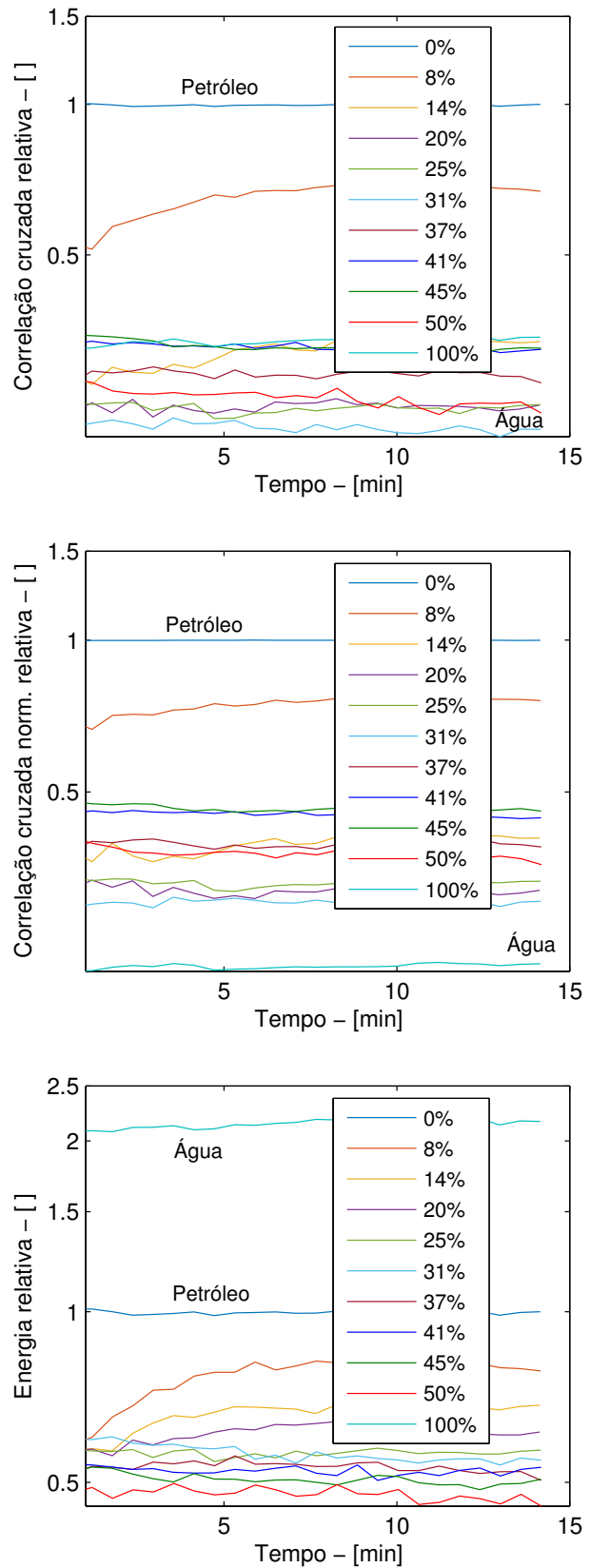

Fonte: Autor.

comportamento pode ser devido a um erro experimental de estabilização da emulsão ou de superposição entre os ecos $a_{1}(t)$ e $a_{2}(t)$, já que não foi observado nos experimentos realizados com a célula modificada. Outras possíveis causas são: uma distribuição não uniforme das gotículas de água no béquer, devido a sua baixa concentração, e uma interação forte entre a onda e as gotículas de água para esse valor específico de 
concentração. É necessário analisar a relação existente entre a concentração de água e o tamanho das gotas, para verificar se este é próximo do comprimento de onda, ou se, para este valor, a frequência de ressonância coincide com a frequência do transdutor.

Os gráficos de correlação cruzada e de correlação cruzada com os sinais normalizados têm um comportamento similar, ou seja, é igual a 1 para a concentração de $0 \%$ e inferior para o resto das concentrações. A energia relativa de onda vai diminuindo com o aumento da concentração de água na emulsão, e duplica seu valor nos ensaios realizados com água pura (100\%); isto significa que a água pura é aproximadamente duas vezes menos atenuante, ou dissipativa, que o petróleo puro. Observa-se que a energia relativa tarda alguns minutos em alcançar um valor estável, mas logo permanece constante por várias horas (como é o caso do Teste 1). Esta dispersão adicional, nos primeiros minutos, é consequência das bolhas de ar introduzidas na amostra durante o processo de mistura, porém estas começam a boiar e desaparecem na superfície da amostra.

A Figura 25 mostra os valores médios e os desvios padrões dos parâmetros relativos de cada concentração calculados ao longo do tempo, para os Testes 1 e 2. Esses resultados mostram uma dependência com a quantidade de água nas emulsões. As curvas dos dois testes têm o mesmo comportamento para cada parâmetro, havendo uma diferença relativa máxima de $15 \%$ na correlação cruzada, de $16 \%$ na correlação cruzada com os sinais normalizados, e de $7 \%$ na energia de onda. Estas diferenças podem ser devidas a variações de temperatura nas emulsões, que afetam a densidade e a velocidade de propagação, ou por causa da coalescência das gotas da fase dispersa, produto da diferença entre os tempos de medição dos testes; lembrando que, ao considerar todos os ensaios, o primeiro teste teve uma duração total de três dias e o segundo uma duração total de algumas horas.

A correlação cruzada e a correlação cruzada com os sinais normalizados têm um comportamento similar: seus valores decrescem com o aumento da quantidade de água nas emulsões, até alcançar uma concentração de aproximadamente $20 \%$, e logo mantêm-se constantes. Assim, o método da correlação cruzada é mais apropriado para o monitoramento de baixas concentrações, pois tem-se uma melhor resolução.

A energia de onda diminui com o aumento da quantidade de água nas emulsões, seguramente pela dispersão e outros fenômenos produzidos pelas gotículas de água (fase dispersa). A menor atenuação ocorre no petróleo puro, como era esperado, e 
Figura 25: Valor médio e desvio padrão dos valores relativos de correlação cruzada, correlação cruzada com os sinais normalizados e energia de onda, em função da concentração de água nas emulsões.
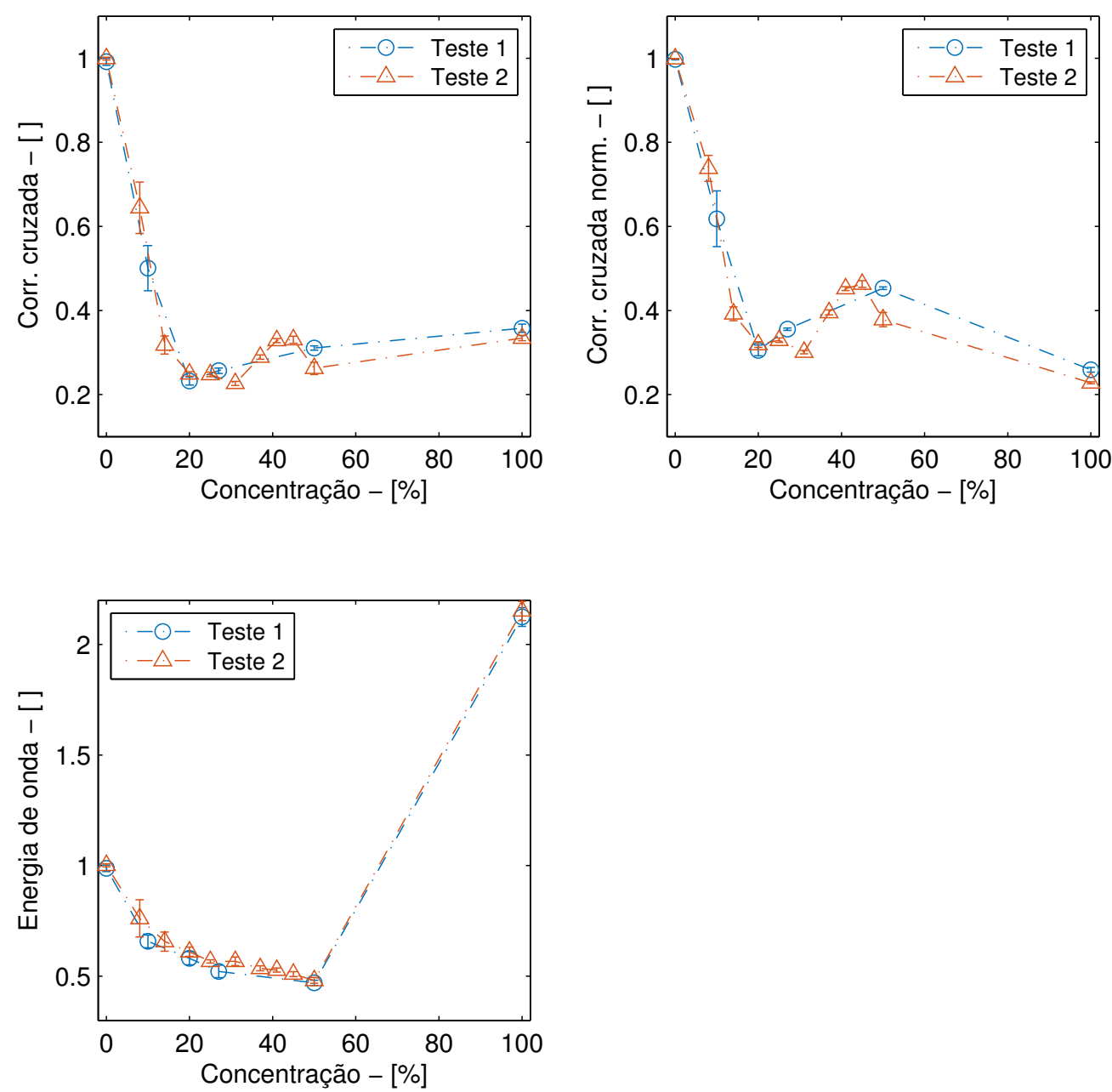

Fonte: Autor.

a maior, na concentração de 45\%. Logo, para o ensaio com água, obteve-se um valor relativo de 2,10 em relação ao petróleo puro. Os valores deste parâmetro variam gradualmente, inferindo-se que esta metodologia abrange uma faixa maior de concentrações. Os desvios padrões são pequenos, inclusive para o Teste 1, cuja duração foi de várias horas para cada concentração. Isto significa que os parâmetros utilizados para monitorar as variações relativas das amostras são bastante estáveis ao longo do tempo; sutilmente dependentes da coalescência e fortemente dependentes da concentração de água das emulsões. Este comportamento também foi observado em (MCCLEMENTS et al., 1990) para a velocidade de propagação. 


\subsubsection{Velocidade de propagação usando a célula de espalhamento}

A Figura 26 mostra a velocidade de propagação em função da concentração de água das emulsões. Esta foi calculada a partir do primeiro segmento do sinal de dispersão, localizando o tempo associado aos valores máximo e mínimo, o tempo associado ao valor máximo da envoltória do segmento (calculada com a transformada de Hilbert), e o tempo em que o segmento de sinal ultrapassa pela primeira vez um limiar de tensão acima do nível de ruído (threshold method). Os resultados obtidos com cada sinal foram plotados na forma de pontos para cada concentração. Assim, para o Teste 1, foram plotados 100 pontos para a concentração de $0 \%, 840$ para 10\%, 200 para 20\%, 900 para 27\%, 400 para 50\% e 55 para 100\%. Para o Teste 2, foram plotados 25 pontos para cada concentração. Já o desvio destes pontos está relacionado com a estabilidade da propriedade ao longo do tempo. Com isso, vê-se que o método do valor mínimo e o do limiar de ruído têm um desvio bastante baixo, pois seus valores estão aglomerados em uma mesma região (sem valores dispersos). Com relação ao comportamento das curvas, a velocidade de propagação aumenta com a quantidade de água na emulsão, mas nota-se que os pontos do Teste 2 têm um comportamento inesperado, que será discutido adiante.

Em ambos os testes, a velocidade de propagação do petróleo puro encontrava-se entre 1390 m/s e 1400 m/s. Logo, a velocidade de propagação da água coincidia com o valor teórico $(1497 \mathrm{~m} / \mathrm{s})$, pois a partir deste ensaio foi calculado o comprimento característico mencionado na seção 3.6. Ressalta-se que estas duas substâncias puras apresentaram um desvio padrão bastante baixo em todos os métodos implementados.

Acredita-se que houve um imprevisto durante o procedimento experimental que levou a um erro sistemático no Teste 2. Observa-se que, até uma concentração de aproximadamente $30 \%$, os pontos têm um comportamento similar para ambos os testes. Entretanto, a partir deste valor, a velocidade de propagação aumenta rapidamente no segundo teste. Uma possibilidade é o transdutor ter se deslocado em relação às varetas, movimentando-se um pouco para a frente; desta forma, a distância entre sua face e os dispersores diminuiu, aparentando uma velocidade de propagação maior. $\mathrm{O}$ ensaio com água não se viu afetado porque foi o primeiro a ser realizado (antes de sujar a célula com o petróleo). O problema do deslocamento do transdutor durante a limpeza da câmara não afetou os resultados obtidos pelos métodos relativos, porque a distância relativa entre dois pontos de um mesmo sinal não varia mesmo se todo o 
Figura 26: Velocidade de propagação em função da concentração de água das emulsões, medida com a célula de espalhamento. Valores obtidos pelos métodos absolutos.

Teste 1

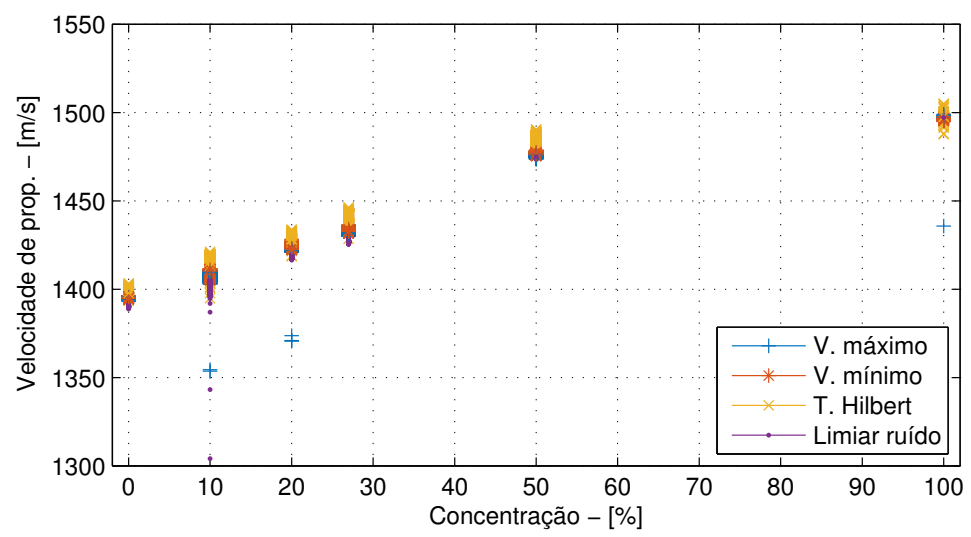

Teste 2

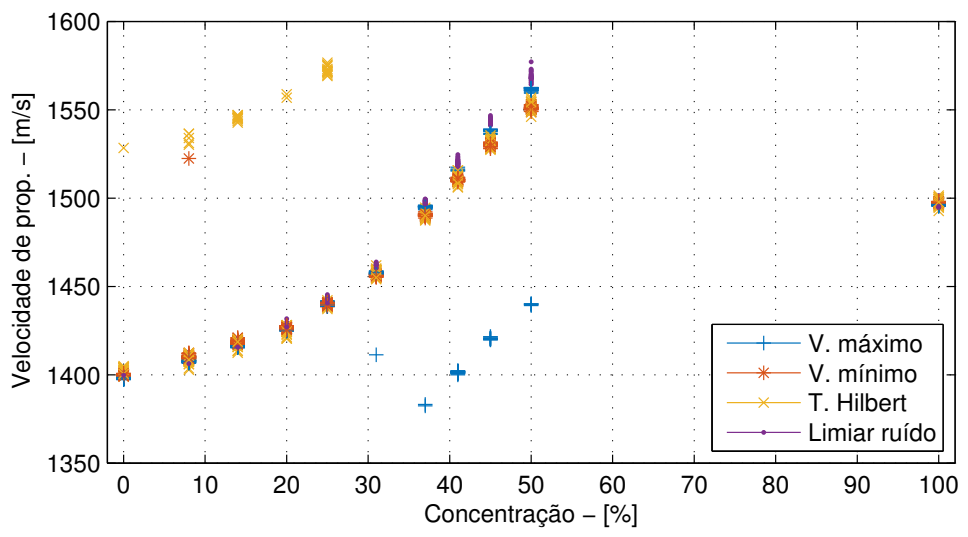

Fonte: Autor.

sinal adiantar ou atrasar um pouco.

A Figura 27 mostra a velocidade de propagação em função da concentração de água das emulsões. Esta foi calculada a partir dos dois primeiros segmentos do sinal de dispersão, usando a diferença temporal entre os valores máximos de cada segmento, a diferença temporal entre os valores mínimos de cada segmento e o atraso associado ao máximo absoluto da correlação cruzada entre os dois segmentos. O método que usa os valores mínimos, tem um desvio bastante baixo, com uma dispersão praticamente nula; logo, o método que utiliza a correlação cruzada, apresenta um desvio um pouco maior; e finalmente, o método que usa os valores máximos, tem um comportamento mais errático. Isto também foi observado na Figura 26, e acontece porque o pico mínimo nos segmentos do sinal está bem diferenciado. Entretanto, na parte superior do sinal existem dois lóbulos que, dependendo da superposição, um deles pode tornarse dominante (ver Figura 9). 
Figura 27: Velocidade de propagação em função da concentração de água das emulsões, medida com a célula de espalhamento. Valores obtidos pelos métodos relativos.

Teste 1

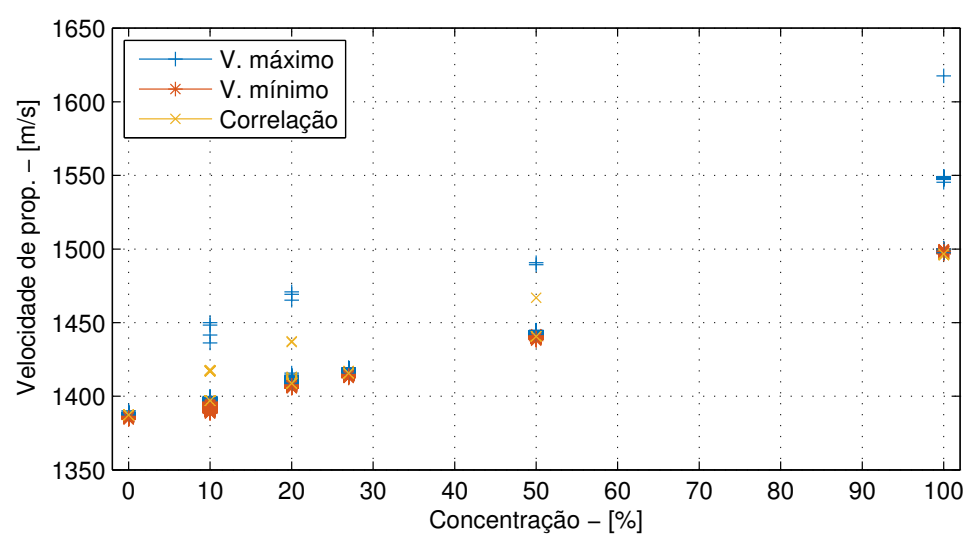

Teste 2

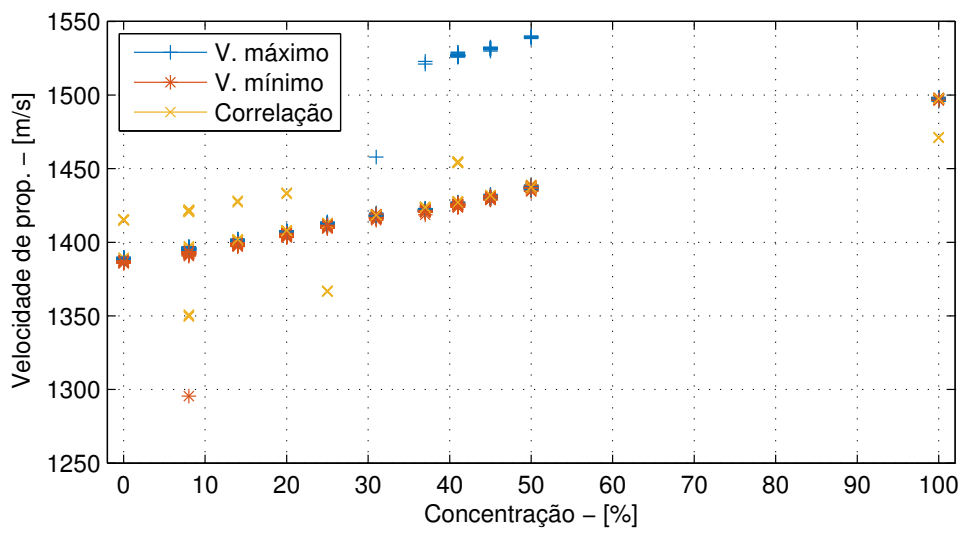

Fonte: Autor.

Quanto ao comportamento dos pontos, a velocidade de propagação é linear e diretamente proporcional à concentração de água das emulsões, obtendo um valor de $1386.5 \mathrm{~m} / \mathrm{s}$ para o petróleo puro em ambos os testes. Posteriormente, foram juntados os resultados dos Testes 1 e 2, obtidos pelo método relativo, e, a partir deles, foi calculado o valor médio em função da concentração; estes novos resultados foram comparados com o modelo teórico de misturas de Urick, descrito na seção 3.2.6.

A Figura 28 mostra o valor médio da velocidade de propagação em função da concentração de água para cada método relativo. $\mathrm{O}$ valor médio foi calculado usando todos os sinais de todos os experimentos realizados. Nota-se que esta propriedade tem uma dependência linear positiva com a quantidade de água nas emulsões, como foi comentado anteriormente. Os métodos com menor desvio, e consequentemente melhor tendência, foram o do valor mínimo e o da correlação cruzada. O método do valor máximo, teve um desvio muito grande para as concentrações de $41 \%$ e $45 \%$, 
Figura 28: Valor médio da velocidade de propagação em função da concentração de água para cada método relativo. Valores obtidos usando todos os sinais de todos os experimentos.

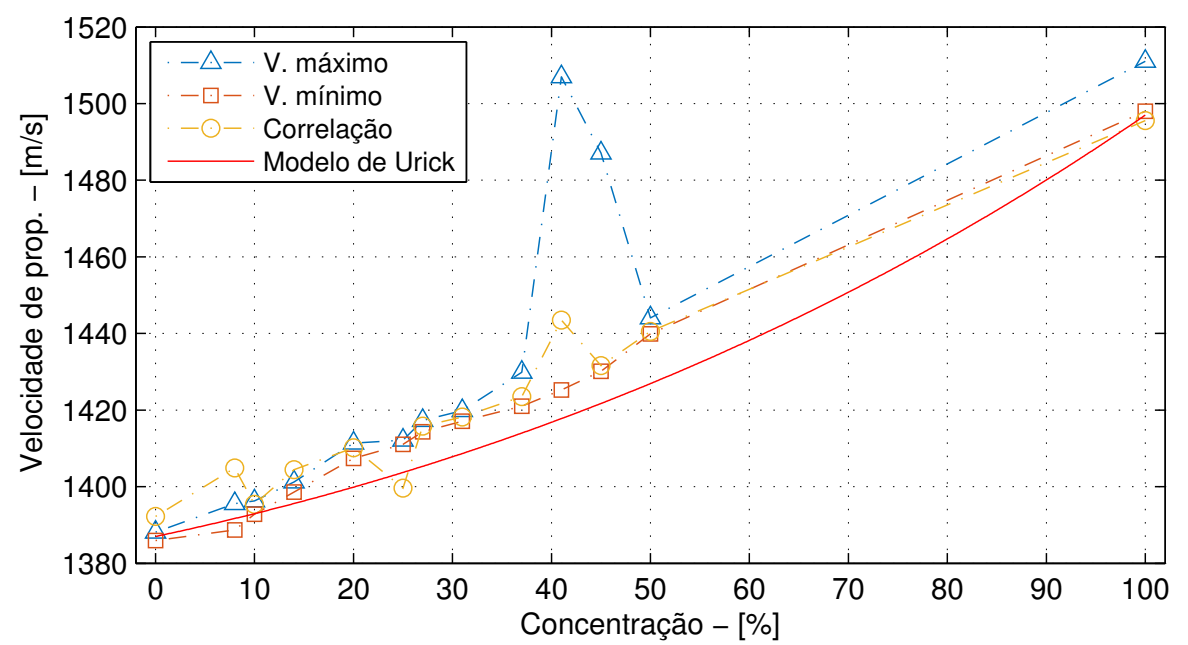

Fonte: Autor.

principalmente devido aos valores do Teste 2. Logo, a máxima diferença relativa com relação ao modelo teórico de Urick foi: $6,28 \%$ no método do valor máximo, $0,64 \%$ no método do valor mínimo, e 1,76\% no método da correlação cruzada.

\subsection{Resultados obtidos usando a célula de espalha- mento modificada}

O procedimento experimental descrito na seção 3.9 foi utilizado para a célula modificada. A temperatura foi monitorada durante os ensaios utilizando o termômetro digital Delta Ohm HD2127.1, com dois termopares. Para cada aquisição, foi calculada a média das duas leituras de temperatura. A Figura 29 mostra o valor médio e o desvio padrão das 55 temperaturas obtidas em função da concentração de água das emulsões, para os 5 experimentos realizados. O desvio padrão em cada ensaio é pequeno, o que indica um bom controle da temperatura durante as aquisições com cada amostra. Já, entre um ensaio e outro, existem pequenas flutuações. As curvas para os experimentos realizados a $20^{\circ} \mathrm{C}$ têm o mesmo comportamento e valores próximos, com máxima variação, ao longo do dia de medição, de aproximadamente $0,10^{\circ} \mathrm{C}$. As curvas dos experimentos realizados a $25^{\circ} \mathrm{C}$ encontram-se um pouco mais afastada (uma da outra), porém coincidem em alguns pontos; a máxima variação, ao longo do dia de medição, foi de aproximadamente $0,13^{\circ} \mathrm{C}$. Por último, a variação da temperatura no experimento 
realizado $30^{\circ} \mathrm{C}$ foi de aproximadamente $0,30^{\circ} \mathrm{C}$.

Figura 29: Valor médio e desvio padrão da temperatura em função da concentração de água para cada experimento. Resultados obtidos usando termômetro digital durante as aquisições com a célula de espalhamento modificada.
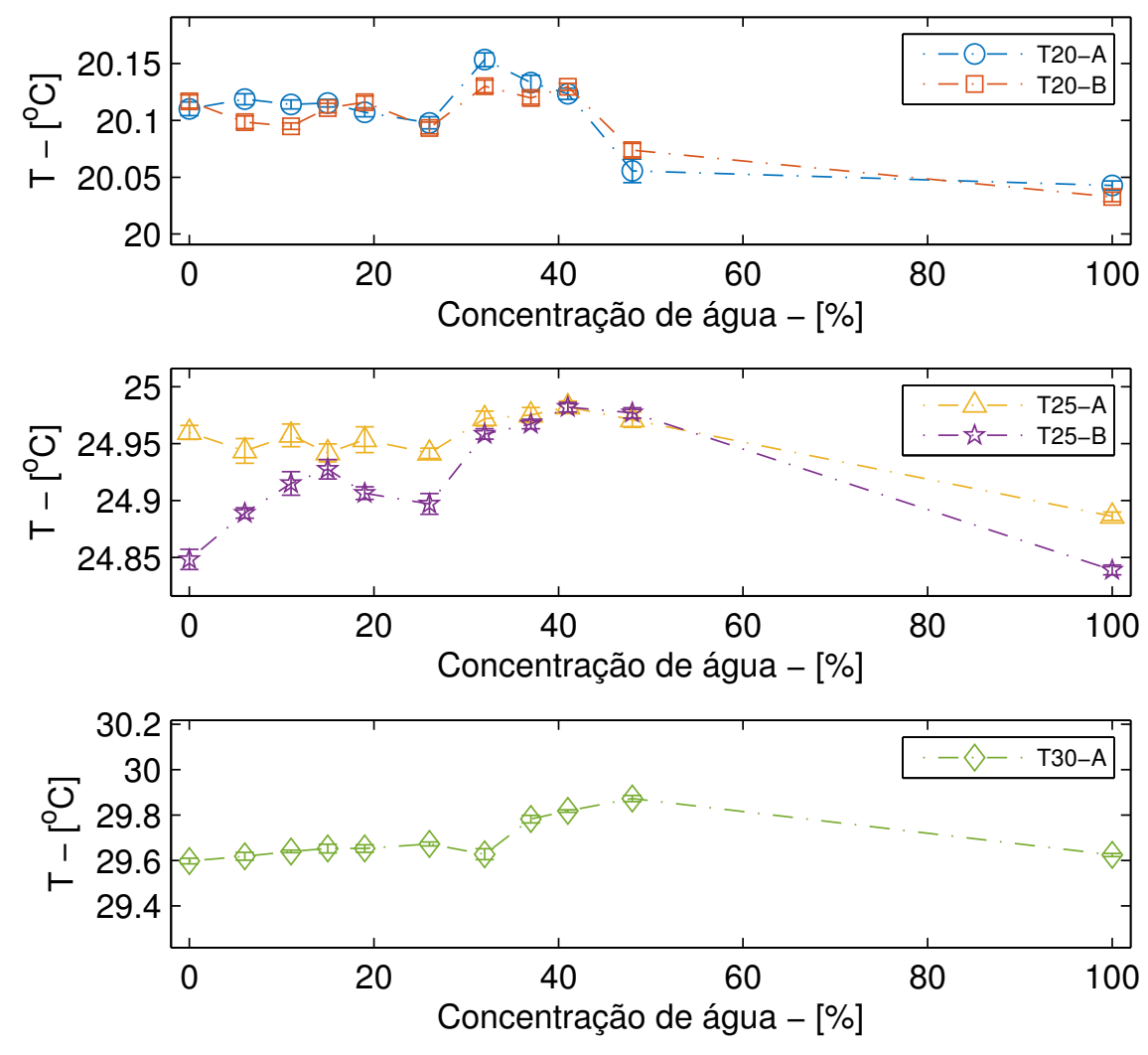

Fonte: Autor.

Conforme aumentava a temperatura dos experimentos, tornava-se mais difícil realizar o controle desta variável, pois o gradiente, com relação à temperatura ambiente, era cada vez maior e promovia-se a transferência de calor. A temperatura na cidade de São Paulo, para as datas em que foram realizados os experimentos, estava próxima de $18^{\circ} \mathrm{C}$, e esta apresentava flutuações ao longo do dia. Embora a água para as emulsões foi colocada no banho termostático para estabilizá-la termicamente, nos experimentos realizados a $20^{\circ} \mathrm{C}$, percebeu-se que o agitador esquentava a amostra de 1 a $2^{\circ} \mathrm{C}$; para mitigar esse efeito, a água para as emulsões era refrigerada antes de incorporá-la. No experimento realizado a $25^{\circ} \mathrm{C}$, foi visto que o calor adicionado pelo trabalho do agitador sob a amostra era compensado com a perda de calor devido à diferença de temperatura com o ambiente. Já, para o experimento realizado a $30^{\circ} \mathrm{C}$, foi necessário misturar água quente com água em temperatura natural, para completar a quantidade a adicionar nas emulsões. Apesar dos inconvenientes, sempre se esperou a estabilização 
térmica das amostras para começar as aquisições dos sinais.

\subsubsection{Variações nas amostras usando a célula de espalhamento mo- dificada}

Primeiramente, as variações relativas das amostras foram monitoradas a partir do sinal de dispersão em toda sua extensão (a forma do sinal é mostrada na Figura 12b). A Figura 30 mostra o valor médio e o desvio padrão dos 55 valores relativos de correlação cruzada, correlação cruzada com os sinais normalizados e energia de onda, em função da concentração de água das emulsões: a) na faixa de 0 a $100 \%$, e b) na faixa de 0 a $50 \%$ de água (zoom in). Para os 5 experimentos realizados, os parâmetros foram calculados usando a totalidade do sinal de dispersão, ou seja, o sinal formado pelas reflexões da primeira e da segunda fileira de dispersores. Em termos gerais, o desvio padrão de todos os pontos das curvas é pequeno, o que indica uma boa estabilidade dos parâmetros ao longo do tempo de medição. Isto é resultado de esperar que os três parâmetros se estabilizassem para começar a aquisição dos sinais.

As duas correlações cruzadas tem um comportamento aproximadamente linear decrescente para concentrações de água inferiores a $20 \%$, e um comportamento mais errático para concentrações maiores. A energia de onda diminui com o aumento da quantidade de água nas emulsões, seguramente devido à atenuação e à dispersão produzida pelas gotículas de água (fase dispersa). A menor atenuação ocorre no petróleo puro, e a maior, na concentração de $48 \%$. Para os ensaios com água pura, foram obtidos valores relativos de energia próximos de 2 . Estes comportamentos, para a correlação e para a energia de onda, também foram vistos nos resultados obtidos com a célula antes de modificá-la (Figura 25): com os métodos que usam a correlação obteve-se boa sensibilidade para baixas concentrações de água e, com o método que usa a energia de onda, boa sensibilidade em toda a faixa de concentrações medidas.

As curvas de correlação cruzada apresentam um comportamento imprevisível e não repetitivo com relação à temperatura, não parece haver alguma tendência ou padrão. Embora as duas curvas associadas aos experimentos realizados a $20^{\circ} \mathrm{C}$ se superpõem, as dos experimentos realizados a $25^{\circ} \mathrm{C}$ não o fazem; aliás, a curva T25-B encontra-se mais próxima da curva T30-A do que da curva T25-A. Estes comportamentos, fazem com que os parâmetros de correlação cruzada não sejam bons candidatos para a determinação da concentração volumétrica de água nas emulsões. 
Figura 30: Valor médio e desvio padrão dos valores relativos de correlação cruzada, correlação cruzada com os sinais normalizados e energia de onda, em função da concentração de água das emulsões. Resultados obtidos com a célula de espalhamento modificada, usando a totalidade do sinal de dispersão. Para uma melhor visualização das curvas, à direita não se mostram os parâmetros para a concentração de $100 \%$.
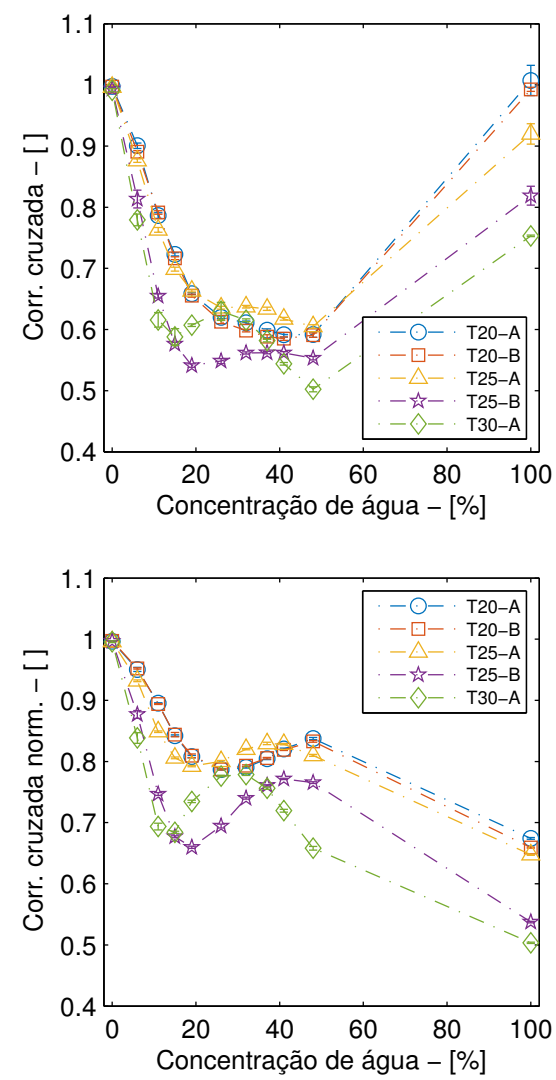

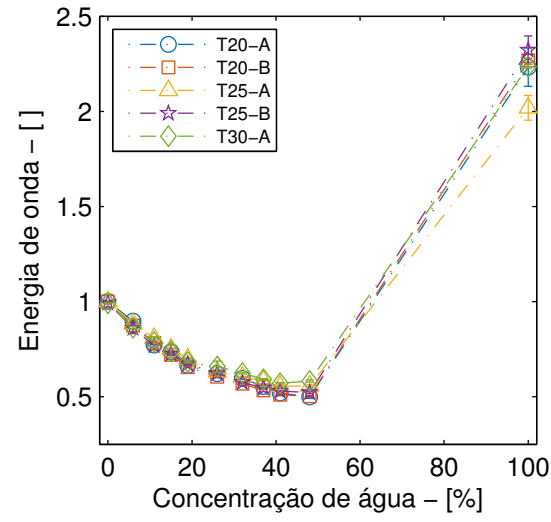

a)
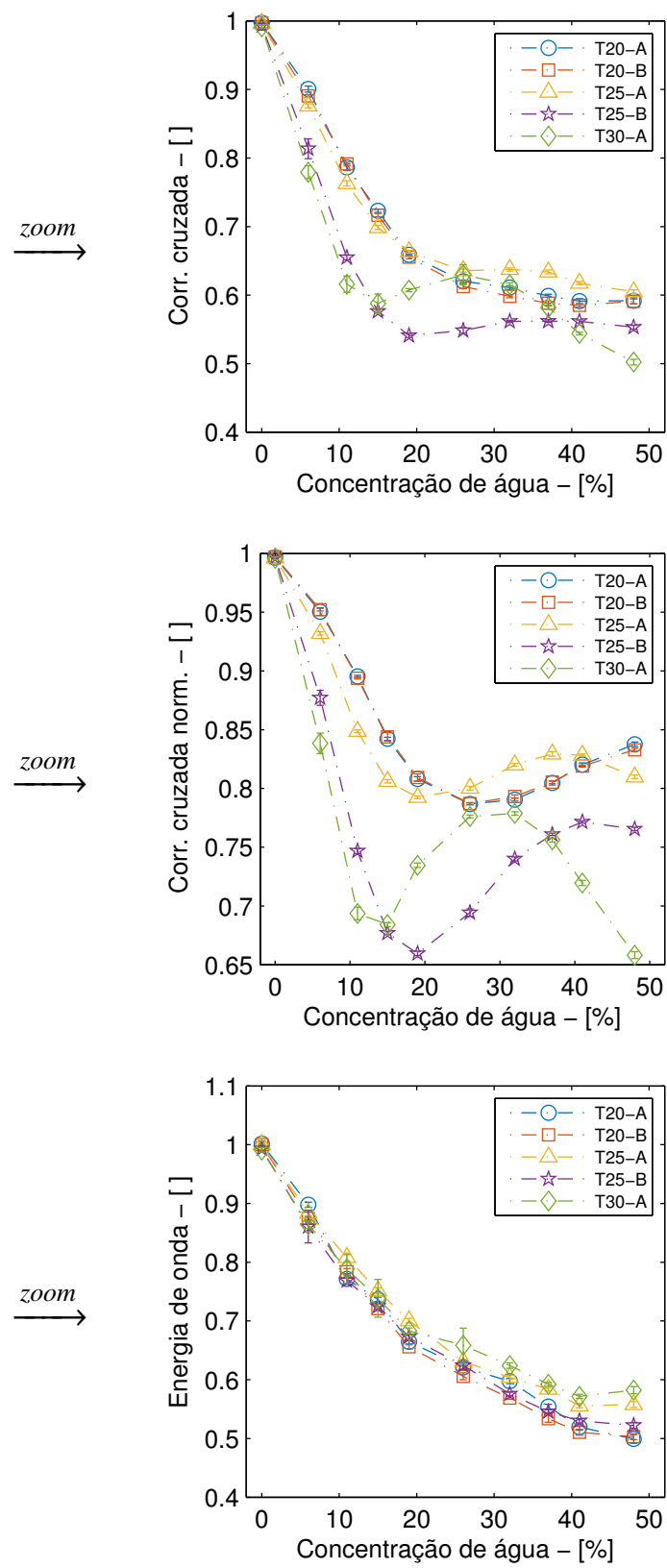

b)

Fonte: Autor.

Por outro lado, as curvas de energia de onda apresentam um comportamento repetitivo e independente da temperatura, ou seja, todas as curvas estão muito próximas e superpostas. Verifica-se que o desvio entre as curvas aumenta conforme aumenta a concentração de água das emulsões, alcançando um valor máximo de 11,5\% na con- 
centração de 48\%; no entanto, este ainda é pequeno. Assim, a medição dos parâmetros da energia de onda pode ser usada na determinação da concentração de água nas emulsões, mesmo quando estas apresentem pequenas variações de temperatura (pelo menos na faixa de 20 a $\left.30^{\circ} \mathrm{C}\right)$.

As variações relativas nas amostras também foram analisadas a partir do primeiro segmento do sinal de dispersão, como mostram os resultados da Figura 31, para as concentrações: a) na faixa de 0 a $100 \%$, e b) na faixa de 0 a $50 \%$ de água (zoom in). Observa-se novamente que os desvios padrões de todos os pontos das curvas são pequenos, o que indica uma boa estabilidade dos parâmetros ao longo do tempo.

As curvas de correlação cruzada diminuem conforme aumenta a concentração de água, e todas elas se superpõem independentemente da temperatura. Seu desvio, com relação à tendência do grupo, aumenta para concentrações de água superiores a 20\%, sendo máximo, com valor de $6 \%$, na concentração de $48 \%$. Este desvio pode ser devido à dispersão produzida pela fase dispersa, já que para altas concentrações de água as emulsões tornam-se mais instáveis.

As curvas de correlação cruzada normalizada apresentam um comportamento decrescente em função da concentração de água, sendo aproximadamente lineares para concentrações inferiores a 48\%. Estas curvas se agrupam de acordo com a temperatura dos experimentos, e sua inclinação torna-se mais negativa conforme esta aumenta. $\mathrm{O}$ máximo desvio destas curvas é inferior a $0,37 \%$.

As curvas de energia de onda têm um comportamento semelhante ao da correlação cruzada, diminuem com o aumento da concentração de água e se superpõem independentemente da temperatura. A curva do experimento realizado a $30^{\circ} \mathrm{C}$ apresenta o maior desvio com relação à tendência do grupo, alcançando um valor máximo, de $16,5 \%$, na concentração de $48 \%$. Este desvio provavelmente se deve à instabilidade dinâmica da emulsão para altas concentrações de água, somado à dificuldade de trabalhar com temperaturas mais altas do que a do ambiente. A grande diferença de temperatura, com relação à do ambiente, promovia a transferência de calor durante o processo de mistura. Isto formava gradientes de temperatura dentro da amostra, portanto era necessário esperar um tempo para conseguir a estabilização e a uniformização térmica, o que terminava atrasando a captura dos sinais e promovendo a separação das fases da emulsão.

A correlação cruzada mede o grau de similaridade entre dois sinais, considerando 
Figura 31: Valor médio e desvio padrão dos valores relativos de correlação cruzada, correlação cruzada com os sinais normalizados e energia de onda, em função da concentração de água das emulsões. Resultados obtidos com a célula de espalhamento modificada, usando o primeiro segmento do sinal de dispersão. Para uma melhor visualização das curvas, à direita não se mostram os parâmetros para a concentração de $100 \%$.
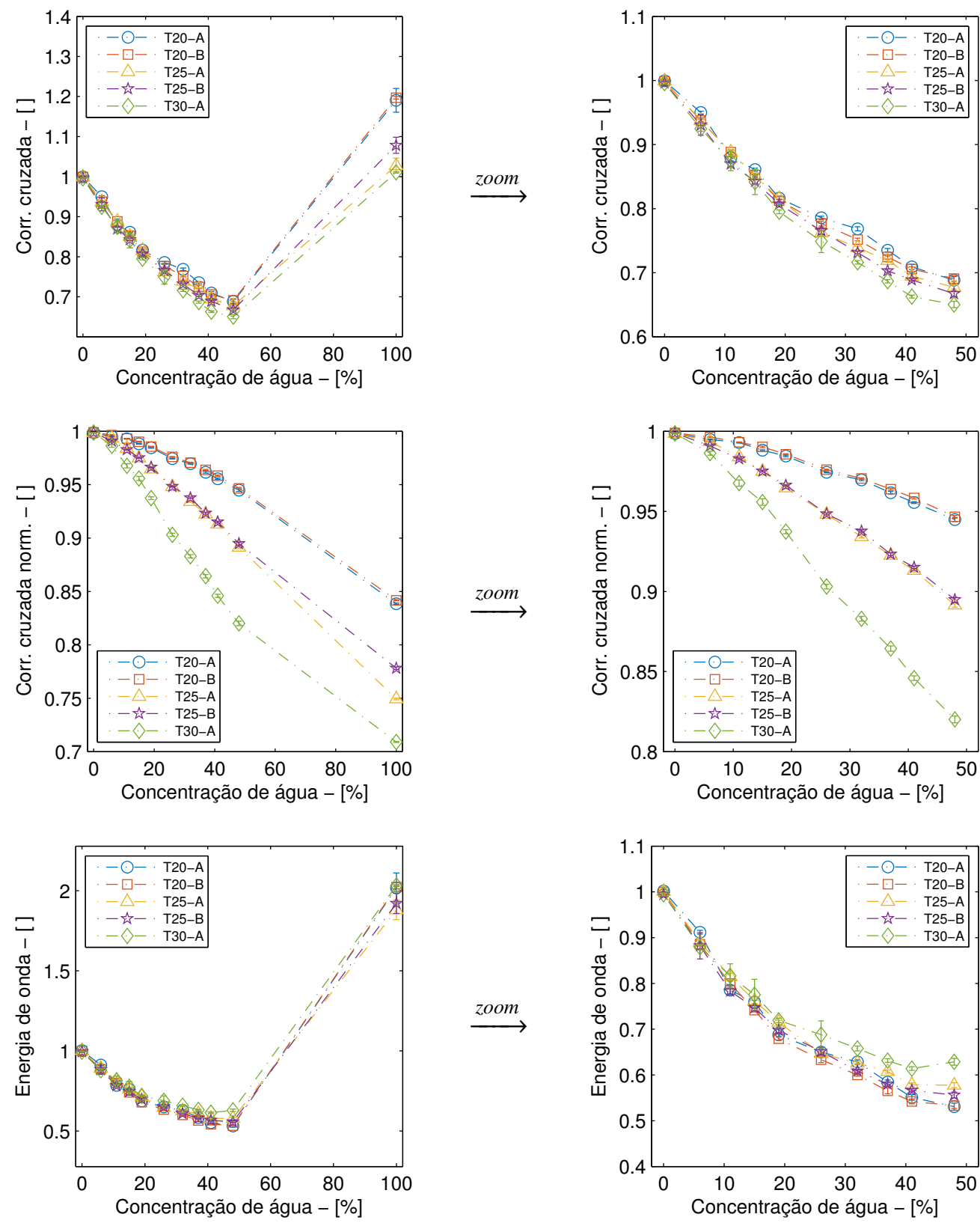

a)

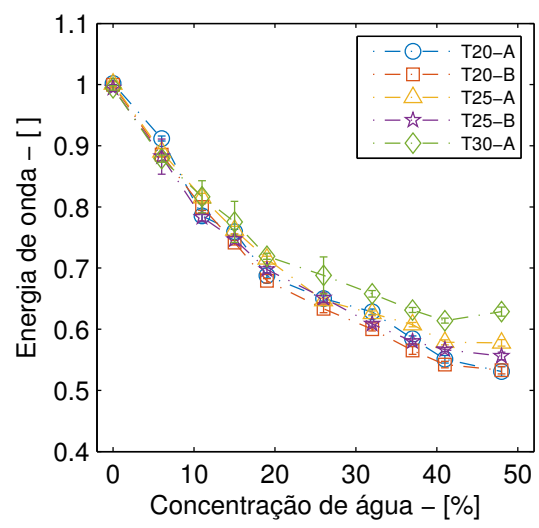

b)

Fonte: Autor.

sua amplitude e fase. O fato de que a correlação cruzada tenha um comportamento similar ao da energia, pode significar que a amplitude vê-se mais afetada que a fase do sinal por conta da presença da fase dispersa. Aliás, quando o efeito da variação 
da amplitude foi cancelado com a correlação cruzada com os sinais normalizados, as curvas dos experimentos separaram-se e agruparam-se em função da temperatura.

Em termos gerais, há uma boa repetitividade nos resultados para todos os parâmetros: correlação cruzada e energia de onda, independentemente da temperatura, e correlação cruzada normalizada, para experimentos realizados à mesma temperatura. Assim, os três parâmetros podem ser usados na determinação da concentração de água das emulsões. Inicialmente, poderia pensar-se em utilizar a energia de onda, já que apresentou um comportamento estável quando calculada a partir do sinal inteiro e a partir do seu primeiro segmento. Entretanto, foi visto durante as medições que este parâmetro tardava mais em estabilizar-se do que a correlação cruzada normalizada, que praticamente desde o início da medição adotava um valor estável. Isso pode indicar que a dispersão e a coalescência afetam principalmente a amplitude do sinal, enquanto sua forma, ou seja, sua fase, está mais relacionada com a temperatura. A velocidade de propagação é altamente dependente da temperatura e desta dependem os tempos de chegada das reflexões de dispersores individuais, que terminam "construindo" o sinal mediante o repetitivo fenômeno de superposição.

\subsubsection{Velocidade de propagação usando a célula de espalhamento modificada}

A Figura 32 mostra a velocidade de propagação da amostra em função da concentração de água para cada valor de temperatura. Esta foi calculada, no gráfico da esquerda, localizando o tempo associado ao máximo do primeiro segmento do sinal de dispersão, e, no gráfico da direita, localizando o tempo associado ao mínimo. Os resultados obtidos com cada sinal foram plotados na forma de pontos para cada concentração, estando o desvio relacionado com a estabilidade da propriedade ao longo do tempo. Deste modo, vê-se que a velocidade de propagação é pouco dependente da dinâmica da emulsão (da coalescência). Os dois gráficos são praticamente os mesmos, indicando que os picos, máximo e mínimo, deslocam-se no tempo de forma idêntica conforme varia a quantidade de água e a temperatura.

Os pontos pertencentes a um mesmo experimento descrevem um comportamento aproximadamente linear (um ajuste desta natureza é plotado em linha tracejada para cada temperatura). Enquanto a temperatura dos experimentos aumenta de 20 a $30^{\circ} \mathrm{C}$, a velocidade de propagação da água aumenta de 1482 a 1509 m/s, no entanto, a do 
Figura 32: Velocidade de propagação em função da concentração de água das emulsões, medida com a célula de espalhamento modificada. Valores obtidos pelos métodos absolutos.
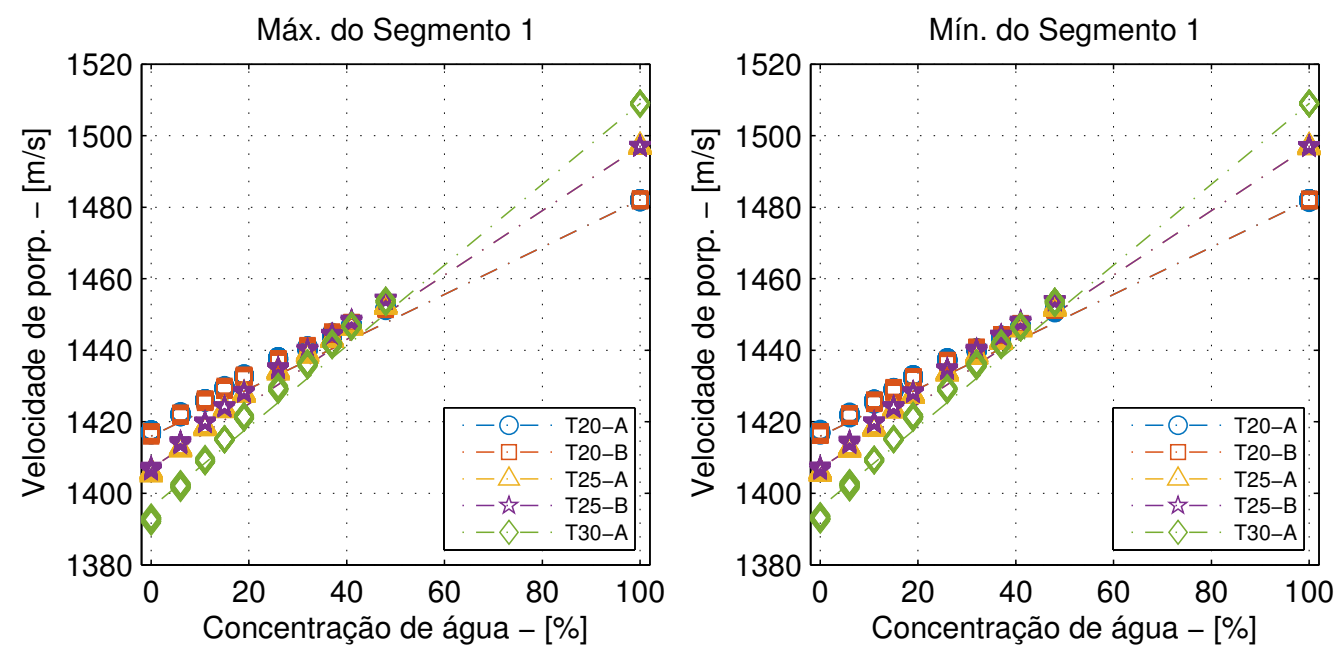

Fonte: Autor.

petróleo puro diminui de 1417 a 1392 m/s. Isto, faz com que as curvas se cruzem em um mesmo ponto, aproximadamente na concentração de 40\%. Para tal concentração, a velocidade de propagação é $1443 \mathrm{~m} / \mathrm{s}$ (independentemente da temperatura). Comportamentos similares foram observados nas curvas de velocidade em (CHAUDHURI; OSTERHOUDT; SINHA, 2012). Já que os resultados são repetitivos e consistentes com a temperatura dos experimentos: os pontos da curva T20-A se superpõem com os da T20-B, e os da curva T25-A com os da T25-B, a velocidade de propagação das emulsões pode ajudar na determinação da sua concentração de água.

A Figura 33 mostra a velocidade de propagação da amostra em função da concentração de água para cada valor de temperatura. Foi calculada, no gráfico superior esquerdo, com a diferença temporal entre os máximos dos segmentos $a_{1}(t)$ e $a_{2}(t)$, no gráfico superior direito, com a diferença temporal entre os mínimo destes segmentos, e, no gráfico inferior esquerdo, mediante sua correlação cruzada.

Os resultados obtidos mediante a diferença temporal entre máximos têm grande dispersão: os pontos da curva T20-B alternam entre dois valores numéricos para cada concentração, e os pontos da curva T30-A encontram-se acima do valor esperado (linha verde tracejada). O comportamento errático destes pontos deve-se à dificuldade do algoritmo para encontrar um único valor máximo no segmento $a_{2}(t)$, pois, como foi visto na Figura 32, os pontos calculados a partir do segmento $a_{1}(t)$ apresentam boa precisão e exatidão. Da mesma forma, a maioria dos pontos do gráfico de correlação 
Figura 33: Velocidade de propagação em função da concentração de água das emulsões, medida com a célula de espalhamento modificada. Valores obtidos pelos métodos relativos.
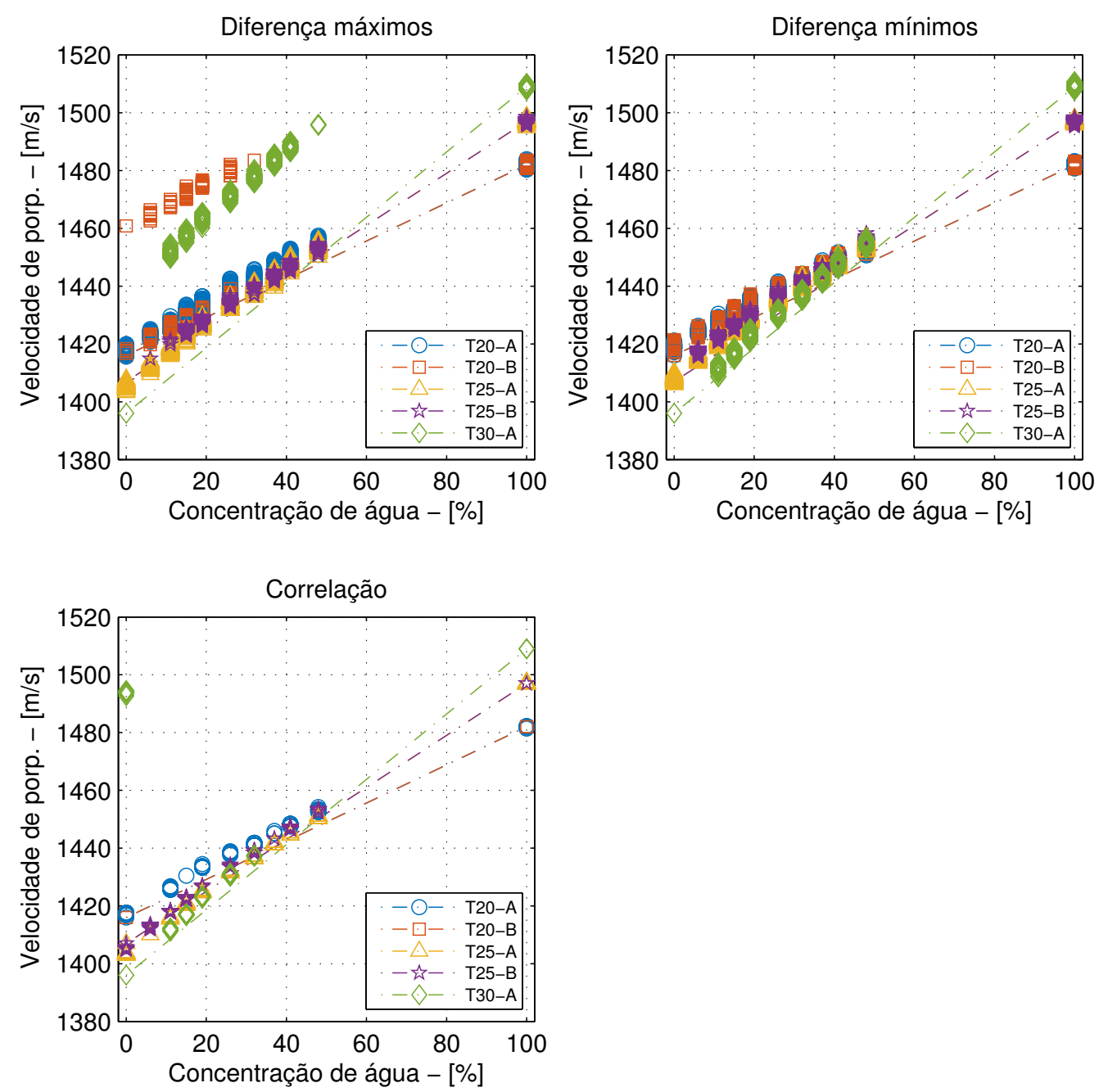

Fonte: Autor.

cruzada, entre os segmentos $a_{1}(t)$ e $a_{2}(t)$, resultaram por fora da faixa considerada como "de valores esperados" (de 1380 a $1520 \mathrm{~m} / \mathrm{s}$ ).

Os sinais, após modificar a célula, encontram-se mais atenuados e afetados pela dispersão. Isso acontece porque as fileiras de dispersores encontram-se mais afastadas da face do transdutor, resultando em uma maior interação das ondas com a emulsão. Na Figura 12, que mostra os sinais antes e depois de modificar a célula, a amplitude das reflexões 1 e 2 diminuíram em aproximadamente 30 e $85 \%$, respectivamente. A segunda reflexão foi a mais afetada, pois antes estava em superposição construtiva com um segundo eco proveniente da primeira fileira. Embora, eliminar esta superposição 
foi a motivação para modificar a célula, provavelmente isso acabou comprometendo os resultados para a velocidade através dos métodos relativos; o fato de estar em superposição aumentava a amplitude do eco facilitando a localização de um único valor máximo e, provavelmente, facilitava a correlação entre os segmentos $a_{1}(t)$ e $a_{2}(t)$.

Os experimentos com a célula modificada foram realizados um ano e três meses depois dos primeiros resultados apresentados, contudo, os parâmetros do pulsador foram configurados com os mesmos ajustes. Para verificar que a queda de amplitude nos sinais devia-se principalmente à modificação na célula, e não a mudanças na eletrônica dos equipamentos, dois sinais de dispersão foram comparados para um ensaio realizado com água pura, obtendo uma diminuição do 7\% na amplitude da primeira reflexão. Além disso, mudanças no sinal podem ser devidas à defasagem que existe entre filas de dispersores; como a nova primeira fileira encontra-se deslocada para um lado em $l_{x} / 3$ (ver Figura 11), o sinal pode construir-se de forma distinta, atenuando alguns picos e amplificando outros.

Para a velocidade de propagação, os resultados obtidos pelos métodos absolutos parecem ser mais exatos, consequentemente, estes podem ser utilizados para determinar a concentração de água das emulsões. 


\section{CONCLUSÕES E TRABALHOS FUTUROS}

\subsection{Conclusões}

Foram empregadas duas células ultrassônicas na caracterização de emulsões água em óleo, sendo uma com linhas de retardo e outra com barras de espalhamento. Foram implementadas técnicas de processamento dos sinais como a transformada de Fourier, a transformada de Hilbert, a correlação cruzada e o método de agrupação de dados $k$ medoids. A célula com linhas de retardo foi utilizada na determinação das propriedades de emulsões água em óleo com concentrações compreendidas entre $0 \%$ e 45\%. Já a célula com barras de espalhamento possibilitou estudar o comportamento de emulsões água em petróleo em função do tempo, da concentração de água e da temperatura, para concentrações entre $0 \%$ e 50\%. Também foram propostas metodologias para calcular a velocidade de propagação nas amostras utilizando o sinal de dispersão.

$\diamond$ Célula com linhas de retardo:

Os resultados obtidos com esta célula foram comparados aos obtidos pelo modelo teórico de misturas de Urick, apresentando as seguintes diferenças relativas: 0,50\% para a velocidade de propagação, 1,15\% para a densidade, $0,18 \%$ para o coeficiente de reflexão e $0,75 \%$ para a impedância acústica. Todas estas propriedades apresentaram um comportamento aproximadamente linear e diretamente proporcional à concentração de água. A densidade do óleo utilizado (Deiton Hidra 68) foi de $868 \mathrm{Kg} / \mathrm{m}^{3} \mathrm{e}$ sua velocidade de propagação foi de $1454 \mathrm{~m} / \mathrm{s}$. A densidade obtida estava dentro da faixa mencionada pelo fabricante na ficha técnica do produto, e apresentou um erro de 1,70\% com relação a um óleo ISO 68 produzido pela companhia Petrobras. Para a atenuação acústica não foi possível levantar a curva teórica em função da concentração, porém o valor obtido para a água pura apresentou um erro significativo de duas ordens de grandeza (1900\%) ao ser comparado com os valores da literatura. Esse erro pode ser devido a alterações na forma do terceiro eco, produto das interações com os 
diferentes meios e interfaces. Foi observado que as propriedades estudadas são bastante sensíveis a variações em alguns dos parâmetros envolvidos na sua determinação, sendo a atenuação acústica a mais sensível delas. Verificou-se que uma diferença de $2 \%$ nos valores da transformada de Fourier do terceiro eco, gerou a grande divergência mencionada acima. O desvio padrão em todos os ensaios, para todas as propriedades, foi baixo, o que significa que as propriedades são bastante estáveis ao longo do tempo, mais dependentes da quantidade de água na emulsão do que do tamanho das gotas.

As curvas experimentais foram calibradas a partir do ensaio realizado com água pura, dado que os erros das curvas sem calibrar já eram baixos (o maior era de 6,28\%, obtido na densidade, e o menor era de $0,18 \%$, obtido no coeficiente de reflexão). Com a calibração foi possível diminuir os erros associados às incertezas dos instrumentos de medição, por exemplo, no caso da densidade, o erro diminuiu a 1,15\%. A análise da propagação da incerteza de medição serviu para corroborar que os desvios nas curvas sem calibrar deviam-se às incertezas dos instrumentos de medição utilizados.

\section{$\diamond$ Célula de espalhamento:}

O comportamento das emulsões foi estudado a partir de variações relativas de parâmetros como a correlação cruzada, a correlação cruzada com os sinais normalizados e a energia de onda, utilizando como referência o petróleo puro. Os parâmetros medidos eram bastante estáveis ao longo do tempo, só não apresentaram esse comportamento nas concentrações de $10 \%$ no Teste 1 e $8 \%$ no Teste 2 , provavelmente devido a um problema de estabilização da amostra, já que nos experimentos realizados com a célula modificada estes comportamentos erráticos não foram vistos. Ainda assim, podem haver outras causas como: uma distribuição não uniforme das gotículas de água no béquer, por sua baixa concentração, ou uma interação forte entre a onda e as gotículas de água para esse valor específico de concentração. O parâmetro mais fácil de interpretar foi a energia de onda que estava relacionada à atenuação e à dispersão produzida pela fase dispersa. A atenuação aumentava com a quantidade de água, como esperado, e nos primeiros minutos de medição havia uma dispersão adicional ocasionada pelas bolhas de ar introduzidas na amostra durante o processo de mistura (homogeneização).

Os métodos que utilizam a correlação cruzada parecem mais apropriados para o monitoramento de emulsões com concentrações de água inferiores a $20 \%$, pois nesta faixa obteve-se uma maior sensibilidade. Para maiores concentrações, pode ser mais apropriado utilizar o método da energia de onda. Logo, a repetitividade no compor- 
tamento das curvas obtidas em ambos os testes e a baixa diferença relativa, principalmente no método da energia (7\%), sugere que esta curva possa ser utilizada para a determinação da concentração de água das emulsões.

Os desvios padrão dos parâmetros estudados foram bastante baixos, inclusive para o Teste 1, que teve uma grande duração. Este comportamento também foi observado nos resultados da célula com linhas de retardo, concluindo que os parâmetros e propriedades das emulsões estudadas são bastante estáveis ao longo do tempo, fortemente dependentes da concentração de água e levemente dependentes do tamanho das gotas da fase dispersa (associado ao fenômeno de coalescência).

Foram propostas várias metodologias para calcular a velocidade de propagação das amostras a partir do sinal de dispersão. Estas foram classificadas em duas categorias, absolutas e relativas. As relativas foram as mais exatas porque a distância temporal entre dois pontos de um mesmo sinal não varia, mesmo considerando pequenos atrasos ou adiantamentos do sinal. Essa vantagem ajuda a mitigar imprevistos experimentais, como um movimento do transdutor durante os ensaios. Dentro das metodologias relativas, aquela que utiliza o valor mínimo dos segmentos teve um desvio menor, pois estes valores encontram-se bem diferenciados. Entretanto, usando o valor máximo o desvio foi maior, devido a que existem dois lóbulos positivos que disputam a dominância. Por causa disso, quando a velocidade oscilava, o fazia entre dois valores discretos e não de forma aleatória.

As metodologias implementadas permitiram calcular a velocidade de propagação do petróleo puro, sendo esta de $1387 \mathrm{~m} / \mathrm{s}$. E, novamente, obteve-se um comportamento linear e diretamente proporcional à concentração de água, embora o modelo de misturas de Urick sugira uma curva convexa. A máxima diferença relativa com relação ao modelo teórico foi $0,64 \%$, no método relativo do valor mínimo, $1,76 \%$, no método relativo da correlação cruzada, e 6,28\% no método relativo do valor máximo. Finalmente, observou-se que esta propriedade é estável no tempo, e as discrepâncias têm origem na dificuldade de encontrar um ponto de referência estável sobre o sinal de dispersão, e não em mudanças das emulsões.

\section{$\diamond$ Célula de espalhamento modificada:}

O comportamento das variações relativas, usando o sinal de dispersão em toda sua extensão, foi idêntico ao obtido com a célula antes de realizar as modificações. Usando o primeiro segmento do sinal de dispersão, obteve-se um comportamento previsível, 
repetitivo e monotônico para os três parâmetros analisados; todos eles decrescentes com o aumento da quantidade de água. A energia de onda e a correlação cruzada são dependentes da concentração de água e independentes da temperatura, para cada parâmetro, as curvas dos experimentos se sobrepõem. O máximo desvio entre as curvas de correlação foi $6 \%$, e entre as curvas de energia foi 16,5\%, ambos ocorreram para a concentração de $48 \%$. Já os resultados da correlação cruzada com os sinais normalizados mostraram-se dependentes de ambas as propriedades (concentração de água e temperatura). As curvas obtidas descreveram retas que se agruparam segundo a temperatura e apresentaram maiores inclinações para as temperaturas mais altas. O máximo desvio dessas curvas foi inferior a $0,37 \%$.

Como a curva de energia de onda é similar à curva de correlação cruzada, provavelmente o efeito da amplitude dos sinais predomine sobre o da fase. Quando o efeito da variação da amplitude foi cancelado com a correlação cruzada com os sinais normalizados, as curvas dos experimentos separaram-se e agruparam-se em função da temperatura. Aliás, observações durante as medições sugerem que a dispersão e a coalescência podem afetar principalmente a amplitude dos sinais, enquanto a temperatura tem maior incidência sobre sua fase. Seguramente a velocidade de propagação é a responsável pelas mudanças na forma dos sinais, ao incidir sobre os tempos de chegada das reflexões de dispersores individuais.

A velocidade de propagação tem um comportamento aproximadamente linear em função da concentração de água. Com o aumento da temperatura dos experimentos de 20 a $30^{\circ} \mathrm{C}$, a velocidade de propagação da água aumentou de 1482 a $1509 \mathrm{~m} / \mathrm{s}$ e a do petróleo puro diminui de 1417 a 1392 m/s. Assim, as curvas dos experimentos se cruzaram na concentração de aproximadamente 40\%, mostrando que, para esta concentração, a velocidade de propagação independe da temperatura. Além disso, entre os métodos empregados para o cálculo da velocidade de propagação, os métodos relativos apresentaram maiores desvios do que os métodos absolutos, ocorrendo saltos entre valores discretos e dificuldades para correlacionar os segmentos de sinal $a_{1}(t)$ e $a_{2}(t)$. Tais problemas foram associados à atenuação excessiva da segunda reflexão que, com o afastamento das fileiras da face do transdutor, acaba interagindo por mais tempo com a emulsão.

De forma resumida, as Tabelas 5 e 6 mostram as comparações entre os resultados obtidos com as células de espalhamento, respectivamente, para os parâmetros relativos (correlação cruzada, correlação cruzada com os sinais normalizados e energia de onda) 
e para a velocidade de propagação (métodos absolutos e relativos). A comparação é dada segundo as modificações realizadas e as metodologias empregadas.

Tabela 5: Comparação dos resultados obtidos com a célula de espalhamento para as variações relativas. $\mathrm{CE}_{1}$ e $\mathrm{CE}_{2}$ representam o estado da célula, antes e depois de ter sido modificada, respectivamente, e $\phi$ representa a concentração volumétrica de água das emulsões.

\begin{tabular}{|c|c|c|c|}
\cline { 2 - 3 } \multicolumn{1}{c|}{} & \multicolumn{1}{c|}{} & & \\
\hline Correlação cruzada & $\begin{array}{c}\text { Boa resolução para } \\
\phi<20 \% .\end{array}$ & $\begin{array}{c}\text { Boa resolução para } \\
\phi<20 \% .\end{array}$ & $\begin{array}{c}\mathrm{CE}_{2}+\text { (primeiro } \\
\text { segmento do sinal) }\end{array}$ \\
\hline $\begin{array}{c}\text { Correlação cruzada } \\
\text { normalizada }\end{array}$ & $\begin{array}{c}\text { Boa resolução para } \\
\phi<20 \% .\end{array}$ & $\begin{array}{c}\text { Boa resolução para } \\
\phi<20 \% .\end{array}$ & $\begin{array}{c}\text { Boa resolução para toda } \\
\text { a faixa de } \phi \text { medida. }\end{array}$ \\
\cline { 1 - 3 } Energia de onda & $\begin{array}{c}\text { Boa resolução para toda } \\
\text { a faixa de } \phi \text { medida. }\end{array}$ & $\begin{array}{c}\text { Boa resolução para toda } \\
\text { faixa de } \phi \text { medida. }\end{array}$ & \\
\hline
\end{tabular}

Tabela 6: Comparação dos resultados obtidos com a célula de espalhamento para a velocidade de propagação. $\mathrm{CE}_{1}$ e $\mathrm{CE}_{2}$ representam o estado da célula, antes e depois de ter sido modificada, respectivamente, e $\phi$ representa a concentração volumétrica de água das emulsões.

\begin{tabular}{|c|c|c|}
\hline & $\begin{array}{c}=1 \\
\mathrm{CE}_{1}\end{array}$ & $\mathrm{CE}_{2}$ \\
\hline $\begin{array}{l}\text { Primeiro segmento } \\
\text { do sinal de dispersão } \\
\text { (métodos absolutos) }\end{array}$ & $\begin{array}{l}\text { - Dificuldades experimentais devido } \\
\text { ao deslocamento do transdutor. }\end{array}$ & $\begin{array}{l}\text { - Comportamento linear em função de } \phi \text {; } \\
\text { - Resultados repetitivos; } \\
\text { - Desvios padrões pequenos. }\end{array}$ \\
\hline $\begin{array}{l}\text { Segmentos } 1 \text { e } 2 \\
\text { do sinal de dispersão } \\
\text { (métodos relativos) }\end{array}$ & $\begin{array}{l}\text { - Mitigado problema de deslocamento; } \\
\text { - Comportamento linear em função de } \phi ; \\
\text { - Resultados repetitivos. }\end{array}$ & $\begin{array}{l}\text { - Comportamento linear em função de } \phi \text {; } \\
\text { - Dificuldade na identificação de um } \\
\text { único máximo predominante no } \\
\text { segmento } 2 \text { do sinal; } \\
\text { - Baixa correlação entre ambos } \\
\text { segmentos do sinal; } \\
\text { - Atenuação excessiva no segmento } 2 \text {. }\end{array}$ \\
\hline
\end{tabular}

Com a célula modificada, os parâmetros usados nas medições das variações relativas das emulsões tiveram um melhor comportamento quando o primeiro segmento 
do sinal de dispersão foi utilizado. Além disso, a acurácia na determinação da velocidade de propagação das emulsões foi maior ao usar os métodos absolutos, que só empregaram o primeiro segmento do sinal de dispersão. Com esses resultados, podese considerar viável o emprego de uma célula com apenas uma fileira de dispersores para o monitoramento e caracterização de emulsões de água em petróleo.

Os resultados aqui apresentados, são promissores para a medição da concentração de água em óleo na indústria do petróleo. Este trabalho de pesquisa resultou na publicação de um artigo na revista Sensors da MDPI (DURÁN et al., 2021b) e outro no congresso LAUS do IEEE (DURÁN et al., 2021a), que foi vencedor do Prêmio de Melhor Trabalho de Aluno no Simpósio Latino-Americano de Ultrassom - IEEE (LAUS 2021). Em ambas as publicações, são descritas as metodologias implementadas nesta dissertação com relação à medição dos parâmetros relativos e da velocidade de propagação nas emulsões usando a célula de espalhamento.

\subsection{Trabalhos futuros}

Embora se observe uma repetitividade nos resultados obtidos com a célula de espalhamento, é preciso realizar mais testes para certificar a metodologia implementada, aumentando sua confiabilidade. Propõe-se o estudo do comportamento das emulsões a outras temperaturas a fim de obter novas curvas de caracterização, úteis na determinação da concentração de água em óleo. Além disso, deve-se estudar a caracterização de emulsões em movimento, ou seja, quando fluem por tubulações.

Devem-se testar outras distribuições dos dispersores, por exemplo, barras orientadas na direção axial do transdutor, possibilitando que as extremidades destas formem dois círculos a diferentes alturas. Esse arranjo permitiria que os ecos sejam refletidos ao mesmo tempo, resultando em um sinal mais limpo.

Após a caracterização das emulsões por ultrassom, as amostras devem ser analisadas em microscópio, possibilitando a realização de um histograma do tamanho das gotículas. Essa análise permitirá relacionar o tamanho de gota com o fenômeno acústico. 


\section{REFERÊNCIAS}

ABRO, E.; JOHANSEN, G. Improved void fraction determination by means of multibeam gamma-ray attenuation measurements. Flow Measurement and Instrumentation, v. 10, n. 2, p. 99-108, 1999. ISSN 0955-5986. Disponível em: $<$ https://www.sciencedirect.com/science/article/pii/S0955598698000430>.

ALBERTÍ, E. Procesado Digital de Seales - I Fundamentos Para Comunicaciones y Control. UPC, S.L., Edicions, 2009. (Politext (UPC)). ISBN 9788483018507. Disponível em: <https://books.google.com.br/books?id=_2su5I3YfRkC>.

ALVAREZ, G. et al. Small-angle neutron scattering study of crude oil emulsions: Structure of the oil?water interfaces. Langmuir, v. 25, n. 7, p. 3985-3990, 2009. PMID: 19714887. Disponível em: <https://doi.org/10.1021/la802736c>.

BLASINA, F. et al. Development of a multiple-scattering acoustic sensor for process monitoring: Application to monitoring milk coagulation. In: 2017 IEEE International Instrumentation and Measurement Technology Conference (I2MTC). [S.1.: s.n.], 2017. p. 1-5. ISSN null.

BROWN, T. L. et al. Química: la ciencia central. [S.1.]: Pearson educación, 2004.

BUIOCHI, F. Análise dos métodos de medição de densidade de líquidos por ultrassom. Dissertação (Mestrado) - Escola Politécnica da Universidade de São Paulo, 1994.

CHAUDHURI, A.; OSTERHOUDT, C. F.; SINHA, D. N. An algorithm for determining volume fractions in two-phase liquid flows by measuring sound speed. Journal of fluids engineering, American Society of Mechanical Engineers Digital Collection, v. 134, n. 10, 2012.

CHAUDHURI, A. et al. Mass Fraction Measurements in Controlled Oil-Water Flows Using Noninvasive Ultrasonic Sensors. Journal of Fluids Engineering, v. 136, n. 3, 01 2014. ISSN 0098-2202. 031304. Disponível em: $<$ https://doi.org/10.1115/1.4026055>.

CHEN, S.-H. et al. Estimation of cell concentration using high-frequency ultrasonic backscattering. Journal of Medical and Biological Engineering, v. 32, n. 3, p. 157-162, 72012.

D’AVILA, M. A. et al. Mixing of concentrated oil-in-water emulsions measured by nuclear magnetic resonance imaging. Physics of Fluids, v. 15, n. 9, p. 2499-2511, 2003. Disponível em: <https://doi.org/10.1063/1.1583731>.

DUKHIN, A. S.; GOETZ, P. J. Characterization of liquids, nano-and microparticulates, and porous bodies using ultrasound. [S.1.]: Elsevier, 2010. 
DURÁN, A. L. et al. Ultrasonic multiple-backscattering sensor for monitoring of water-in-crude oil emulsions: Temperature effect. 1st Latin America Ultrasonic Symposium (LAUS 2021), IEEE, 2021.

Water content monitoring in water-in-crude-oil emulsions using an ultrasonic multiple-backscattering sensor. Sensors, v. 21, n. 15, 2021. ISSN 1424-8220. Disponível em: <https://www.mdpi.com/1424-8220/21/15/5088>.

ELVIRA, L. et al. Concentration measurement of yeast suspensions using high frequency ultrasound backscattering. Ultrasonics, v. 64, p. $151-161,2016$. ISSN 0041-624X.

FRANCO, E. E.; ADAMOWSKI, J. C.; BUIOCHI, F. Ultrasonic sensor for the presence of oily contaminants in water. Dyna, 2006, Revista DYNA, v. 79, n. 176, p. 4-9, 2012.

GARCIA-GOLDING, F. et al. Sensor for determining the water content of oil-in-water emulsion by specific admittance measurement. Sensors and Actuators A: Physical, v. 47, n. 1, p. 337-341, 1995. ISSN 0924-4247. Disponível em: <https://www.sciencedirect.com/science/article/pii/0924424794009177>.

GODDEERIS, C. et al. Light scattering measurements on microemulsions: Estimation of droplet sizes. International Journal of Pharmaceutics, Elsevier BV, v. 312, n. 1-2, p. 187-195, Apr 2006. Disponível em: <https://doi.org/10.1016/j.ijpharm.2006.01.037>.

HEINDEL, T. J. A Review of X-Ray Flow Visualization With Applications to Multiphase Flows. Journal of Fluids Engineering, v. 133, n. 7, 07 2011. ISSN 0098-2202. 074001. Disponível em: <https://doi.org/10.1115/1.4004367>.

HIGUTI, R. T. Caracterização de líquidos por ultrassom. Dissertação (Mestrado) Escola Politécnica da Universidade de São Paulo, 2001.

HIGUTI, R. T. et al. Ultrasonic characterization of emulsions: milk and water in oil. In: 1999 IEEE Ultrasonics Symposium. Proceedings. International Symposium (Cat. No.99CH37027). [S.1.: s.n.], 1999. v. 1, p. 779-782 vol.1.

IVANOVA, P. G.; ANEVA, Z. V. Assessment and assurance of quality in water measurement by coulometric karl fischer titration of petroleum products. Accreditation and Quality Assurance, Springer, v. 10, p. 543-549, 2006. Disponível em: <https://doi.org/10.1007/s00769-005-0056-x>.

JADOON, S.; MALIK, A.; AMIN, A. A. Separation of sediment contents and water from crude oil of khurmala and guwayer oil fields in kurdistan region by using centrifuge method. International Journal of Advanced Engineering Research and Science, American Chemical Society, v. 4, p. 2919-2922, 2017. Disponível em: $<$ https://dx.doi.org/10.22161/ijaers.4.4.28>.

JAWORSKI, A. J.; DYAKOWSKI, T. Measurements of oil?water separation dynamics in primary separation systems using distributed capacitance sensors. Flow Measurement and Instrumentation, v. 16, n. 2, p. 113-127, 2005. ISSN 0955-5986. 
Tomographic Techniques for Multiphase Flow Measurements. Disponível em: $<$ https://www.sciencedirect.com/science/article/pii/S095559860500018X>.

JOHANSEN, G. et al. A dual sensor flow imaging tomographic system. Measurement Science and Technology, IOP Publishing, v. 7, n. 3, p. 297, 1996.

JULIASTUTI, E.; TANOGONO, E. W.; KURNIADI, D. Detection of water content in lubricating oil using ultrasonics. In: 2017 5th International Conference on Instrumentation, Control, and Automation (ICA). [S.1.: s.n.], 2017. p. 188-192.

KINO, G. Acoustic Waves: Devices, Imaging, and Analog Signal Processing. Prentice-Hall, 1987. (Prentice-Hall Contemporary Topics in Accounting Series). ISBN 9780130030474. Disponível em: $<$ https://books.google.com.br/books?id=hcsYAQAAIAAJ $>$.

KINSLER, L. et al. Fundamentals of Acoustics. Wiley, 2000. ISBN 9780471847892. Disponível em: <https://books.google.com.br/books?id=76IRAQAAIAAJ>.

KOKAL, S. L. et al. Crude oil emulsions: A state-of-the-art review. SPE Production $\mathcal{E}$ facilities, Society of Petroleum Engineers, v. 20, n. 01, p. 5-13, 2005.

MANDAL, A. et al. Characterization of oil-water emulsion and its use in enhanced oil recovery. Industrial $\mathcal{E}$ Engineering Chemistry Research, v. 49, n. 24, p. 12756-12761, 2010 .

MASON, W. Properties of Gases, Liquids, and Solutions: Principles and Methods. Elsevier Science, 2013. ISBN 9781483275086. Disponível em: $<$ https://books.google.com.br/books?id=zb84BQAAQBAJ $>$.

MCCLEMENTS, D. et al. Ultrasonic characterization of a food emulsion. Ultrasonics, v. 28, n. 4, p. 266 - 272, 1990. ISSN 0041-624X. Disponível em: <http://www.sciencedirect.com/science/article/pii/0041624X90900934>.

MCCLEMENTS, D. J.; POVEY, M. J. W. Scattering of ultrasound by emulsions. Journal of Physics D: Applied Physics, IOP Publishing, v. 22, n. 1, p. 38-47, jan 1989.

MENG, G.; JAWORSKI, A. J.; WHITE, N. M. Composition measurements of crude oil and process water emulsions using thick-film ultrasonic transducers. Chemical Engineering and Processing: Process Intensification, v. 45, n. 5, p. 383-391, 2006. ISSN 0255-2701. Disponível em: <https://www.sciencedirect.com/science/article/pii/S0255270105001996>.

MERAL, R. Laboratory evaluation of acoustic backscatter and lisst methods for measurements of suspended sediments. Sensors (Basel), v. 8, n. 2, p. 979-993, 2008.

MOORE, S. A. et al. Using multi-frequency acoustic attenuation to monitor grain size and concentration of suspended sediment in rivers. The Journal of the Acoustical Society of America, v. 133, n. 4, p. 1959-1970, 2013.

OLYMPUS. Material Sound Velocities. 2021. https: //www . olympus-ims . com/ en/ndt-tutorials/thickness-gauge/appendices-velocities/. Accessed: 2010-09-30. 
OPPENHEIM, A. et al. Señales y sistemas. Pearson Educación, 1998. ISBN 9789701701164. Disponível em: $<$ https://books.google.com.br/books?id=g2750K3PxRYC >.

PÉREZ, N. et al. Evaluation of a multiple scattering sensor for water-in-oil emulsion monitoring. In: 2019 International Congress on Ultrasonics (ICU 2019). [S.1.: s.n.], 2019. p. 1-4. ISSN null.

PÉREZ-PÁEZ, R. et al. Separation of oil-water-sludge emulsions coming from palm oil mill process through microwave techniques. Journal of Microwave Power and Electromagnetic Energy, Taylor \& Francis, v. 42, n. 3, p. 39-47, 2007.

PROAKIS, J.; MANOLAKIS, D. Digital Signal Processing. Pearson Prentice Hall, 2007. (Prentice Hall international editions). ISBN 9780131873742. Disponível em: $<$ https://books.google.com.br/books?id=H_5SAAAAMAAJ $>$.

RICHTER, A.; VOIGT, T.; RIPPERGER, S. Ultrasonic attenuation spectroscopy of emulsions with droplet sizes greater than 10 microm. Journal of Colloid and Interface Science, Elsevier BV, v. 315, n. 2, p. 482-492, nov 2007. Disponível em: $<$ https://doi.org/10.1016/j.jcis.2007.06.081>.

SANTOS, E. d. S. et al. The lubricity analysis of cutting fluid emulsions. Materials Research, SciELO Brasil, v. 20, p. 644-650, 2017.

SCHILLING, R.; HARRIS, S. Digital Signal Processing using MATLAB. Cengage Learning, 2016. ISBN 9781305887206. Disponível em: <https://books.google.com.br/books?id=YsEaCgAAQBAJ>.

SCHRAMM, L. L. Emulsions, foams, and suspensions: fundamentals and applications. [S.1.]: John Wiley \& Sons, 2006.

SJÖBLOM, J. et al. Our current understanding of water-in-crude oil emulsions.: Recent characterization techniques and high pressure performance. Advances in Colloid and Interface Science, Elsevier, v. 100, p. 399-473, 2003.

STOKES, D. J.; THIEL, B. L.; DONALD, A. M. Direct observation of water-oil emulsion systems in the liquid state by environmental scanning electron microscopy. Langmuir, American Chemical Society (ACS), v. 14, n. 16, p. 4402-4408, Aug 1998. Disponível em: <https://doi.org/10.1021/la980281c>.

SU, M. et al. Particle sizing in dense two-phase droplet systems by ultrasonic attenuation and velocity spectra. Science in China Series E: Technological Sciences, Springer Science and Business Media LLC, v. 52, n. 6, p. 1502-1510, May 2009. Disponível em: <https://doi.org/10.1007/s11431-009-0172-7>.

THOMAS, J. E. Fundamentos de engenharia de petróleo. [S.1.]: Interciência, 2001.

UMAR, A. A. et al. A review of petroleum emulsions and recent progress on water-in-crude oil emulsions stabilized by natural surfactants and solids. Journal of Petroleum Science and Engineering, Elsevier, v. 165, p. 673-690, 2018. 
URICK, R. J. A sound velocity method for determining the compressibility of finely divided substances. Journal of Applied Physics, v. 18, n. 11, p. 983-987, 1947. Disponível em: <https://doi.org/10.1063/1.1697584>.

WEFERS, F. Partitioned convolution algorithms for real-time auralization. Logos Verlag Berlin, 2015. (Aachener Beitrage zur Technischen Akustik). ISBN 9783832539436. Disponível em: <https://books.google.com.br/books?id=IAbCgAAQBAJ >

WU, J. Advances in K-means Clustering: A Data Mining Thinking. Springer Berlin Heidelberg, 2012. (Springer Theses). ISBN 9783642298073. Disponível em: $<$ https://books.google.com.br/books?id=pI2_F8SqWcQC $>$.

ZANUY, M. Sistemas de Comunicaciones. Marcombo, S.A., 2001. (ACCESO RÁPIDO). ISBN 9788426713049. Disponível em: $<$ https://books.google.com.br/books?id=_arH8J1d1FYC $>$.

ZHAI, L.-S. et al. The ultrasonic measurement of high water volume fraction in dispersed oil-in-water flows. Chemical Engineering Science, v. 94, p. 271-283, 2013. ISSN 0009-2509. Disponível em: $<$ https://www.sciencedirect.com/science/article/pii/S0009250913001504>. 